\title{
Simultaneously and Selectively Imaging Cytoplasm Membrane and Mitochondria Using a Dual-colored Aggregation-induced Emission Probe
}

Yue Zheng ${ }^{1 \ddagger}$, Yiwen Ding ${ }^{1 \ddagger}$, Jiajun Ren ${ }^{2}$, Yu Xiang ${ }^{1}$, Zhigang Shuai ${ }^{2 *}$ and Aijun Tong ${ }^{1 *}$

1. Department of Chemistry, Beijing Key Laboratory for Microanalytical Methods and Instrumentation, Key Laboratory of Bioorganic Phosphorus Chemistry and Chemical Biology (Ministry of Education), Tsinghua University, Beijing 100084 (P. R. China)

2. Department of Chemistry, Key Laboratory of Organic Optoelectronics and Molecular Engineering (Ministry of Education), Tsinghua University, Beijing 100084 (P. R. China) 


\section{Contents}

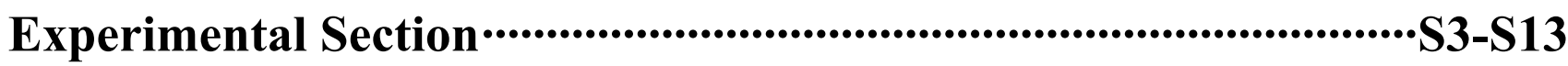

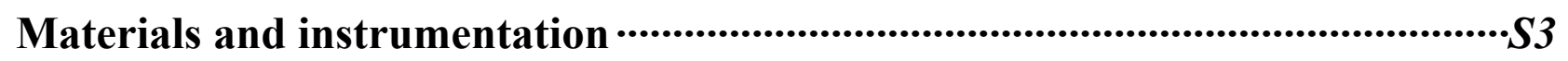

Synthesis

Experimental procedures

Additional Figures and Tables ….............................................................S13-S39

Figures S1-7 Photoluminescence of TPNPDA-C12 …….................................S13

Figures S8-18 Live Cell Imaging by TPNPDA-C12 ……....................................S18

Figures S19-23 Photoluminescence and Imaging of TPNPDA-Cn ……….......S24

Figure S24 Flow Cytometric Analysis ……...................................................S28

Figures S25-45 Characterizations of Synthesized Compounds …………….....S29

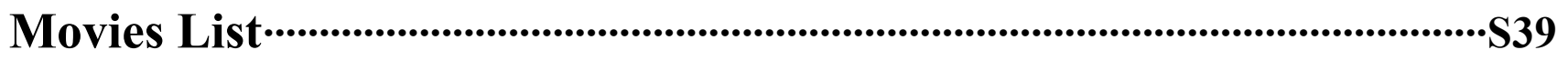

References 


\section{Experimental Section}

\section{Materials and instrumentation}

The chemicals for synthesis including 4-[bis(4-methoxyphenyl)amino]benzaldehyde (\#B4905, purity 98\%), 4-methylpyridine (\#P0417, purity 98\% ) were purchased from TCI (Shanghai, China). 3-BromoN,N,N-trimethylpropan-1-aminium bromide (\#B802775, purity 98\%), boron tribromide (\#C19890, 1 M solution in methylene chloride), 1-bromododecane (\#213738, purity 98\%), 1-bromopentadecane (\#B0936, purity 98\%), and 1-bromooctadecane (\#133192, purity 98\%) were purchased from J\&K (Beijing, China). Piperidine (\#411027, purity 99.5\%), hydrogen peroxide solution $\left(\mathrm{H}_{2} \mathrm{O}_{2}\right.$ solution, \#323381, contains 200 ppm acetanilide as stabilizer, 3 wt. \% in $\mathrm{H}_{2} \mathrm{O}$ ), staurosporine (STS, \#569397, purity 98\%) were purchased from Sigma-Aldrich Co., Ltd. (Shanghai, China). All chemicals were used as received without further purification. Organic solvents and inorganic salts of analytical purity (ethanol, methanol, isopropanol, acetonitrile, tetrahydrofuran, N, N-dimethylformamide, dichloromethane, chloroform, ethyl acetate, diethyl ether, petroleum ether, acetic acid, potassium carbonate, sodium sulfate and sodium chloride) were purchased from Sinopharm Chemical Reagent Beijing Co. (Beijing, China). All aqueous solutions were prepared using ultrapure water, which was obtained through a Millipore Milli-Q water purification system (Billerica, MA) and had an electric resistance at 18.2 M $\Omega$. Dulbecco's modified Eagle's medium (DMEM), Dulbecco's phosphate buffered saline (PBS buffer), Hank’s Balanced Salt Solution (HBSS buffer), fetal bovine serum (FBS), penicillin-streptomycin and $0.25 \%$ trypsin were purchased from Corning Cellgro (NY, USA). HeLa, HepG2 and MCF-7 cells were purchased from National Platform of Experimental Cell Resources for Sci-Tech (Beijing, China). Cell Counting Kit-8 (CCK-8 assay for cell viability) was purchased from 
Dojindo Molecular Technologies, Inc. (Tokyo, Japan). Commercial subcellular organelle fluorescent probes for living cell co-localization including 3,3'-dioctadecyloxacarbocyanine perchlorate (DiO, for cytoplasm membrane, \#D275), MitoTrackerTM Green FM (MTG, for mitochondria, \# M7514), MitoTracker ${ }^{\mathrm{TM}}$ Deep Red FM (MTDR, for mitochondria, \# M22426), LysoTracker ${ }^{\mathrm{TM}}$ Deep Red (LyDR, for lysosome, \# L12492), Hoechst 34580 (for nucleus, \#H21486), ER-TrackerTM Red (glibenclamide BODIPY ${ }^{\circledR}$ TR, for endoplasmic reticulum, \#E34250), BODIPY ${ }^{\circledR}$ TR C5-ceramide complexed to BSA (Golgi-tracker, for Golgi apparatus, \# B-34400) as well as eBioscience ${ }^{\mathrm{TM}}$ Annexin V Apoptosis Detection Kit APC (\#88-8007-74) for flow cytometry were all purchased from Invitrogen Trading Co., Ltd. (Shanghai, China).

All NMR spectra were recorded using a JOEL JNM-ECA400 spectrometer (Tokyo, Japan) operated at $400 \mathrm{MHz}$. All mass spectra were obtained on a Shimadzu MS-IT-TOF ion trap time-of-fight mass spectrometry (Kyoto, Japan). All absorption spectra were measured on a JASCO V-550 UV visible spectrometer (Tokyo, Japan). All fluorescence spectra were recorded with a JASCO FP-8600 fluorescence spectrometer (Tokyo, Japan). The fluorescent photos were taken by a Canon EOS 600D camera. Dynamic light scattering for nanoparticle sizes were determined at $25{ }^{\circ} \mathrm{C}$ by a Horiba's nanoparticle analyzer Nano SZ-100 (Kyoto, Japan). The determination of fluorescence lifetime was carried out on an Edinburgh FLS 920 combined steady state and fluorescence lifetime spectrometer (Livingston, England). Quantum yield $\left(\Phi_{f}\right)$ was measured using a Hamamatsu Photonics K.K. C992012 absolute photoluminescence quantum yield measurement system (Hamamatsu, Japan). For cytotoxicity experiment, the absorption was recorded by Molecular Device SpectraMax M3 microplate reader. All cell imaging was performed on Olympus FV 1000 or Olympus FV 1200 confocal laser 
scanning microscope (CLSM, Tokyo, Japan) in live cell station using 40X lens and 60X lens. For fluorescence lifetime imaging (FLIM-FCS), time-correlated single-photon counting (TCSPC) data sets were acquired on an inverted Olympus FV1200 microscope with a 60X NA equipped with a PicoQuant picoHarp300 (Berlin, Germany) controller. The nondescanned emission was collected from a PicoQuant bandpass filter and detected by a PicoQuant MPD SPAD detector. Photon data were analyzed using SymPhoTime64 mage software. TEM images were taken on a Hitachi Limited H$7650 \mathrm{~B}$ transmission electron microscope (Tokyo, Japan) at $80 \mathrm{kV}$ accelerating voltage. Flow cytometry analysis was performed on a BD FACSCalibur (New Jersey, USA). Fluorescence was determined by counting 10000 usable events, and the data were analyzed by the FlowJo software.

\section{Synthesis}

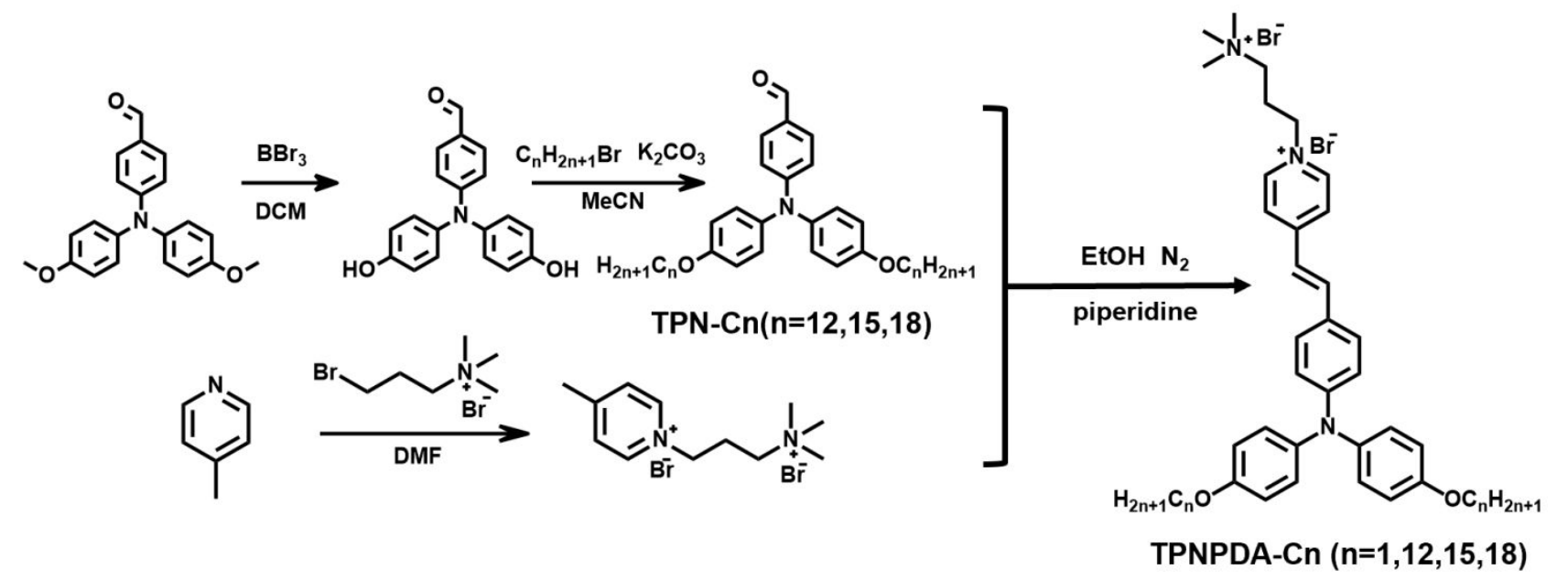

Scheme S1 Synthetic route of TPNPDA-C1, TPNPDA-C12, TPNPDA-C15 and TPNPDA-C18

\section{Synthesis of 1-(3-trimethylammoniopropyl)-4-methylpyridinium dibromide}

4-Methylpyridine (930 mg, $10 \mathrm{mmol}$ ), 3-bromo-N,N,N-trimethylpropan-1-aminium bromide (2.61 g, $10 \mathrm{mmol}$ ) and $10 \mathrm{~mL}$ DMF were stirred at $100{ }^{\circ} \mathrm{C}$ under $\mathrm{N}_{2}$ atmosphere in a $25 \mathrm{~mL}$ round bottom flask. The mixture became homogeneous in 5 minutes and white solid started precipitating in 
15 minutes. After $2 \mathrm{~h}$ reaction, the system was cooled down to ambient temperature and the precipitates were filtered out and recrystallized with ethanol / THF 3 times to get 1-(3-trimethylammoniopropyl)4-methylpyridinium dibromide as a hygroscopic white solid (2.90 g). Yield: $81.92 \%,{ }^{1} \mathrm{H}$ NMR $\left(\mathrm{D}_{2} \mathrm{O}\right.$, $400 \mathrm{MHz}, \mathrm{TMS}), \delta(\mathrm{ppm}): 2.49(\mathrm{~m}, 2 \mathrm{H}), 2.64(\mathrm{~s}, 3 \mathrm{H}), 3.15(\mathrm{~s}, 9 \mathrm{H}), 3.53(\mathrm{t}, \mathrm{J}=8.4 \mathrm{~Hz}, 2 \mathrm{H}), 4.71$ (t, $\mathrm{J}=7.8 \mathrm{~Hz}, 2 \mathrm{H}), 8.09$ (d, J=6.6 Hz, 2H), 9.14 (d, J=6.6 Hz, 2H). ${ }^{13} \mathrm{C}$ NMR ( $\left.\mathrm{D}_{2} \mathrm{O}, 100 \mathrm{MHz}\right), \delta(\mathrm{ppm})$ : $21.64,24.66,53.32,53.36,53.40,57.17,62.60,129.19,143.31,161.07 . \mathrm{MS}(\mathrm{m} / \mathrm{z})$ : calcd. for $\mathrm{C}_{12} \mathrm{H}_{22} \mathrm{~N}_{2} \mathrm{Br}_{2}[\mathrm{M}-2 \mathrm{Br}]^{2+}$ : 97.0886, found: 97.0894 .

\section{Synthesis of 4-(bis(4-hydroxyphenyl)amino)benzaldehyde}

4-[Bis(4-methoxyphenyl)amino]benzaldehyde (334 mg, $1.00 \mathrm{mmol})$ was dissolved in $5 \mathrm{~mL}$ dichloromethane. Then $5 \mathrm{~mL} \mathrm{BBr}_{3}$ solution $(1.0 \mathrm{M}$ solution in dichloromethane) was added and the reaction mixture quickly changed into dark red. The system was stirred for another $2 \mathrm{~h}$ at room temperature and poured into water and then extracted with ethyl acetate $(3 \times 50 \mathrm{~mL})$ to get yellow solution. The extract was washed 3 times by saturated $\mathrm{NaCl}$ solution and dried by anhydrous $\mathrm{Na}_{2} \mathrm{SO}_{4}$. All solvents were removed from the system by rotary evaporation to obtain a yellow cotton-like solid (297mg). Yield: 98.02\%. ${ }^{1} \mathrm{H}$ NMR (DMSO-d6, $\left.400 \mathrm{MHz}, \mathrm{TMS}\right), \delta(\mathrm{ppm}): 6.57$ (d, J=8.8 Hz, 2H) , 6.76 (d, J=8.8 Hz, 4H), 7.05 (d, J=8.8 Hz, 4H), 7.57 (d, J=9.2 Hz, 2H), 9.54 (s, 2H), 9.63 (s, 1H). ${ }^{13} \mathrm{C}$ NMR (DMSO-d6, 100 MHz), $\delta(\mathrm{ppm}): 115.09,117.09,127.03,129.18,131.90,137.08,154.69,156.18$, 190.58. MS (m/z): calcd. for $\mathrm{C}_{19} \mathrm{H}_{16} \mathrm{NO}_{3}[\mathrm{M}+\mathrm{H}]^{+}: 306.1125$, found: 306.1120 .

\section{Synthesis of TPN-C12, TPN-C15 and TPN-C18}

4-[Bis(4-hydroxyphenyl)amino]benzaldehyde (303 mg, $1.00 \mathrm{mmol})$ and $1 \mathrm{~g}$ 1-bromododecane (or $1.2 \mathrm{~g}$ 1-bromopentadecane, or $1.4 \mathrm{~g}$ 1-bromooctadecane, $4 \mathrm{mmol}$ ) were dissolved in $30 \mathrm{~mL}$ acetonitrile. Then $1.2 \mathrm{~g} \mathrm{~K}_{2} \mathrm{CO}_{3}$ was added and the reaction mixture was refluxed under $\mathrm{N}_{2}$ atmosphere for another $48 \mathrm{~h}$ at $60{ }^{\circ} \mathrm{C}$. After that the system was evaporated to remove acetonitrile and added 50 $\mathrm{mL}$ water. Then extracted with ethyl acetate $(3 \times 50 \mathrm{~mL})$ to get yellow solution. The extract was washed 3 times by saturated $\mathrm{NaCl}$ solution and dried by anhydrous $\mathrm{Na}_{2} \mathrm{SO}_{4}$ and concentrated. The residue was chromatographed on silica gel with petroleum: ethyl acetate $\left(40: 1, R_{f}=0.2\right)$ to get yellow oil compound TPN-C12 / TPN-C15 / TPN-C18.

For TPN-C12 (501 mg), yield: 78.04\%. ${ }^{1} \mathrm{H}$ NMR ( $\left.\mathrm{CDCl}_{3}, 400 \mathrm{MHz}, \mathrm{TMS}\right), \delta(\mathrm{ppm}): 0.87$ (t, J=8.0 $\mathrm{Hz}, 6 \mathrm{H}), 1.26$ (m, 36H), $1.77(\mathrm{~m}, 4 \mathrm{H}), 3.93$ (t, J=8.0 Hz, 4H), 6.82-6.84 (m, 2H), 6.85-6.88 (m, 4H), 
7.09-7.11 (m, 4H), 7.60-7.62 (m, 2H), $9.74(\mathrm{~s}, 1 \mathrm{H}) .{ }^{13} \mathrm{C} \mathrm{NMR}\left(\mathrm{CDCl}_{3}, 100 \mathrm{MHz}\right), \delta(\mathrm{ppm}): 14.23,22.79$, 26.16, 29.38, 29.45, 29.50, 29.71, 29.77, 32.02, 68.34, 115.64, 116.76, 127.76, 128.13, 131.51, 138.67, 154.22, 157.02, 190.34. MS (m/z): calcd. for $\mathrm{C}_{43} \mathrm{H}_{63} \mathrm{NO}_{3}[\mathrm{M}+\mathrm{H}]^{+}:$642.4881, found: 642.4766 .

For TPN-C15 (551 mg), yield: 75.89\%. ${ }^{1} \mathrm{H}$ NMR ( $\left.\mathrm{CDCl}_{3}, 400 \mathrm{MHz}, \mathrm{TMS}\right), \delta(\mathrm{ppm}): 0.87$ (t, J=8.0 $\mathrm{Hz}, 6 \mathrm{H}), 1.26(\mathrm{~m}, 48 \mathrm{H}), 1.77(\mathrm{~m}, 4 \mathrm{H}), 3.93$ (t, J=8.0 Hz, 4H), 6.82-6.84 (m, 2H), 6.85-6.87 (m, 4H), 7.09-7.11 (m, 4H), 7.59-7.62 (m, 2H), $9.73(\mathrm{~s}, 1 \mathrm{H}) .{ }^{13} \mathrm{C} \mathrm{NMR}\left(\mathrm{CDCl}_{3}, 100 \mathrm{MHz}\right), \delta(\mathrm{ppm}): 14.23,22.80$, $26.17,29.39,29.47,29.51,29.69,29.72,29.77,29.80,32.03,68.34,76.82,77.14,77.46,115.65$, $116.78,127.79,128.12,131.50,138.69,154.22,157.03,190.30$. MS (m/z): calcd. for $\mathrm{C}_{49} \mathrm{H}_{75} \mathrm{NO}_{3}$ $[\mathrm{M}+\mathrm{H}]^{+}:$726.5820, found: 726.5671 .

For TPN-C18 (628 mg), yield: 77.53\%. ${ }^{1} \mathrm{H}$ NMR ( $\left.\mathrm{CDCl}_{3}, 400 \mathrm{MHz}, \mathrm{TMS}\right), \delta(\mathrm{ppm}): 0.79$ (t, J=8.0 $\mathrm{Hz}, 6 \mathrm{H}), 1.17(\mathrm{~m}, 60 \mathrm{H}), 1.69$ (m, 4H), 3.84 (t, J=8.0 Hz, 4H), 6.74-6.76 (m, 2H), 6.77-6.79 (m, 4H), 7.00-7.02 (m, 4H), 7.51-7.53 (m, 2H), $9.65(\mathrm{~s}, 1 \mathrm{H}) .{ }^{13} \mathrm{C} \mathrm{NMR}\left(\mathrm{CDCl}_{3}, 100 \mathrm{MHz}\right), \delta(\mathrm{ppm}): 14.24,22.81$, 26.19, 29.41, 29.49, 29.53, 29.71, 29.74, 29.80, 29.83, 32.05, 68.32, 115.64, 116.78, 127.81, 128.11, 131.49, 138.69, 154.20, 157.03, 190.23. MS (m/z): calcd. for $\mathrm{C}_{55} \mathrm{H}_{87} \mathrm{NO}_{3}[\mathrm{M}+\mathrm{H}]^{+}: 810.6759$, found: 810.6560 .

\section{Synthesis of TPNPDA-C1, TPNPDA-C12, TPNPDA-C15 and TPNPDA-C18}

1-(3-Trimethylammoniopropyl)-4-methylpyridinium dibromide (354 mg, $1.00 \mathrm{mmol}$ ) and 334 mg 4-[bis(4-methoxyphenyl)amino]benzaldehyde (or $642 \mathrm{mg}$ TPN-C12, or 726 mg TPN-C15, or 810 mg TPN-C18, $1 \mathrm{mmol}$ ) were dissolved in $50 \mathrm{~mL}$ ethanol in a $100 \mathrm{~mL}$ round bottom flask at $78{ }^{\circ} \mathrm{C}$ under $\mathrm{N}_{2}$ atmosphere. After all solid dissolved as homogeneous yellow solution, added $0.8 \mathrm{~mL}$ piperidine into the system and the solution was changed into deep red in 5 minutes. After refluxing overnight, cooled down the system to room temperature then mixed with $5 \mathrm{~g}$ silica gel and evaporated by rotary evaporation. The residue was chromatographed on silica gel for purification. First used chloroform to remove non-salt organic compounds with low-polarity. Then used chloroform: isopropanol: methanol: water: acetic acid (24: 4: 16: 6: $\left.6, R_{f}=0.2-0.5\right)$ to collect deep red solution. The solution was evaporated to remove all solvents and get dark red solid as final product TPNPDAC1, TPNPDA-C12, TPNPDA-C15 and TPNPDA-C18.

For TPNPDA-C1 (600 mg), yield: 89.55\%. ${ }^{1} \mathrm{H}$ NMR (DMSO-d6, $\left.400 \mathrm{MHz}, \mathrm{TMS}\right), \delta(\mathrm{ppm}): 2.41$ $(\mathrm{m}, 2 \mathrm{H}), 3.08(\mathrm{~s}, 9 \mathrm{H}), 3.40(\mathrm{t}, \mathrm{J}=8.0 \mathrm{~Hz}, 2 \mathrm{H}), 3.77(\mathrm{~s}, 6 \mathrm{H}), 4.53(\mathrm{t}, \mathrm{J}=8.0 \mathrm{~Hz}, 2 \mathrm{H}), 6.73-6.75(\mathrm{~m}, 2 \mathrm{H})$, 
6.97-6.99 (m, 4H), 7.13-7.15 (m, 4H), 7.25 (d, J=16.0 Hz, 1H), 7.55-7.57 (m, 2H), 7.98 (d, J=16.0 Hz, 1H), 8.17-8.19 (m, 2H), 8.88-8.89 (m, 2H). ${ }^{13} \mathrm{C}$ NMR (DMSO-d6, $\left.100 \mathrm{MHz}\right), \delta(\mathrm{ppm}): 24.60,52.99$, $55.86,115.74,117.70,119.55,123.45,128.40,130.43,137.02,139.24,142.11,144.48,151.31,157.28$, 179.24. MS (m/z): calcd. for $\mathrm{C}_{33} \mathrm{H}_{39} \mathrm{O}_{2} \mathrm{~N}_{3} \mathrm{Br}_{2}[\mathrm{M}-2 \mathrm{Br}]^{2+}: 254.6516$, found: 254.6527 .

For TPNPDA-C12 (831 mg), yield: 84.97\%. ${ }^{1} \mathrm{H}$ NMR (DMSO-d6, $\left.400 \mathrm{MHz}, \mathrm{TMS}\right), \delta(\mathrm{ppm}): 0.81$ $(\mathrm{t}, \mathrm{J}=8.0 \mathrm{~Hz}, 6 \mathrm{H}), 1.20(\mathrm{~m}, 36 \mathrm{H}), 1.37(\mathrm{~m}, 2 \mathrm{H}), 1.66(\mathrm{~m}, 4 \mathrm{H}), 2.37$ (t, J=8.0 Hz, 2H), $3.04(\mathrm{~s}, 9 \mathrm{H}), 3.91$ (t, J=8.0 Hz, 4H), 4.49 (t, J=8.0 Hz, 2H), 6.68-6.71 (m, 2H), 6.90-6.92 (m, 4H), 7.06-7.08 (m, 4H), $7.20(\mathrm{~d}, \mathrm{~J}=16.0 \mathrm{~Hz}, 1 \mathrm{H}), 7.50-7.52(\mathrm{~m}, 2 \mathrm{H}), 7.92$ (d, J=16.0 Hz, 1H), 8.12-8.13 (m, 2H), 8.84-8.85 (m, 2H). ${ }^{13} \mathrm{C}$ NMR (DMSO-d6, $\left.100 \mathrm{MHz}\right), \delta(\mathrm{ppm}):$ 14.50, 22.64, 24.60, 26.05, 29.25, 29.28, 29.54, 31.84, 52.93, 56.96, 62.29, 68.17, 116.18, 117.66, 119.20, 123.44, 126.24, 128.37, 130.40, 139.08, 144.60, 151.33, 154.30, 156.75, 173.84. MS (m/z): calcd. for $\mathrm{C}_{55} \mathrm{H}_{83} \mathrm{O}_{2} \mathrm{~N}_{3} \mathrm{Br}_{2}[\mathrm{M}-2 \mathrm{Br}]^{2+}$ : 408.8237, found: 408.8241.

For TPNPDA-C15 (902 mg), yield: 85.01\%. ${ }^{1} \mathrm{H}$ NMR (methanol-d3, $\left.400 \mathrm{MHz}, \mathrm{TMS}\right), \delta(\mathrm{ppm})$ : $0.86(\mathrm{t}, \mathrm{J}=8.0 \mathrm{~Hz}, 6 \mathrm{H}), 1.25(\mathrm{~m}, 48 \mathrm{H}), 1.44(\mathrm{~m}, 2 \mathrm{H}), 1.73(\mathrm{~m}, 4 \mathrm{H}), 2.49(\mathrm{t}, \mathrm{J}=8.0 \mathrm{~Hz}, 2 \mathrm{H}), 3.15(\mathrm{~s}, 9 \mathrm{H})$, $3.93(\mathrm{t}, \mathrm{J}=8.0 \mathrm{~Hz}, 4 \mathrm{H}), 4.53(\mathrm{t}, \mathrm{J}=8.0 \mathrm{~Hz}, 2 \mathrm{H}), 6.78-6.80$ (m, 2H), 6.86-6.88 (m, 4H), 7.04-7.06 (m, 4H), 7.14 (d, J=16.0 Hz, 1H), 7.49-7.51 (m, 2H), 7.84 (d, J=16.0 Hz, 1H), 8.03-8.05 (m, 2H), 8.66$8.68(\mathrm{~m}, 2 \mathrm{H}) .{ }^{13} \mathrm{C}$ NMR (Tetrahydrofuran - $\left.\mathrm{d} 8: \mathrm{D}_{2} \mathrm{O}=1: 1(\mathrm{v} / \mathrm{v}), 100 \mathrm{MHz}\right), \delta(\mathrm{ppm}): 13.69,22.66,23.43$, 24.81, 26.18, 29.39, 29.50, 29.70, 29.74, 31.96, 53.32, 56.83, 62.63, 67.90, 115.25, 118.40, 119.85, $123.71,127.30,129.77,139.65,141.04,144.05,150.56,154.28,156.42,180.49 . \mathrm{MS}(\mathrm{m} / \mathrm{z})$ : calcd. for $\mathrm{C}_{61} \mathrm{H}_{95} \mathrm{O}_{2} \mathrm{~N}_{3} \mathrm{Br}_{2}[\mathrm{M}-2 \mathrm{Br}]^{2+}$ : 450.8707, found: 450.8687 .

For TPNPDA-C18 (928 mg), yield: 80.98\%. ${ }^{1} \mathrm{H}$ NMR (DMSO-d6, $\left.400 \mathrm{MHz}, \mathrm{TMS}\right), \delta(\mathrm{ppm}): 0.85$ $(\mathrm{t}, \mathrm{J}=8.0 \mathrm{~Hz}, 6 \mathrm{H}), 1.23(\mathrm{~m}, 60 \mathrm{H}), 1.40(\mathrm{~m}, 2 \mathrm{H}), 1.70(\mathrm{~m}, 4 \mathrm{H}), 2.39$ (t, J=8.0 Hz, 2H), 3.07 (s, 9H), 3.95 (t, J=8.0 Hz, 4H), 4.50 (t, J=8.0 Hz, 2H), 6.73-6.75(m, 2H), 6.94-6.97 (m, 4H), 7.10-7.12 (m, 4H), 7.24 (d, J=16.0 Hz, 1H), 7.54-7.56 (m, 2H), 7.96 (d, J=16.0 Hz, 1H), 8.16-8.17 (m, 2H), 8.83-8.84 (m, 2H). ${ }^{13} \mathrm{C}$ NMR (THF : $\left.\mathrm{H}_{2} \mathrm{O}=3: 1(\mathrm{v} / \mathrm{v}), 100 \mathrm{MHz}\right), \delta(\mathrm{ppm}): 13.30,17.25,21.34,21.62,22.28,23.80$, $24.23,28.78,29.06,29.33,31.57,53.06,56.33,65.43,68.87,115.03,117.85,123.33,127.01,127.77$, 129.83, 139.18, 140.86, 143.78, 150.29, 153.97, 156.19, 179.85. MS (m/z): calcd. for $\mathrm{C}_{67} \mathrm{H}_{107} \mathrm{O}_{2} \mathrm{~N}_{3} \mathrm{Br}_{2}$ $[\mathrm{M}-2 \mathrm{Br}]^{2+}:$ 492.9176, found: 492.9140. 


\section{Experimental procedures}

\section{Calculation Details}

All the calculations are done using Gaussian16 package ${ }^{1}$. The molecular structure of TPNPDA (the dodecyl is substituted with ethyl) at $\mathrm{S}_{0}\left(\mathrm{~S}_{1}\right)$ state is optimized with density functional theory (DFT) and the response properties are calculated with time dependent density functional theory (TDDFT). Due to the serious problem that TDDFT underestimates the excitation energies of charge transfer excited states, we benchmark several functionals (M06, M06-2X, M06-HF, M11, LC- $\omega-H P B E)$ with 6-31g(d) basis when optimizing $\mathrm{S}_{1}$ geometry. The corresponding $\mathrm{S}_{1}$ excitation energies and oscillator strengths are listed in Table S1. Except M06-HF, all the other four functionals obtain a $\mathrm{S}_{1}$ excitation energy much smaller than the fluorescence peak $(650 \mathrm{~nm})$ in glycerin in a non-aggregated state. Only M06HF could obtain a reasonable result with excitation energy at $609 \mathrm{~nm}$, which is not surprising because M06-HF was designed to describe the charge transfer type excitations ${ }^{2}$. Therefore, all the results shown below are calculated with M06-HF functional. The optimized $\mathrm{S}_{0}$ and $\mathrm{S}_{1}$ geometry are shown in Figure 2(e) and Figure S6. The major difference is the dihedral angles of the three benzene rings in the donor moiety (Table S1). Among them, $\angle \mathrm{C} 1-\mathrm{N} 2-\mathrm{C} 3-\mathrm{C} 4$ determines the dihedral angle between the donor and acceptor, which is directly related to the excitation character. Commonly, a larger dihedral angle between the donor and acceptor indicates a larger portion of charge transfer $(\mathrm{CT})$ component in the excited state, resulting in a smaller energy gap and oscillator strength ${ }^{3}$. This structure-property relation in TPNPDA-C12 was verified by scanning the $\mathrm{S}_{0} / \mathrm{S}_{1}$ potential energy surface along the $\angle \mathrm{C} 1-\mathrm{N} 2-\mathrm{C} 3-$ C4 dihedral angle from a perpendicular geometry through a fully relaxed twisted $\mathrm{S}_{1}$ geometry to a planar geometry (close to the $\mathrm{S}_{0}$ state). The excitation energy increases from $1.56 \mathrm{eV}(795 \mathrm{~nm})$ to 2.19 $\mathrm{eV}(566 \mathrm{~nm})$ and the oscillator strength increases from 0.12 to 1.91 as shown in Figure 2(f) and Figure 
S7. The natural transition orbitals are also calculated between the $S_{0}$ and $S_{1}$ state with the one particle transition density matrix, which characterizes the real space excitation property to distinguish between charge transfer state and local excitation state as shown in Figure 2(f).

\section{Cell Culture}

Hela, HepG2 and MCF-7 cells were cultured in the DMEM containing 10\% FBS and antibiotics (100 units $/ \mathrm{mL}$ penicillin and $0.1 \mathrm{mg} / \mathrm{mL}$ streptomycin) in a $5 \% \mathrm{CO}_{2}$ humidity incubator at $37{ }^{\circ} \mathrm{C}$.

\section{Cytotoxicity}

CCK-8 assays were used to evaluate the cytotoxicity of the probes. Cells were seeded in 96-well plates $(100 \mu \mathrm{L}$ per well) at a density of $6000-8000$ cells/well. At the same time, culture medium without cells was also introduced into the wells $(100 \mu \mathrm{L}$ per well) as blank. Stock solutions of the probes in ethanol with different concentrations were prepared. After overnight culturing, $1 \mu \mathrm{L}$ stock solutions or ethanol were added to each well to get final dye concentrations at $0 \mu \mathrm{M}, 4 \mu \mathrm{M}, 8 \mu \mathrm{M}, 12 \mu \mathrm{M}, 16 \mu \mathrm{M}$ and 20 $\mu \mathrm{M} .24$ hours later, $10 \mu \mathrm{L} \mathrm{CCK}-8$ solution was added into each well. After 1.5 hours of incubation, the absorption of each well at $450 \mathrm{~nm}$ was recorded via a plate reader, marked as As (for wells containing cells, culture medium and probes), Ac (for wells containing cells and culture medium), Ab1 (for wells containing culture medium and probes), Ab2 (for wells containing only culture medium). Each trial was performed with 5 wells parallel. The viability of cells treated with the probes were then calculated with the following equation S1:

$$
\text { Cell Viability }=\frac{A s-A b 1}{A c-A b 2}(\text { Equation } \mathrm{S} 1)
$$

\section{Fluorescence Lifetime Imaging}

HeLa cells were stained by TPNPDA-C12 using modified staining procedures mentioned above. After 
imaging on CLSM, samples were then excited by the picosecond $405 \mathrm{~nm}$ or $488 \mathrm{~nm}$ pulses generated by a $0.2 \mathrm{MHz}$ laser. The emission signals were collected though a 550/49 $\mathrm{nm}$ or $615 / 60 \mathrm{~nm}$ bandpass filter, respectively. Images of $512 \times 512$ pixels were obtained. Analysis of the acquired FLIM data was performed by first binning ( 3 pixels $\times 3$ pixels) the time dependent photon image and assigning a minimum threshold count of 100 recorded photons for modeling. Lifetime values derived from the exponential fits are then displayed as a heat-map image.

\section{Co-localization Experiments}

Co-localization of cytoplasm membrane by DiO $1 \mathrm{mM} \mathrm{DiO}$ stock solution was prepared in DMSO. After that, $5 \mu \mathrm{L}$ of DiO stock solution and $10 \mu \mathrm{L}$ of TPNPDA-C12 or TPNPDA-C15 stock solution were added to $1 \mathrm{~mL}$ cultured HeLa cells. The cells were incubated with the probe at $37^{\circ} \mathrm{C}$. After $10 \mathrm{~min}$, washed cells for 3 times by $1 \times$ DPBS buffer, then added $1 \mathrm{~mL}$ culture medium for living cell imaging. Fluorescent image of $\mathrm{DiO}$ was excited by $488 \mathrm{~nm}$ laser and collected at $\mathrm{DiO}$ channel (500-600 nm).

Co-localization of mitochondria by MTDR 1 mM MTDR stock solution was prepared in DMSO. After that, $0.25 \mu \mathrm{L}$ MTDR stock solution was added to $1 \mathrm{~mL}$ cultured HeLa cells. After incubating at $37^{\circ} \mathrm{C}$ for $20 \mathrm{~min}$, add $10 \mu \mathrm{L}$ of TPNPDA-C1 or TPNPDA-C12 stock solution and further incubated at $37^{\circ} \mathrm{C}$ for $10 \mathrm{~min}$. Then washed cells for 3 times by $1 \times$ DPBS buffer and added $1 \mathrm{~mL}$ culture medium for living cell imaging. Fluorescent image of MTDR was excited by $635 \mathrm{~nm}$ laser and collected at Cy5 channel $(655-755 \mathrm{~nm})$.

Co-localization of lysosome by LyDR $1 \mathrm{mM}$ LyDR stock solution was prepared in DMSO. Then dilute $1 \mu \mathrm{L}$ LyDR stock solution by $10 \mathrm{~mL}$ DMEM. Washed $1 \mathrm{~mL}$ HeLa cell twice and then add $1 \mathrm{~mL}$ diluted LyDR and incubated at $37^{\circ} \mathrm{C}$. After $20 \mathrm{~min} 10 \mu \mathrm{L}$ of TPNPDA-C12 was added and incubated 
at $37^{\circ} \mathrm{C}$ for further $10 \mathrm{~min}$. Then washed cells for 3 times by $1 \times$ DPBS buffer and added $1 \mathrm{~mL}$ culture medium for living cell imaging. Fluorescent image of LyDR was excited by $635 \mathrm{~nm}$ laser and collected at Cy5 channel $(655-755 \mathrm{~nm})$.

Co-localization of nucleus by Hoechst $3458010 \mathrm{mg} / \mathrm{mL}$ Hoechst stock solution was prepared in water. Then dilute $5 \mu \mathrm{L}$ Hoechst stock solution in $10 \mathrm{~mL} 1 \times$ DPBS buffer. Washed $1 \mathrm{~mL}$ HeLa cell twice and then add $1 \mathrm{~mL}$ diluted Hoechst and incubated at $37{ }^{\circ} \mathrm{C}$ for $30 \mathrm{~min}$. Then washed cells for 3 times by $1 \times$ DPBS buffer and added $1 \mathrm{~mL}$ culture medium and incubated at $37^{\circ} \mathrm{C}$ for more than 30 min. After that, $10 \mu \mathrm{L}$ of TPNPDA-C12 was added and incubated at $37{ }^{\circ} \mathrm{C}$ for further $10 \mathrm{~min}$. Then washed cells for 3 times by $1 \times$ DPBS buffer and added $1 \mathrm{~mL}$ culture medium for living cell imaging. Fluorescent image of Hoechst was excited by $405 \mathrm{~nm}$ laser and collected at 425-475 $\mathrm{nm}$.

Co-localization of endoplasmic reticulum by ER-tracker Red 1mM ER-tracker Red stock solution was prepared in DMSO. Then dilute to $1 \mu \mathrm{M}$ in HBSS buffer. Washed $1 \mathrm{~mL}$ HeLa cell twice and then add $1 \mathrm{~mL}$ diluted ER-tracker Red and $10 \mu \mathrm{L}$ TPNPDA-C12 incubated at $37^{\circ} \mathrm{C}$ for $20 \mathrm{~min}$. Then washed cells for 3 times by HBSS buffer and added $1 \mathrm{~mL}$ culture medium for living cell imaging. Fluorescent image of ER-tracker Red was excited by $559 \mathrm{~nm}$ laser and collected by TRITC filter.

Co-localization of Golgi apparatus by Golgi-tracker Prepare $1 \mathrm{mM}$ sphingolipid stock solution in chloroform:ethanol (19:1 v/v). Dispense $50 \mu \mathrm{L}$ of sphingolipid stock solution into a small glass test tube and dry, first under a stream of nitrogen, and then under vacuum for 1 hour. Redissolve in 200 $\mu \mathrm{L}$ ethanol. Measure $10 \mathrm{~mL}$ pH 7.4 HBSS/HEPES into a $50 \mathrm{~mL}$ plastic centrifuge tube. Add $3.4 \mathrm{mg}$ $(0.34 \mathrm{mg} / \mathrm{mL})$ of defatted BSA. Agitate the tube containing the $10 \mathrm{~mL}$ of the BSA solution on a vortex mixer. Inject the sphingolipid solution in ethanol $(200 \mu \mathrm{L})$ into the vortex to get prepared Golgi-tracker. Incubate the cells for 30 minutes at $4^{\circ} \mathrm{C}$ with $1 \mathrm{~mL} 5 \mu \mathrm{M}$ Golgi-tracker in HBSS/HEPES. Rinse the 
sample several times with ice-cold medium and incubate in $1 \mathrm{~mL}$ culture medium with $10 \mu \mathrm{L}$ TPNPDA-C12 at $37^{\circ} \mathrm{C}$ for a further 30 minutes. Then washed cells for 3 times by HBSS/HEPES buffer and added $1 \mathrm{~mL}$ culture medium for living cell imaging. Fluorescent image of Golgi-tracker was excited by $559 \mathrm{~nm}$ laser and collected by TRITC filter.
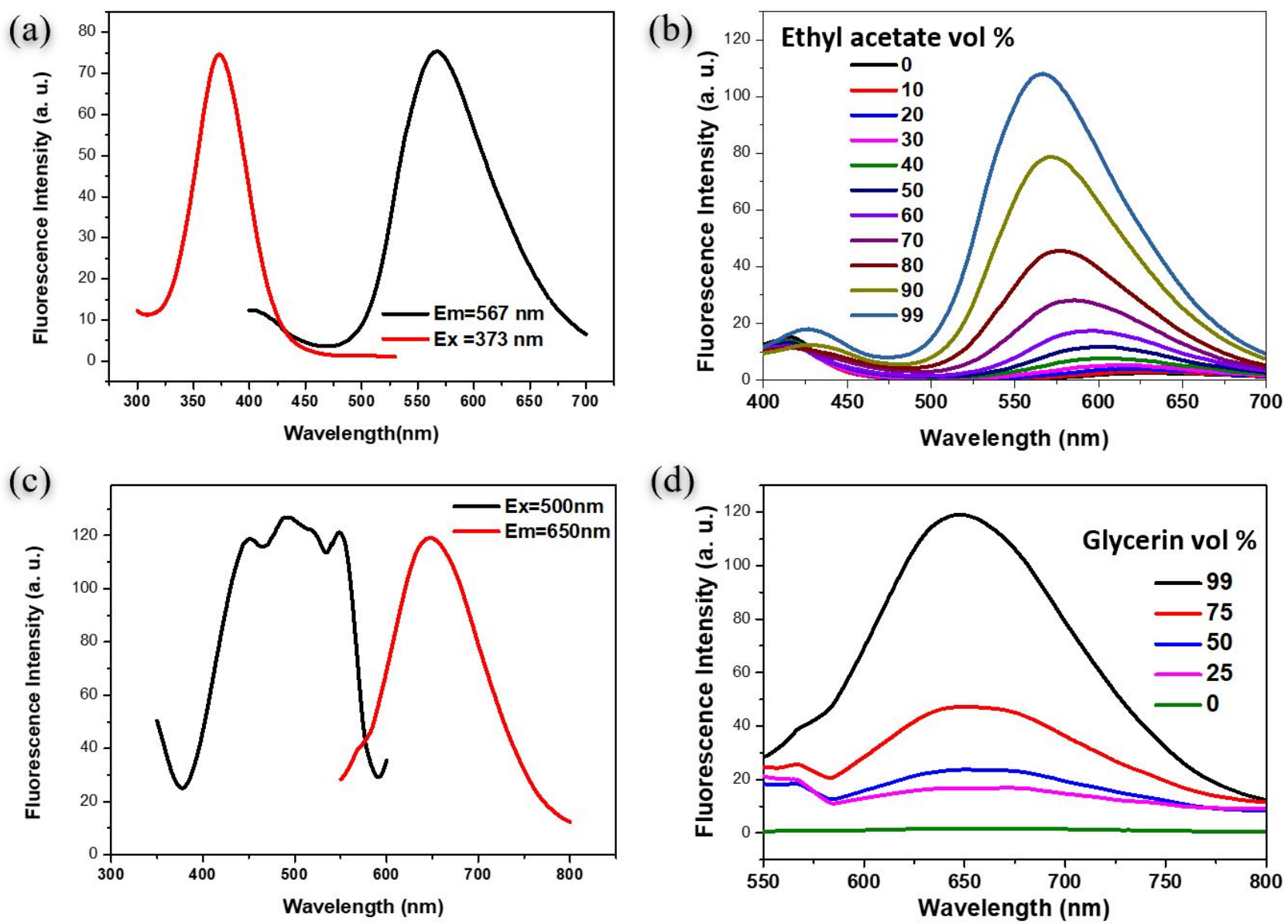

Figure S1 (a) Excitation and emission fluorescence spectra of $100 \mu \mathrm{M}$ TPNPDA-C12 solution in 99\% ethyl acetate solution. (b) Fluorescence spectra of $100 \mu \mathrm{M}$ TPNPDA-C12 with different ethyl acetate/ethanol volume fraction. (c) Excitation and emission fluorescence spectra of $100 \mu \mathrm{M}$ TPNPDA-C12 solution in 99\% glycerin solution. (d) Fluorescence spectra of $100 \mu \mathrm{M}$ TPNPDA-C12 with different glycerin/ethanol volume fraction. 
(a)

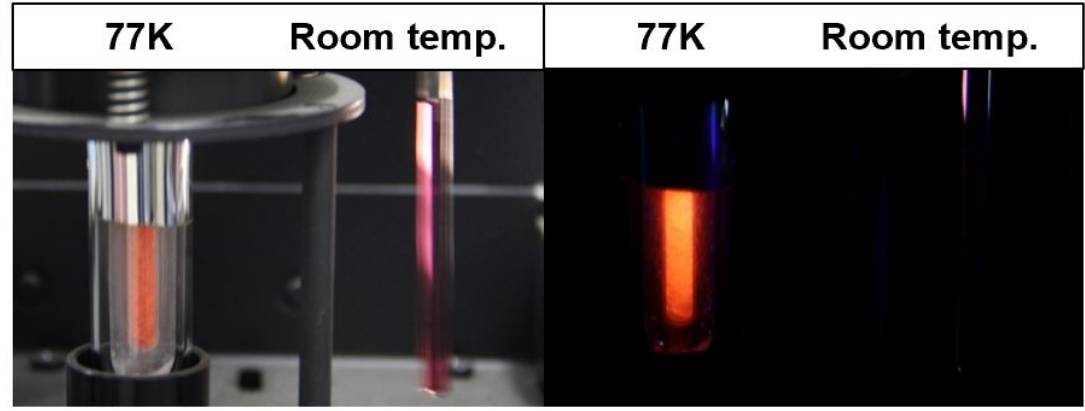

(b)

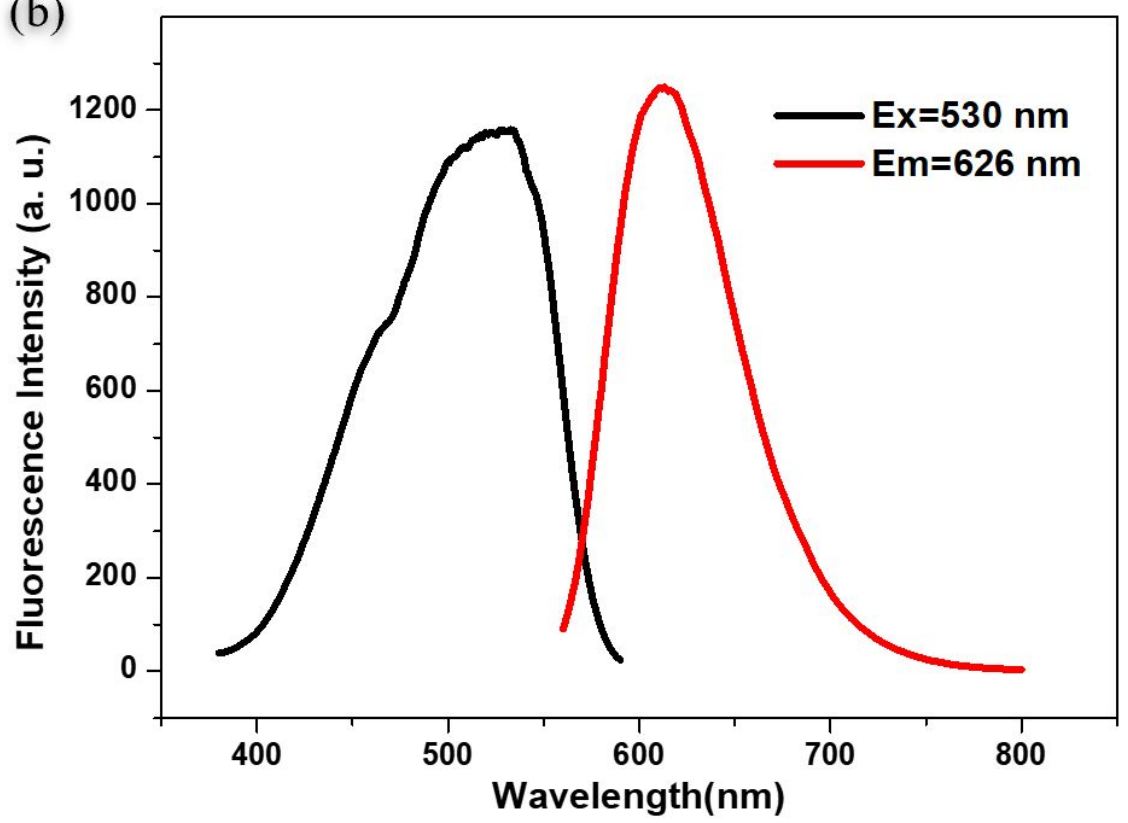

Figure S2 (a) Left Photograph of $100 \mu \mathrm{M}$ TPNPDA-C12 ethanol solution in liquid nitrogen (77 K) or ambient environment under room light. Right Fluorescence photograph of $100 \mu \mathrm{M}$ TPNPDA-C12 ethanol solution in liquid nitrogen $(77 \mathrm{~K})$ or ambient environment. Pictures taken under $365 \mathrm{~nm}$ UV lamp. (b) Excitation and emission fluorescence spectra of $100 \mu \mathrm{M}$ TPNPDA-C12 ethanol solution in liquid nitrogen $(77 \mathrm{~K})$ 
(a)
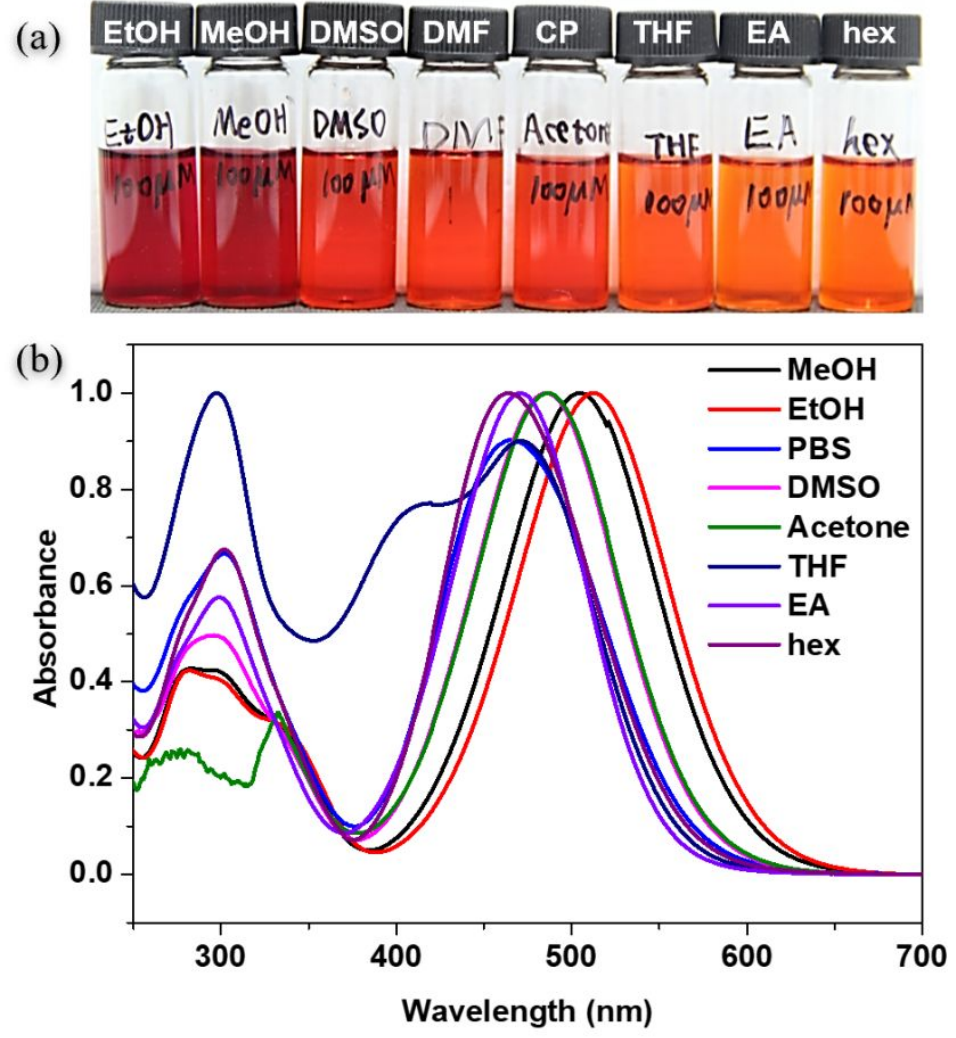

Figure S3 (a) Photograph of $100 \mu \mathrm{M}$ TPNPDA-C12 solution in different solvents. (b) UV absorption spectra of TPNPDA-C12 solution in different solvents.

(a)

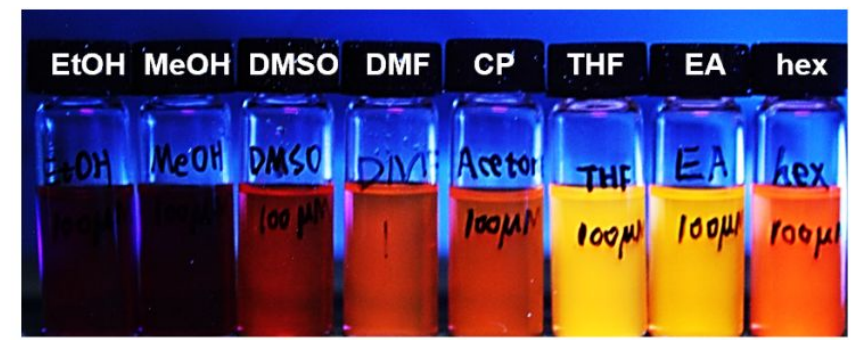

(b)

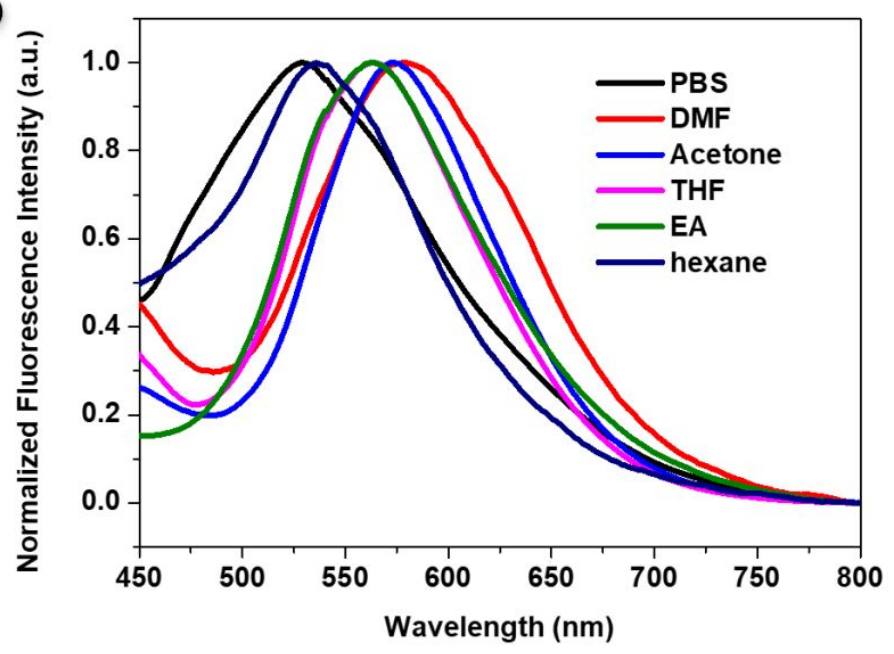

Figure S4 (a) Fluorescence photograph of $100 \mu \mathrm{M}$ TPNPDA-C12 solution in different solvents. 
Pictures taken under $365 \mathrm{~nm}$ UV lamp. (b) Normalized fluorescence spectra of TPNPDA-C12 solution in different solvents. $\lambda_{\mathrm{ex}}=370 \mathrm{~nm}$.
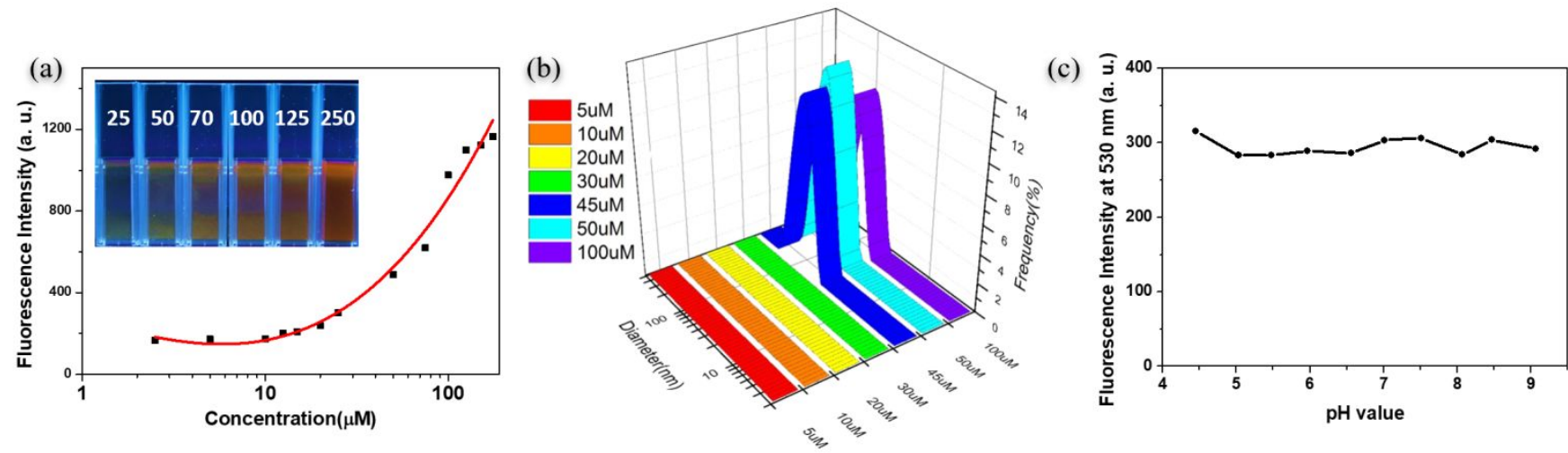

Figure S5 (a) Plot of fluorescence intensity at $530 \mathrm{~nm}$ versus the concentration of TPNPDA-C12 in PBS buffer. Inset: fluorescence photographs of 25-250 $\mu \mathrm{M}$ TPNPDA-C12 in PBS buffer taken under 365 nm UV lamp. (b) Dynamic light scattering (DLS) analysis for TPNPDA-C12 in PBS buffer with different concentrations. (c) Fluorescence intensity of TPNPDA-C12 at $\lambda=530 \mathrm{~nm}$ under $\mathrm{pH}$ range of 4.45-9.07

\begin{tabular}{|c|c|c|c|c|c|}
\hline Functional & M06 & M06-2X & M11 & LC-w-HPBE & M06-HF \\
\hline $\begin{array}{c}\mathbf{S}_{\mathbf{1}} \text { excitation } \\
\text { energy (eV) }\end{array}$ & 0.89 & 0.06 & 0.80 & 1.08 & 2.04 \\
\hline $\begin{array}{c}\mathbf{S}_{\mathbf{1}} \text { excitation } \\
\text { wavelength } \\
\text { (nm) }\end{array}$ & 1391.9 & 20308.7 & 1555.7 & 1147.7 & 608.7 \\
\hline $\begin{array}{c}\text { Oscillator } \\
\text { strength } \boldsymbol{f}\end{array}$ & 0.0003 & 0.0001 & 0.0198 & 0.0630 & 1.8010 \\
\hline
\end{tabular}

Table S1 The $\mathrm{S}_{1}$ state excitation energy and oscillator strength at optimized $\mathrm{S}_{1}$ geometry with different functionals 

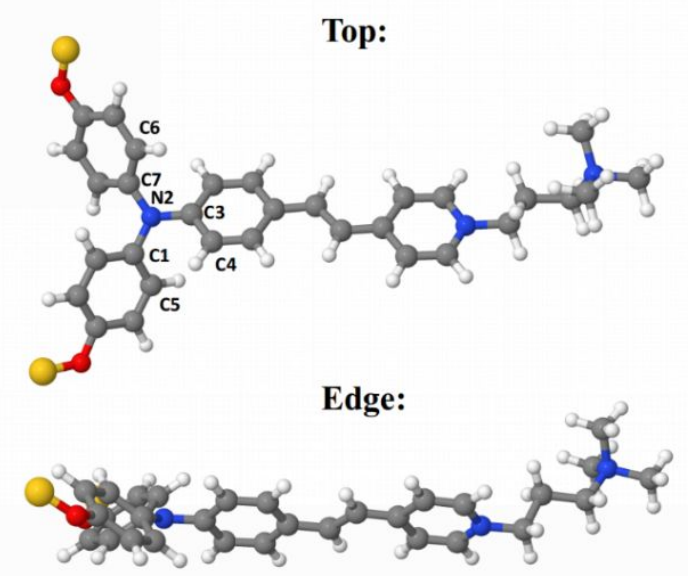

Figure S6 Top view and edge view of the optimized TPNPDA geometry at $\mathrm{S}_{1}$ state.

\begin{tabular}{|c|c|c|c|c|c|}
\hline Geometry & $\begin{array}{c}\text { Dihedral angle } \\
\angle \mathbf{C 5 - C 1 - N 2 -} \\
\left.\mathbf{C 3} \mathbf{(}^{\circ}\right)\end{array}$ & $\begin{array}{c}\text { Dihedral angle } \\
\angle \mathbf{C 6 - C 7 - N 2 -} \\
\mathbf{C 3}\left(^{\circ}\right)\end{array}$ & $\begin{array}{c}\text { Dihedral angle } \\
\angle \mathbf{C 1 - N 2}-\mathbf{C 3}- \\
\left.\mathbf{C 4} \mathbf{(}^{\circ}\right)\end{array}$ & $\begin{array}{c}\text { Excitation } \\
\text { energy E (eV) }\end{array}$ & $\begin{array}{c}\text { Oscillator } \\
\text { strength } \boldsymbol{f}\end{array}$ \\
\hline $\mathbf{S}_{\mathbf{0}}$ & 60.7 & 64.3 & 12.6 & 2.43 & 2.13 \\
\hline $\mathbf{S}_{\mathbf{1}}$ & 39.8 & 40.6 & 34.0 & 2.04 & 1.80 \\
\hline
\end{tabular}

Table S2 Selected dihedral angles, $\mathrm{S}_{1}$ excitation energy and oscillator strength of TPNPDA at optimized $\mathrm{S}_{0}$ and $\mathrm{S}_{1}$ geometry

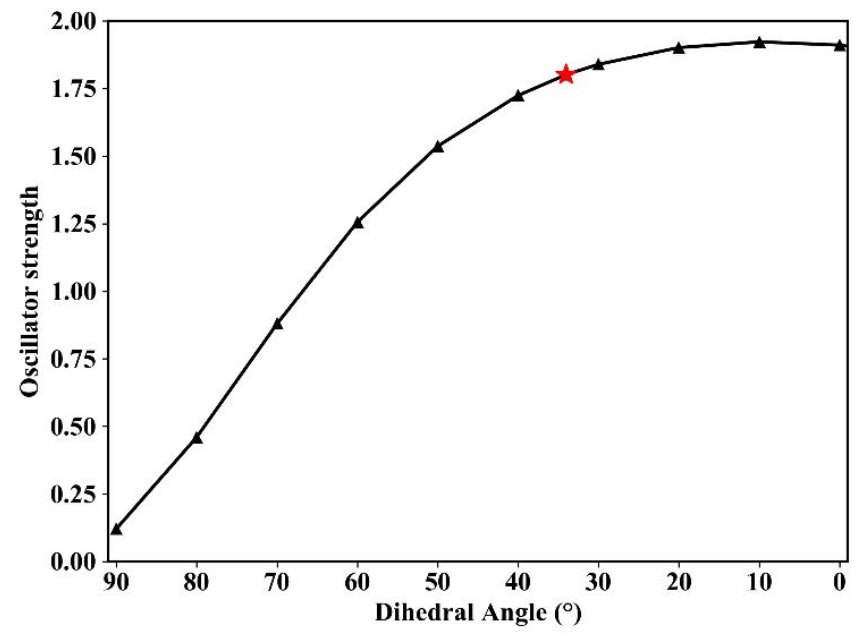

Figure S7 The oscillator strength with different C1-N2-C3-C4 dihedral angles from $90^{\circ}$ to $0^{\circ}$. 


\begin{tabular}{|c|c|c|c|c|c|c|}
\hline Solvent & $\begin{array}{c}\lambda_{\text {abs max }} 1(\mathrm{~nm}) / \varepsilon\left(10^{4}\right. \\
\left.\mathrm{L} \cdot \mathrm{mol}^{-1} \mathrm{~cm}^{-1}\right)\end{array}$ & $\begin{array}{c}\lambda_{\text {abs max }} 2(\mathrm{~nm}) / \varepsilon \\
\left(10^{4} \mathrm{~L}_{\mathrm{mol}} \mathrm{cm}^{-1}\right)\end{array}$ & $\begin{array}{c}\lambda \mathrm{ex} / \lambda \mathrm{em} \\
(\mathrm{nm})\end{array}$ & $\tau(\mathrm{ns})$ & $\begin{array}{c}\text { Quantum } \\
\text { yield (\%) }\end{array}$ & $\begin{array}{c}\text { Average } \\
\text { diameter }(\mathrm{nm})\end{array}$ \\
\hline ethanol & $282 / 0.6952$ & $510 / 1.6302$ & $/$ & $/$ & $/$ & 5.5 \\
\hline $\begin{array}{c}99 \% \text { ethyl } \\
\text { acetate }\end{array}$ & $299 / 1.3595$ & $471 / 2.3609$ & $373 / 567$ & 2.3083 & 2.2 & 104.1 \\
\hline $99 \%$ & $299 / 1.6076$ & $501 / 1.0648$ & $500 / 650$ & 0.1128 & 3.2 & 2.8 \\
\hline
\end{tabular}

Table S3 Summarization of dual-color photoluminescence properties of TPNPDA-C12
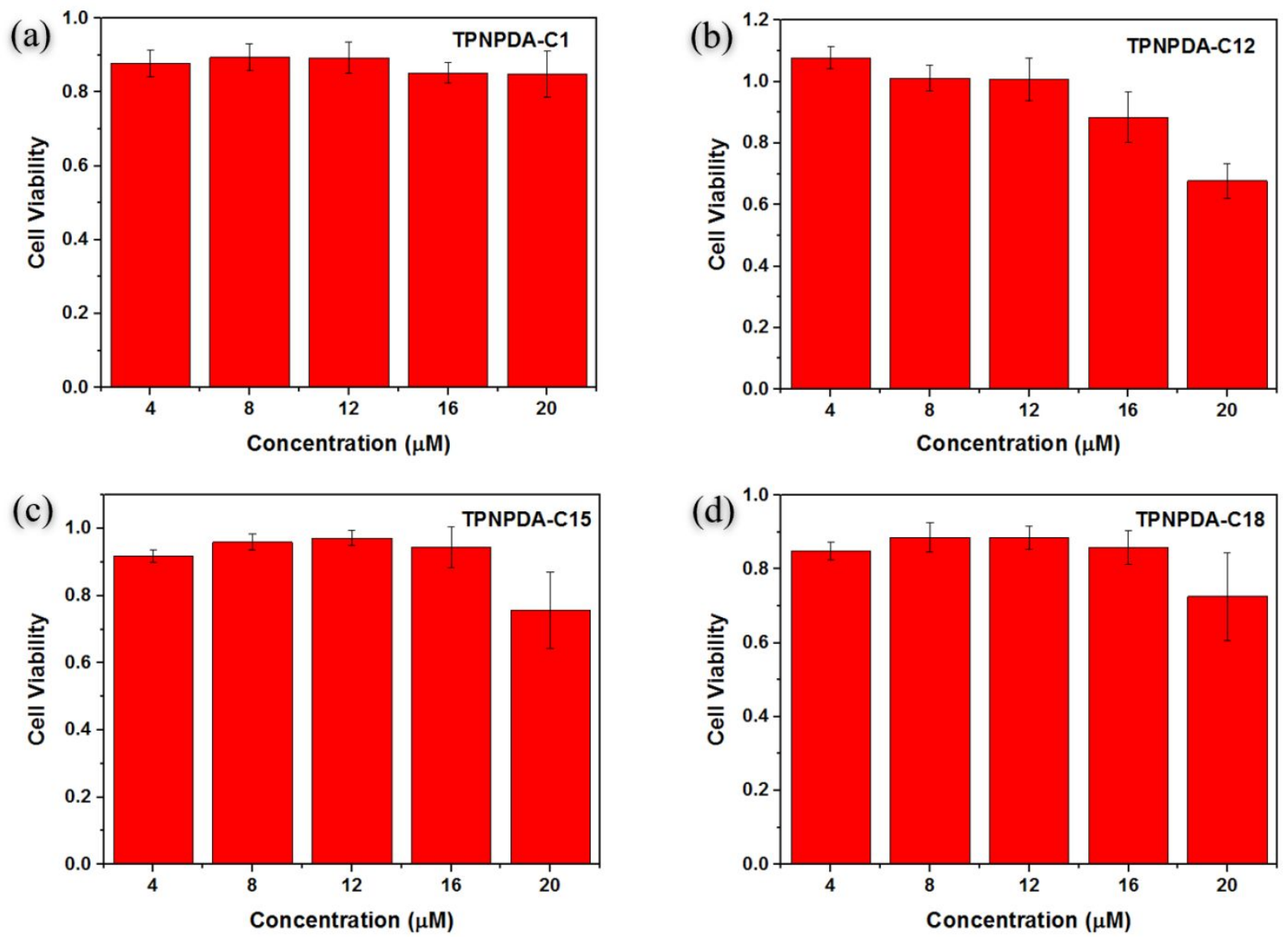

Figure S8 Cytotoxicity of (a) TPNPDA-C1 (b) TPNPDA-C12 (c) TPNPDA-C15 (d) TPNPDA-C18 for HeLa cells. Error bars represent standard error of mean for five repeated measurements. 

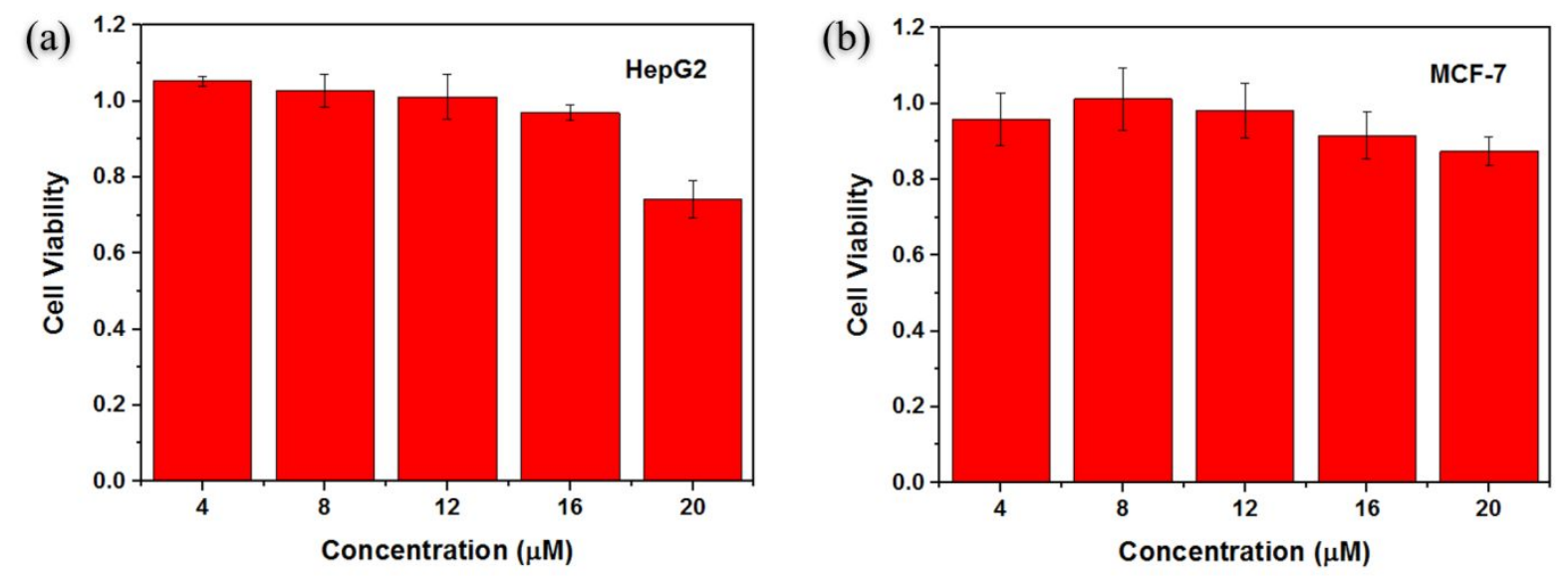

Figure S9 Cytotoxicity of TPNPDA-C12 for (a) HepG2 and (b) MCF-7 cells. Error bars represent standard error of mean for five repeated measurements.
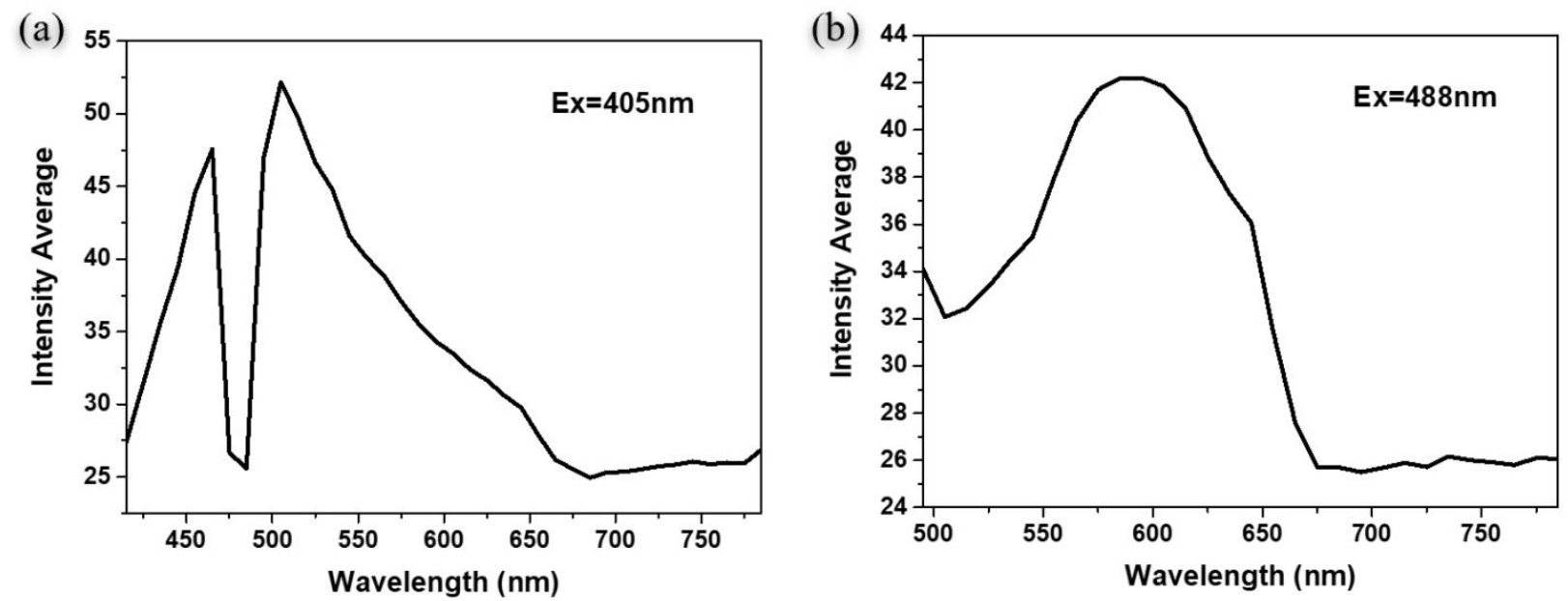

Figure S10 Plot of the mean emission intensity of Hela cells stained by TPNPDA-C12 from scans over various $\lambda$ zones from 450 to $750 \mathrm{~nm}$ with $10 \mathrm{~nm}$ integration. (a) Excited by $405 \mathrm{~nm}$ laser. (b) Excited by $488 \mathrm{~nm}$ laser. The plot was gained by a confocal microscope under lambda mode. 
(a)

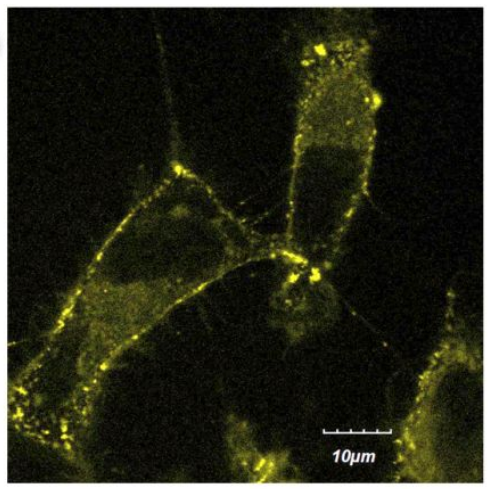

(d)

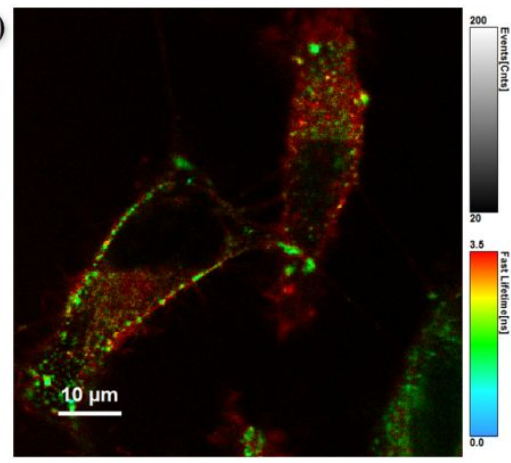

(b)

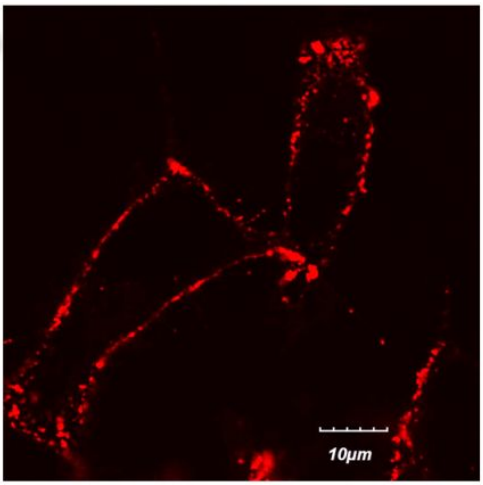

(c)

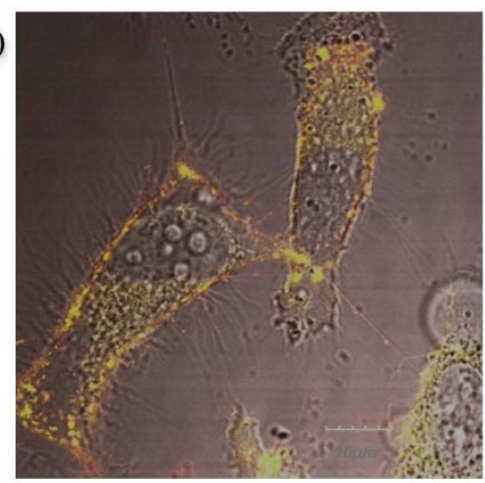

(e)
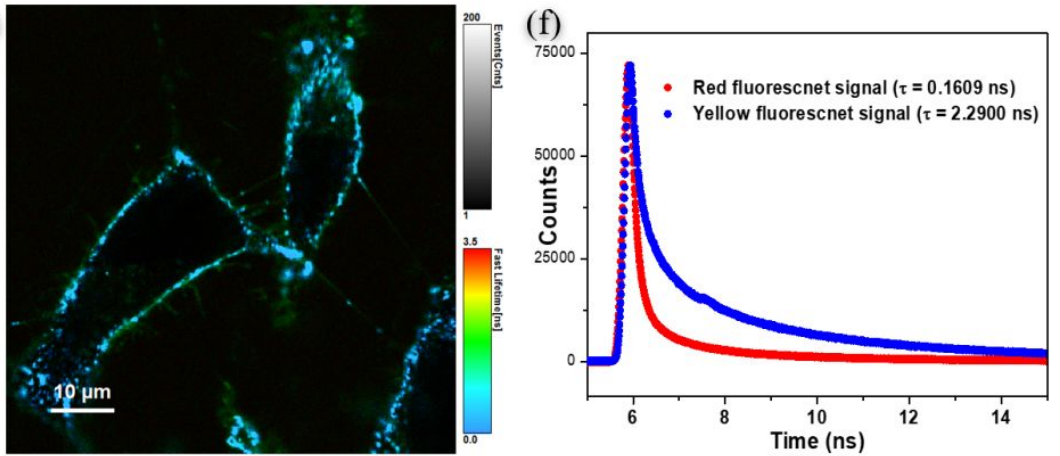

Figure S11 Confocal fluorescence images of HeLa cells stained with TPNPDA-C12 in (a) yellow channel (490-560 nm), (b) red channel $(600-700 \mathrm{~nm})$, (c) merged channel with bright field. Fluorescence lifetime images of HeLa cells stained with TPNPDA-C12 in (d) yellow channel (550 $25 \mathrm{~nm})$ scanned under $405 \mathrm{~nm}$ laser and (e) red channel $(615 \pm 30 \mathrm{~nm})$ scanned under $488 \mathrm{~nm}$ laser. Fluorescence lifetime values from 0.0 to $3.5 \mathrm{~ns}$ are represented by pseudocolors from blue to red as shown in the color scale bar on the right of (d) and (e). Scale bar is $10 \mu \mathrm{m}$. (f) Fluorescence decay curves and lifetimes in yellow and red channels analyzed by FLIM system. 


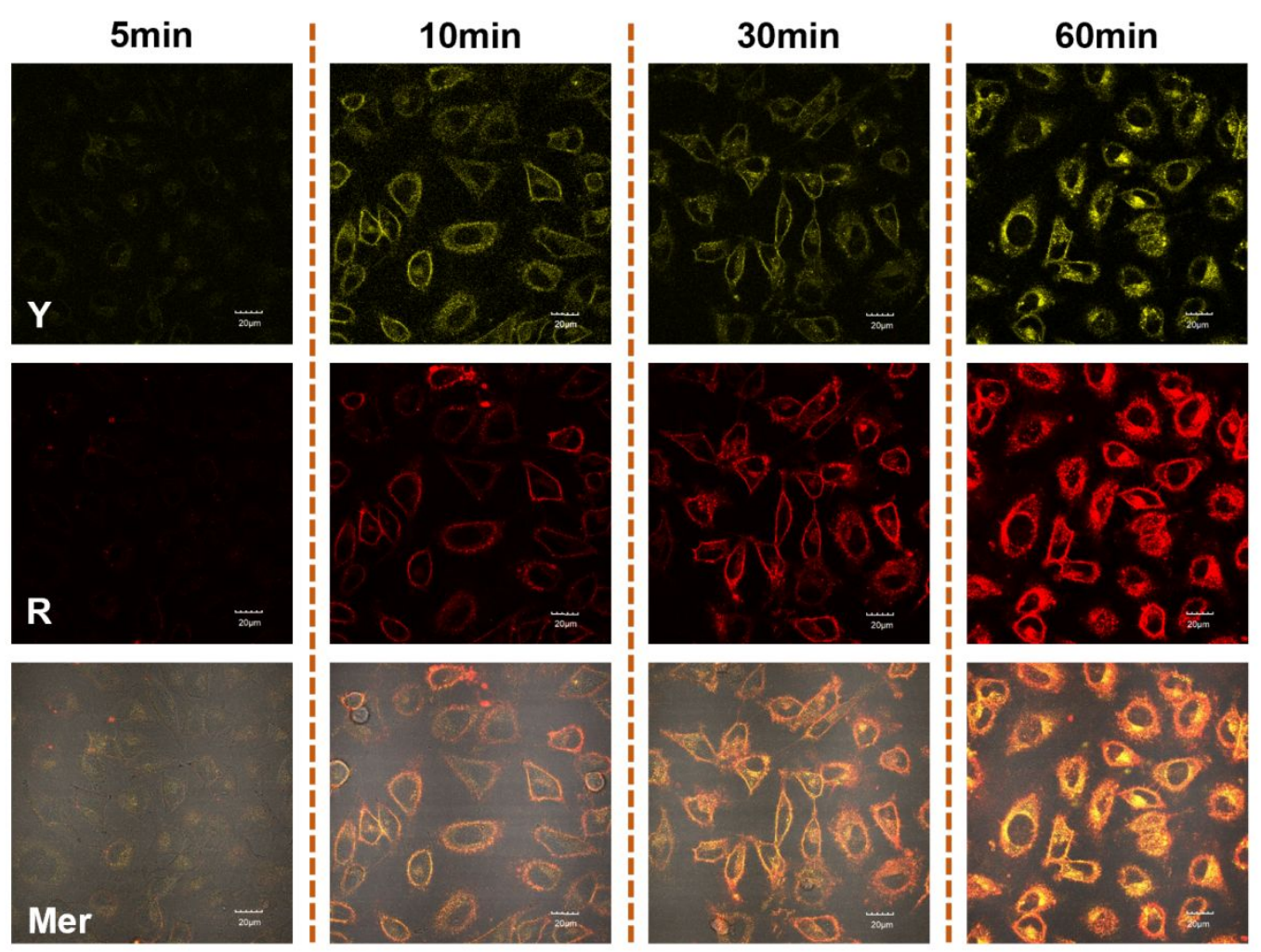

Figure S12 Experimental modification for live cell staining conditions (incubating time). Confocal fluorescence images of HeLa cells incubated at $37{ }^{\circ} \mathrm{C}$ with $10 \mu \mathrm{M}$ TPNPDA-C12 for different incubation time. Scale bar is $20 \mu \mathrm{m}$.

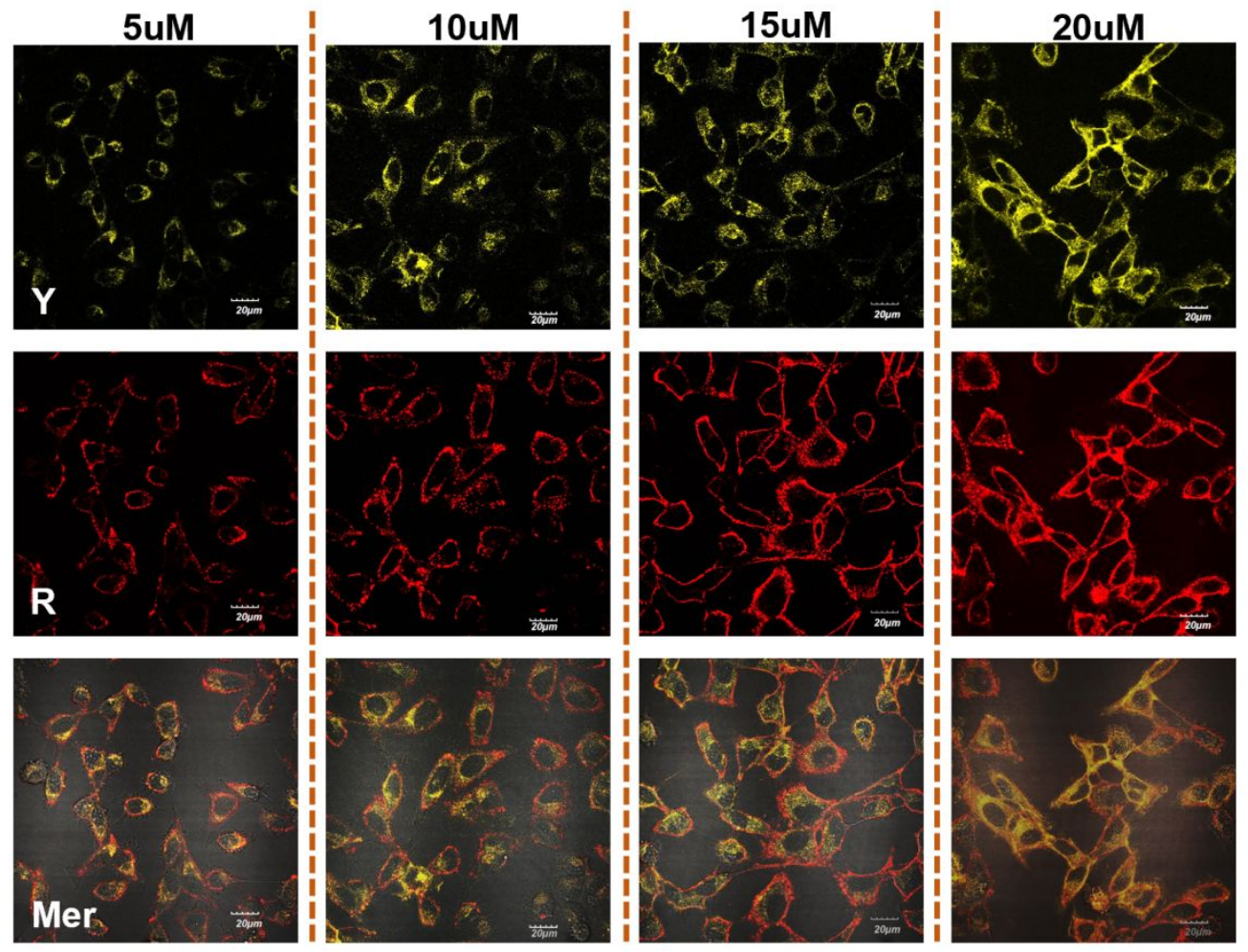

Figure S13 Experimental modification for live cell staining conditions (dye concentration). Confocal 
fluorescence images of HeLa cells incubated at $37{ }^{\circ} \mathrm{C}$ with TPNPDA-C12 at different dye concentration for $10 \mathrm{~min}$. Scale bar is $20 \mu \mathrm{m}$.

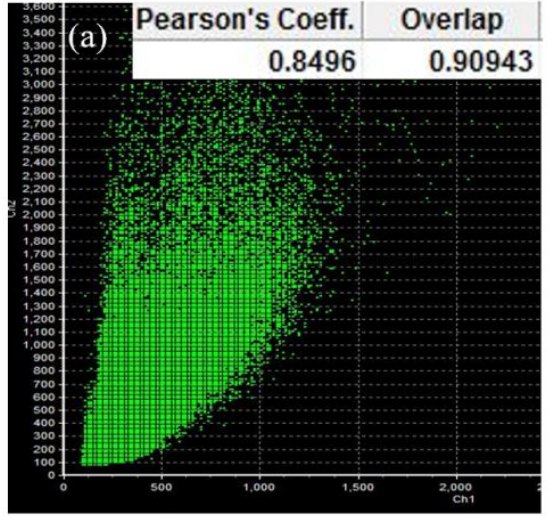

DiO and Red channel

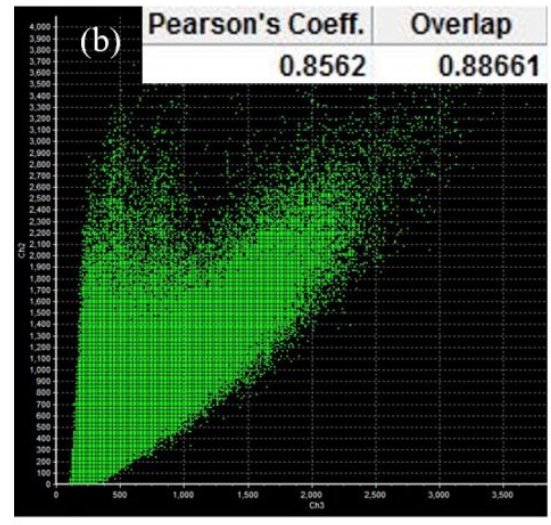

MTDR and Yellow channel

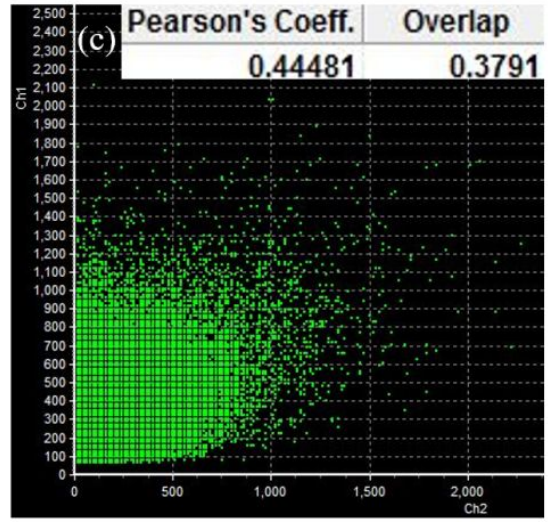

LyDR and Yellow channel

Figure S14 Co-localization scatter plots and correlation coefficients for TPNPDA-C12 with commercial subcellular organelle probes of HeLa cells. (a) Red channel and DiO for cytoplasm membrane co-localization. Pearson's correlation coefficient is 0.85. (b) Yellow channel and MTDR for mitochondria co-localization. Pearson's correlation coefficient is 0.86 . (c) Yellow channel and LyDR for lysosome. Pearson's correlation coefficient is 0.44 .

(a)

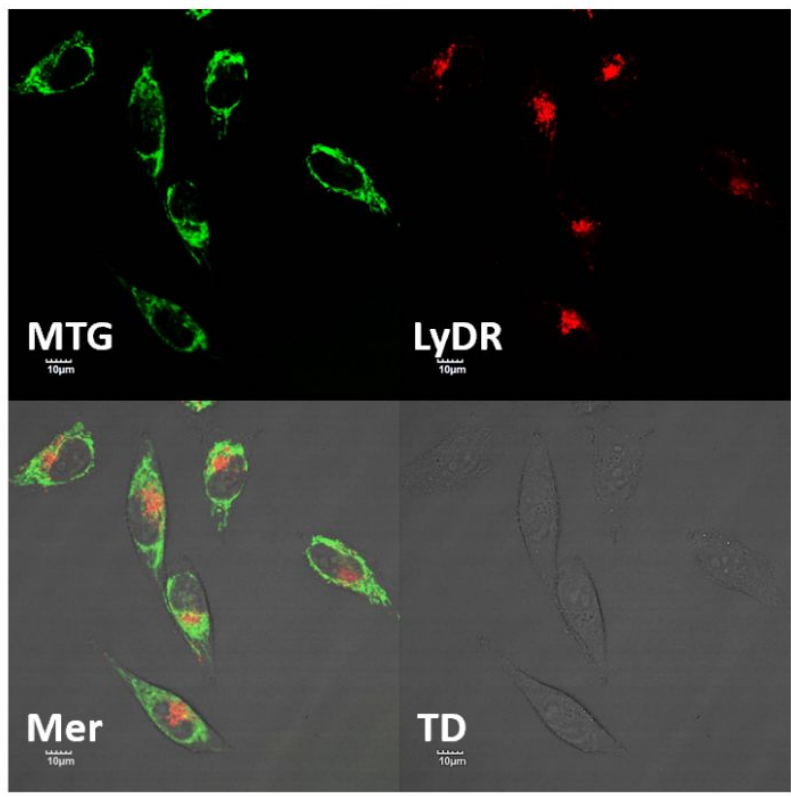

(b)

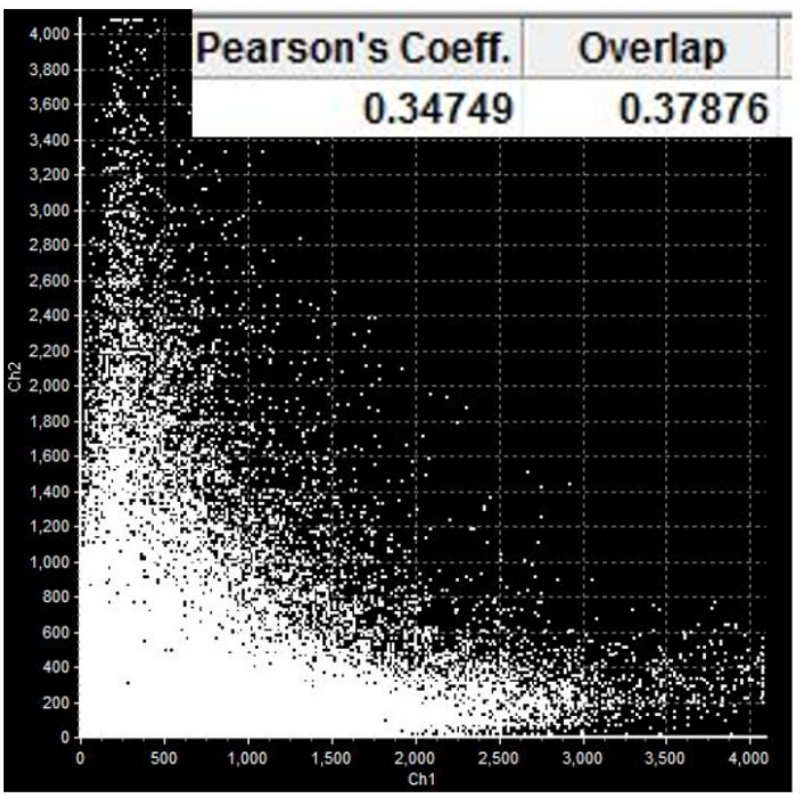

Figure S15 (a) Confocal fluorescence images of HeLa cells for co-localization of MTG with LyDR. Scale bar is $10 \mu \mathrm{m}$. (b) Co-localization scatter plot and correlation coefficient of MTG with LyDR for HeLa cells. Pearson's correlation coefficient is 0.35 , which is similar to Yellow channel and LyDR for lysosome co-localization. 

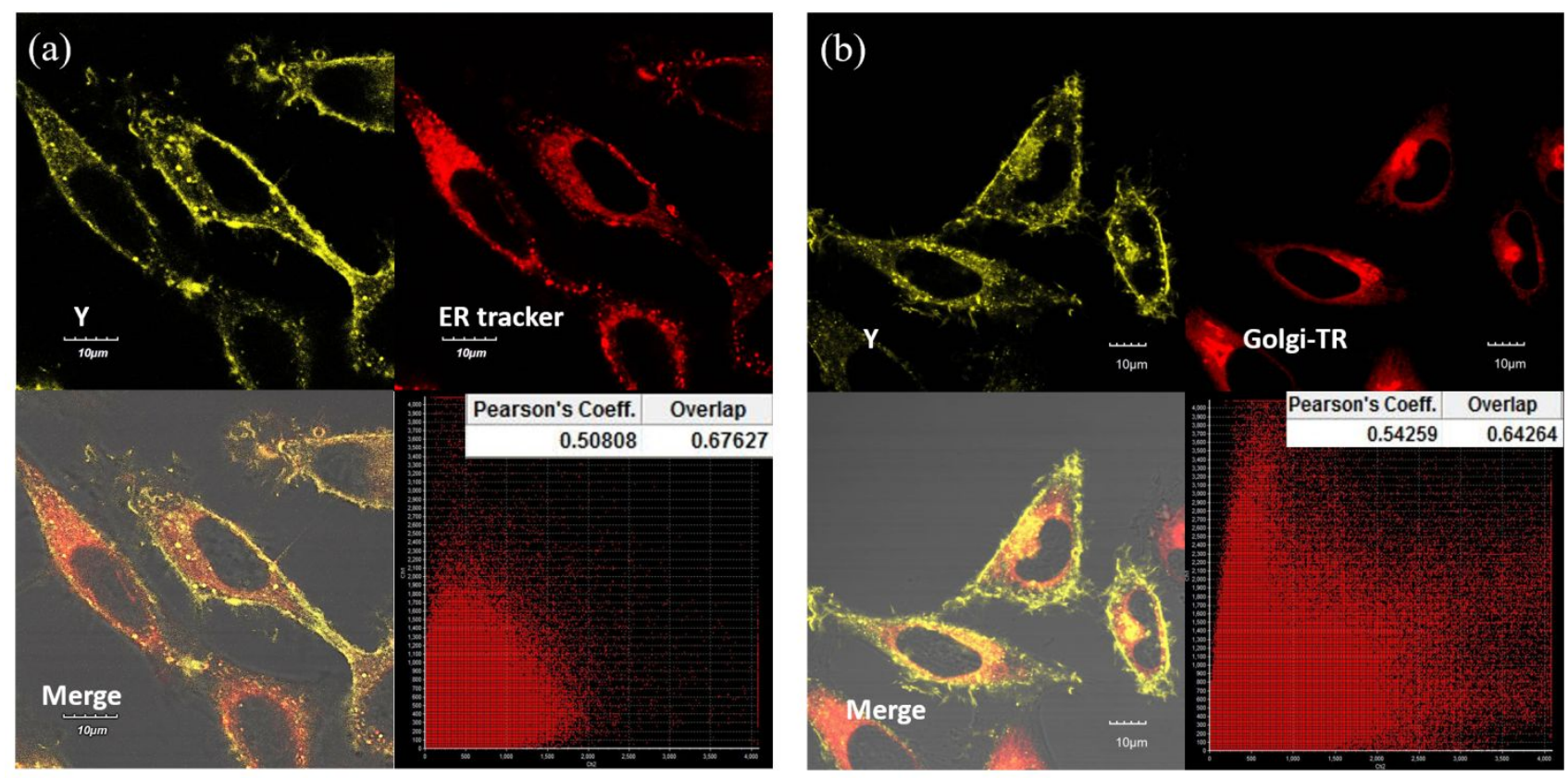

Figure S16 Confocal fluorescence images and co-localization scatter plots of Hela cells co-stained with TPNPDA-C12 and (a) ER-tracker Red (b) Golgi-tracker. Scale bar is $10 \mu \mathrm{m}$. Pearson's correlation coefficients are 0.51 and 0.54 , respectively.
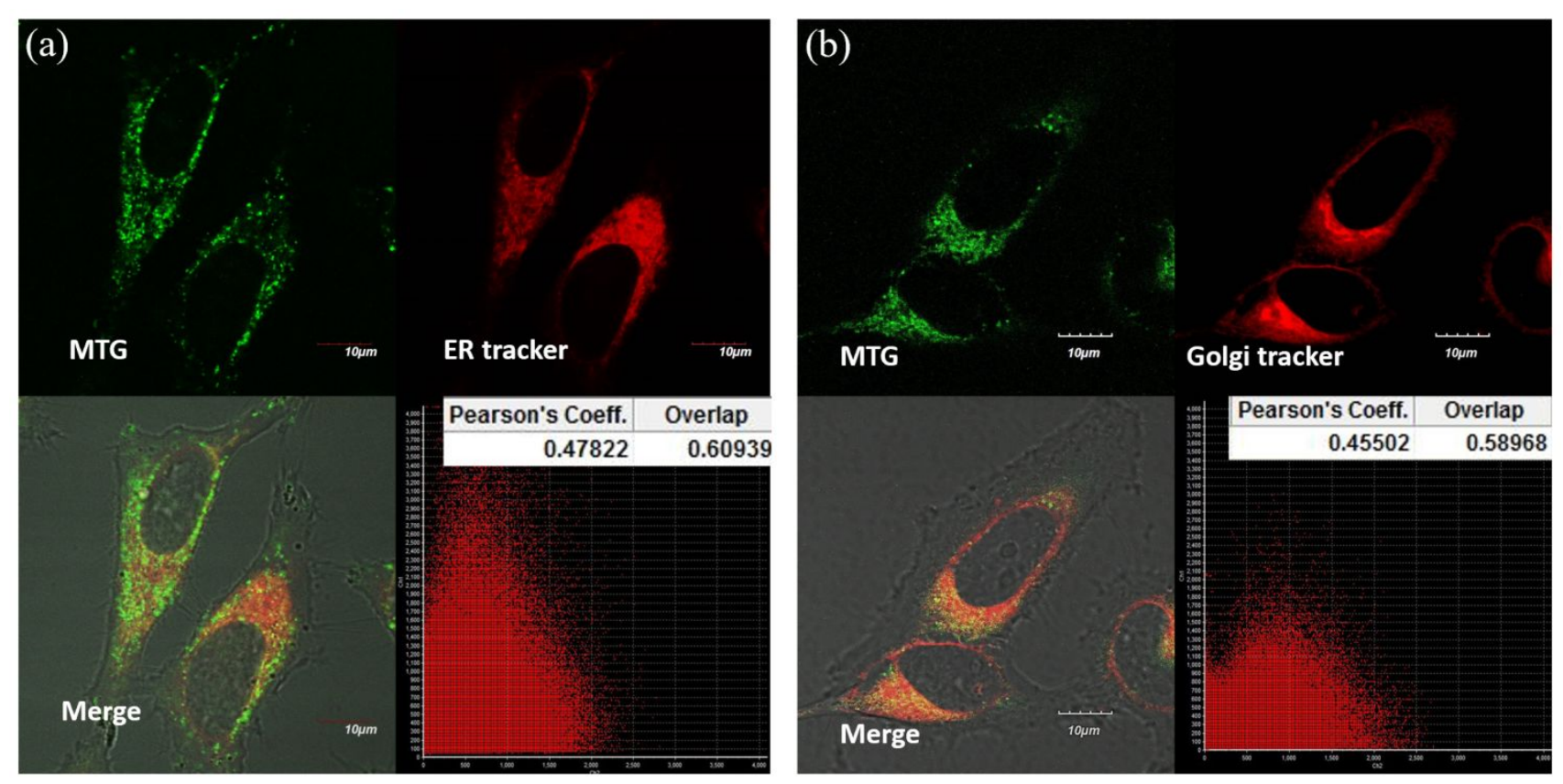

Figure S17 Confocal fluorescence images and co-localization scatter plots of Hela cells co-stained with mitotracker green and (a) ER-tracker Red (b) Golgi-tracker. Scale bar is $10 \mu \mathrm{m}$. Pearson's correlation coefficients are 0.48 and 0.46 , respectively. 
(a) HepG2

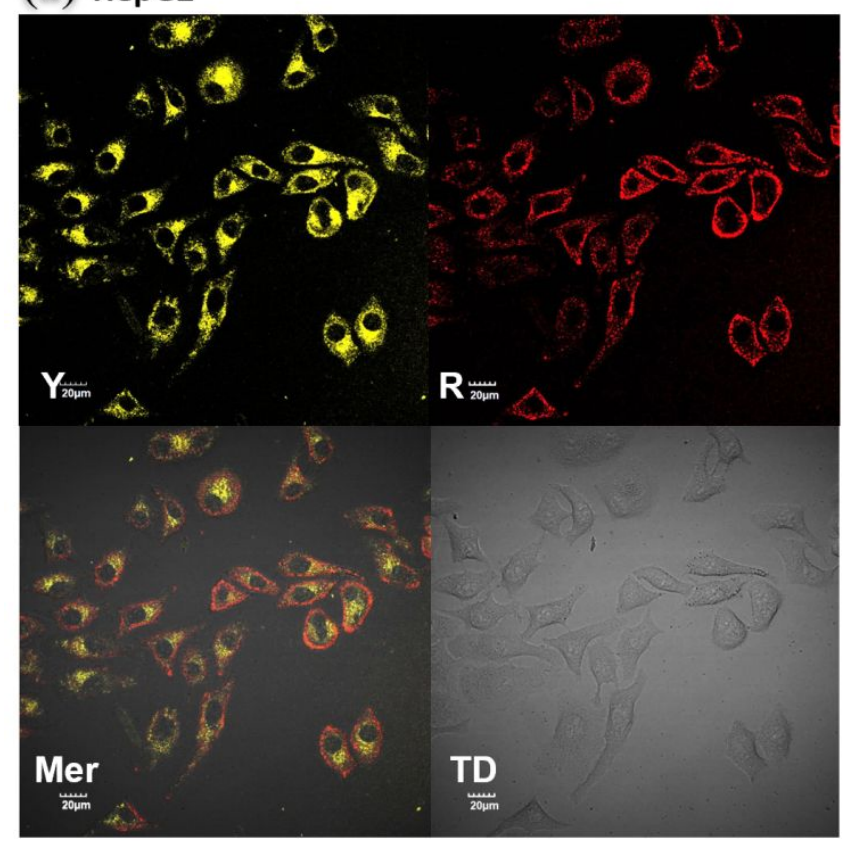

(b) MCF-7

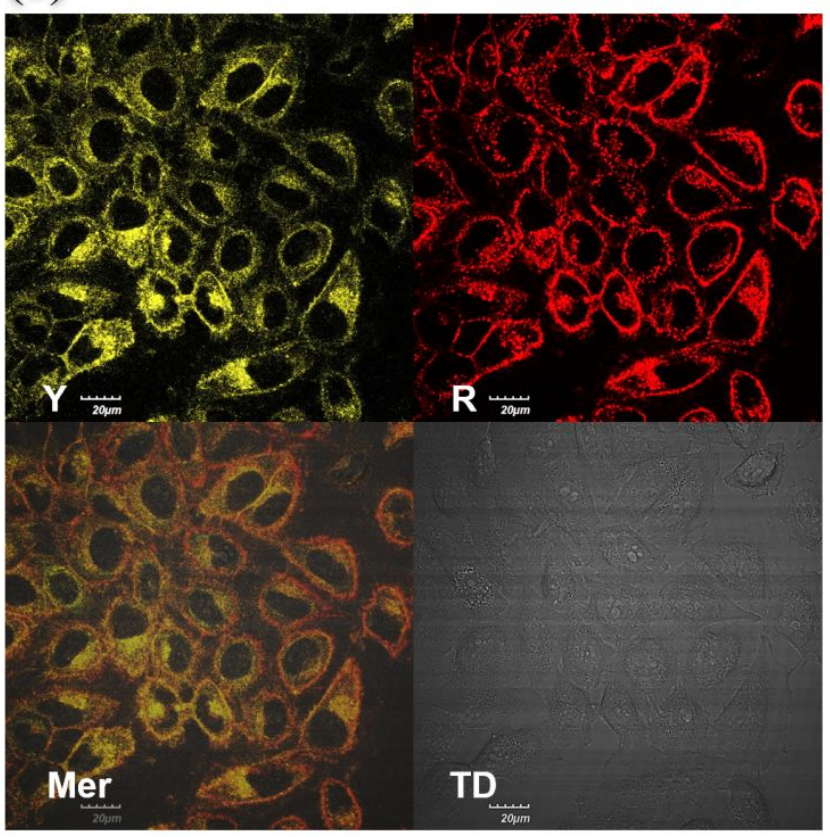

Figure S18 Confocal fluorescence images of (a) HepG2 and (b) MCF-7 cells stained with TPNPDAC12. Scale bar is $20 \mu \mathrm{m}$.
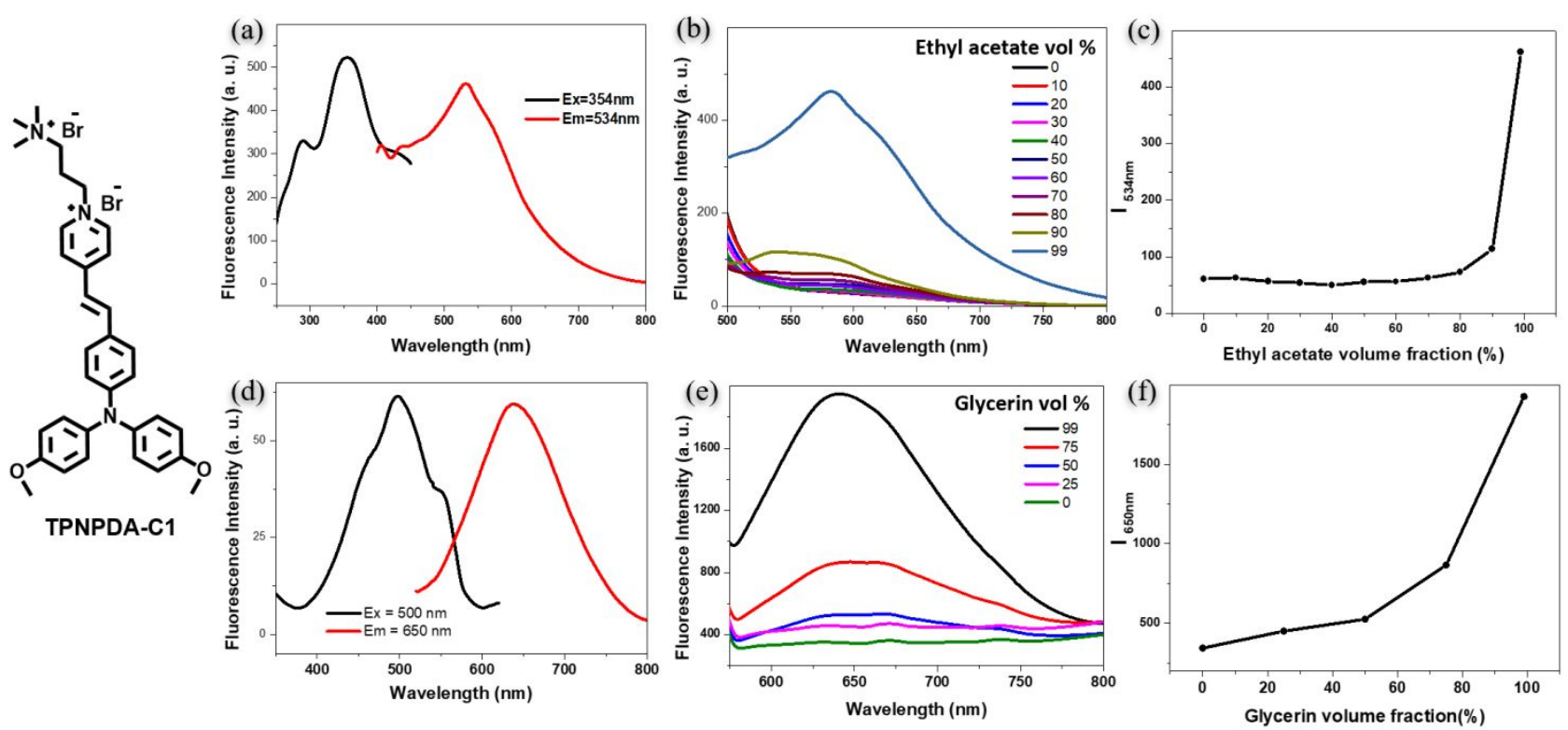

Figure S19 (a) Excitation and emission fluorescence spectra of $100 \mu \mathrm{M}$ TPNPDA-C1 solution in 99\% ethyl acetate solution. (b) Fluorescence spectra of $100 \mu \mathrm{M}$ TPNPDA-C1 with different ethyl acetate/ethanol volume fraction. $\lambda_{\mathrm{ex}}=370 \mathrm{~nm}$. (c) Fluorescence intensity of $100 \mu \mathrm{M}$ TPNPDA-C1 at $534 \mathrm{~nm}$ with different ethyl acetate/ethanol volume fraction. $\lambda_{\mathrm{ex}}=370 \mathrm{~nm}$. (d)Excitation and emission 
fluorescence spectra of $100 \mu \mathrm{M}$ TPNPDA-C1 solution in 99\% glycerin solution. (e) Fluorescence spectra of $100 \mu \mathrm{M}$ TPNPDA-C1 with different glycerin/ethanol volume fraction. $\lambda_{\text {ex }}==500 \mathrm{~nm}$. (f) Fluorescence intensity of $100 \mu \mathrm{M}$ TPNPDA-C1 at $650 \mathrm{~nm}$ with different glycerin/ethanol volume fraction. $\lambda_{\mathrm{ex}}==500 \mathrm{~nm}$.
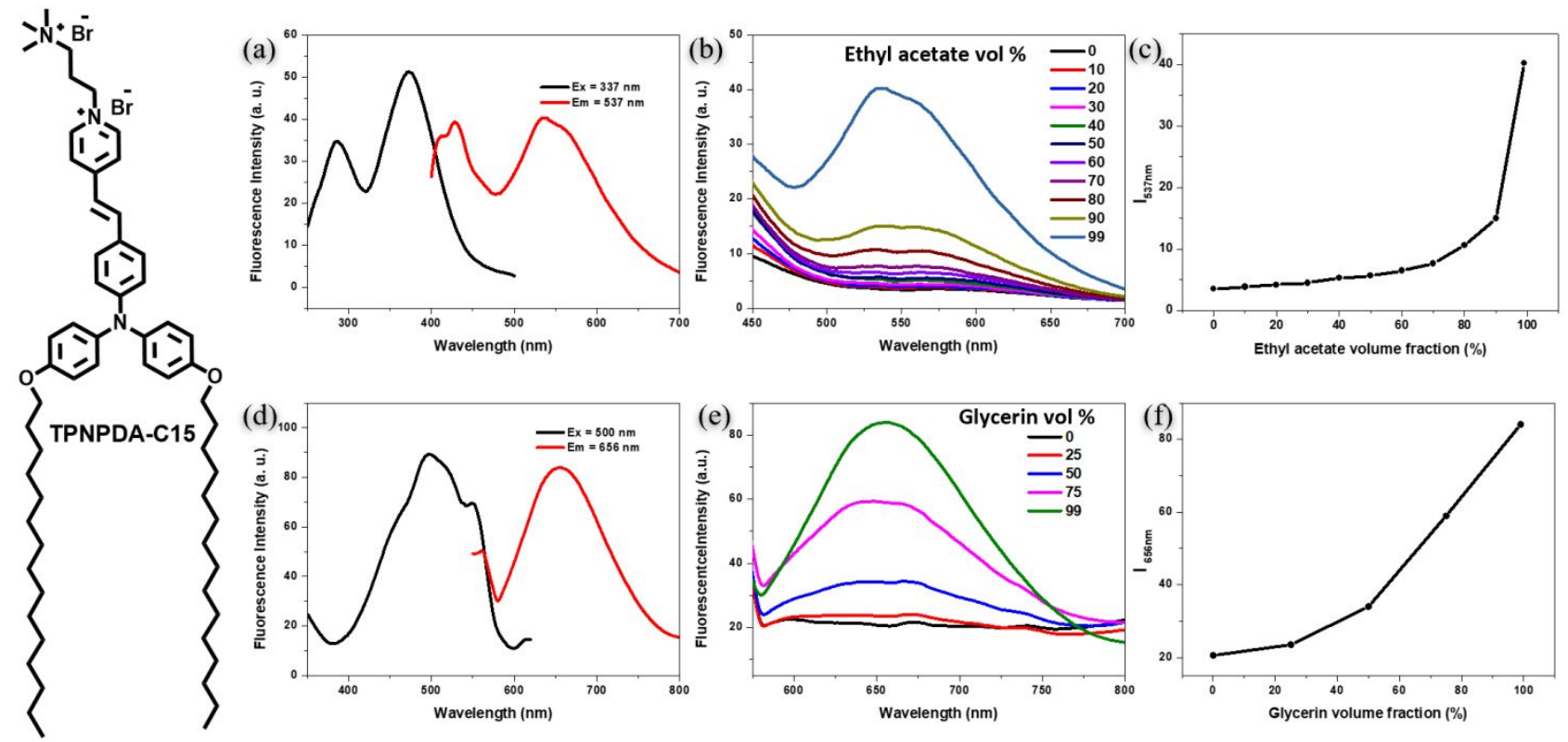

Figure S20 (a) Excitation and emission fluorescence spectra of $100 \mu \mathrm{M}$ TPNPDA-C15 solution in 99\% ethyl acetate solution. (b) Fluorescence spectra of $100 \mu \mathrm{M}$ TPNPDA-C15 with different ethyl acetate/ethanol volume fraction. $\lambda_{\mathrm{ex}}=370 \mathrm{~nm}$. (c) Fluorescence intensity of $100 \mu \mathrm{M}$ TPNPDA-C15 at $537 \mathrm{~nm}$ with different ethyl acetate/ethanol volume fraction. $\lambda_{\mathrm{ex}}=370 \mathrm{~nm}$. (d)Excitation and emission fluorescence spectra of $100 \mu \mathrm{M}$ TPNPDA-C15 solution in 99\% glycerin solution. (e) Fluorescence spectra of $100 \mu \mathrm{M}$ TPNPDA-C15 with different glycerin/ethanol volume fraction. $\lambda_{\mathrm{ex}}=500 \mathrm{~nm}$. (f) Fluorescence intensity of $100 \mu \mathrm{M}$ TPNPDA-C15 at $650 \mathrm{~nm}$ with different glycerin/ethanol volume fraction. $\lambda_{\mathrm{ex}}=500 \mathrm{~nm}$. 

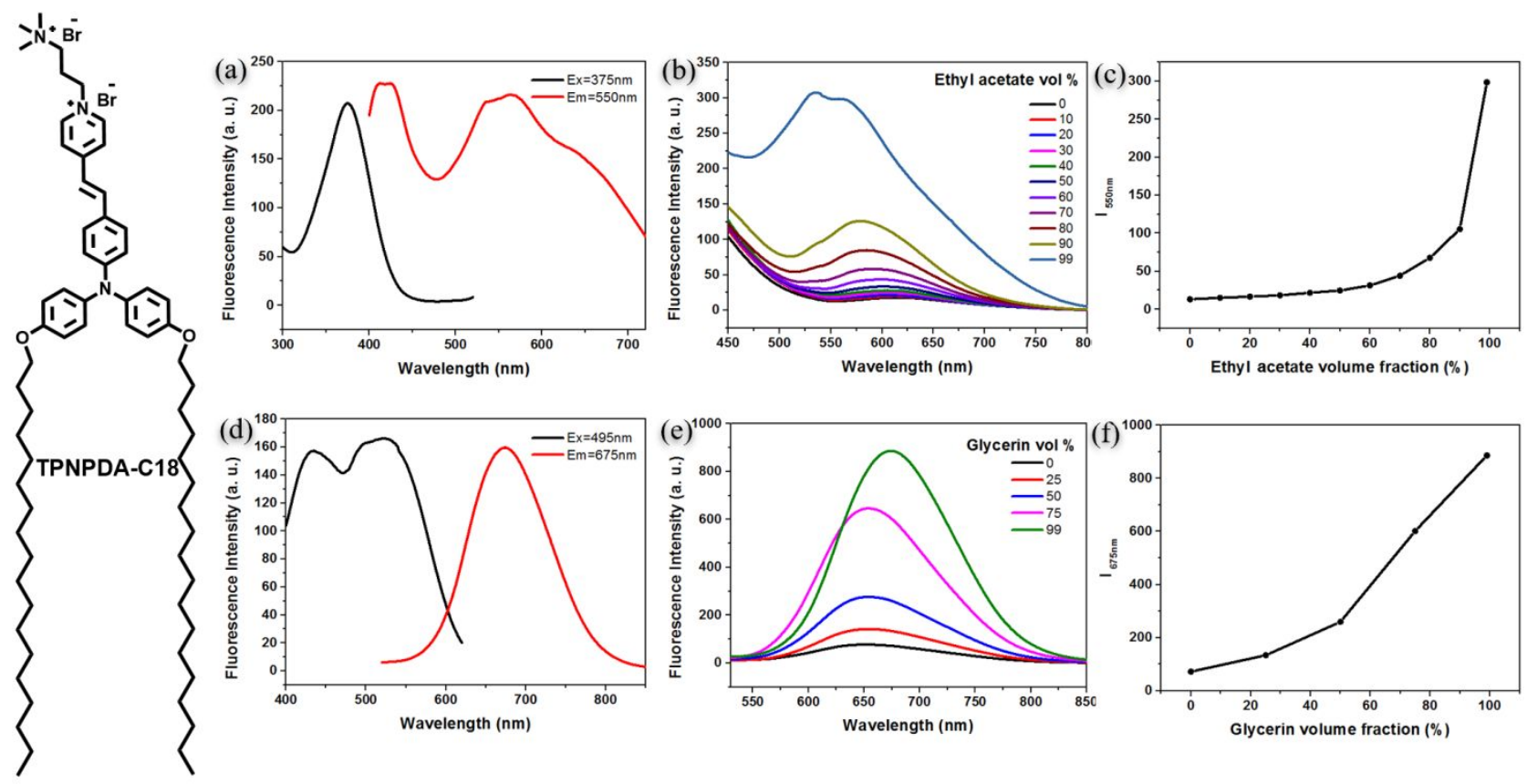

Figure S21 (a) Excitation and emission fluorescence spectra of $100 \mu \mathrm{M}$ TPNPDA-C18 solution in 99\% ethyl acetate solution. (b) Fluorescence spectra of $100 \mu \mathrm{M}$ TPNPDA-C18 with different ethyl acetate/ethanol volume fraction. $\lambda_{\mathrm{ex}}=370 \mathrm{~nm}$. (c) Fluorescence intensity of $100 \mu \mathrm{M}$ TPNPDA-C18 at $537 \mathrm{~nm}$ with different ethyl acetate/ethanol volume fraction. $\lambda_{\mathrm{ex}}=370 \mathrm{~nm}$. (d)Excitation and emission fluorescence spectra of $100 \mu \mathrm{M}$ TPNPDA-C18 solution in 99\% glycerin solution. (e) Fluorescence spectra of $100 \mu \mathrm{M}$ TPNPDA-C18 with different glycerin/ethanol volume fraction. $\lambda_{\text {ex }}=500 \mathrm{~nm}$. (f) Fluorescence intensity of $100 \mu \mathrm{M}$ TPNPDA-C18 at $650 \mathrm{~nm}$ with different glycerin/ethanol volume fraction. $\lambda_{\mathrm{ex}}=500 \mathrm{~nm}$. 


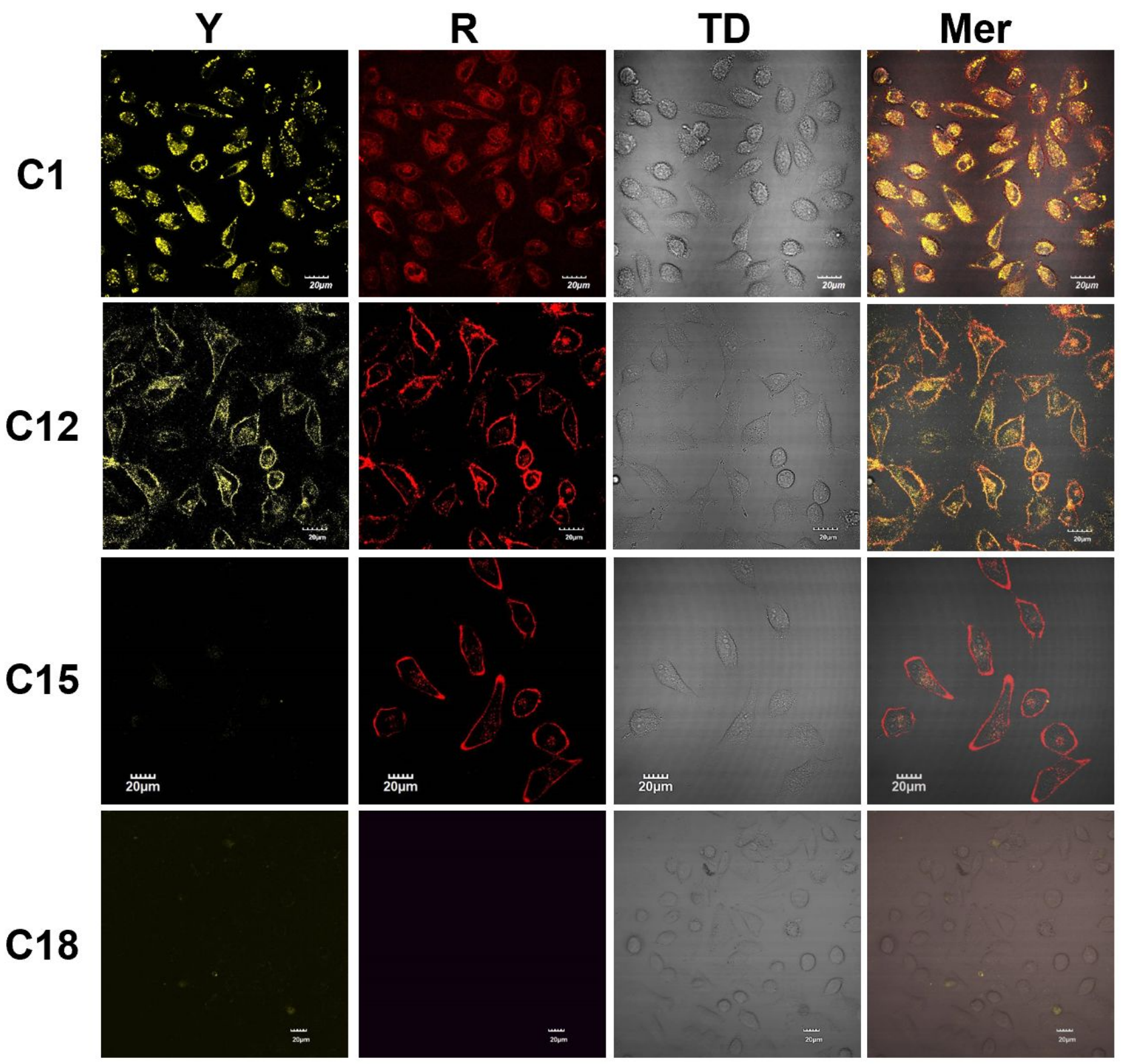

Figure S22 Confocal fluorescence images of HeLa cells stained with TPNPDA-C1, TPNPDA-C12, TPNPDA-C15 and TPNPDA-C18 (10 $\mu \mathrm{M}$ probes incubated for $30 \mathrm{~min})$. Scale bar is $20 \mu \mathrm{m}$. 
(a)

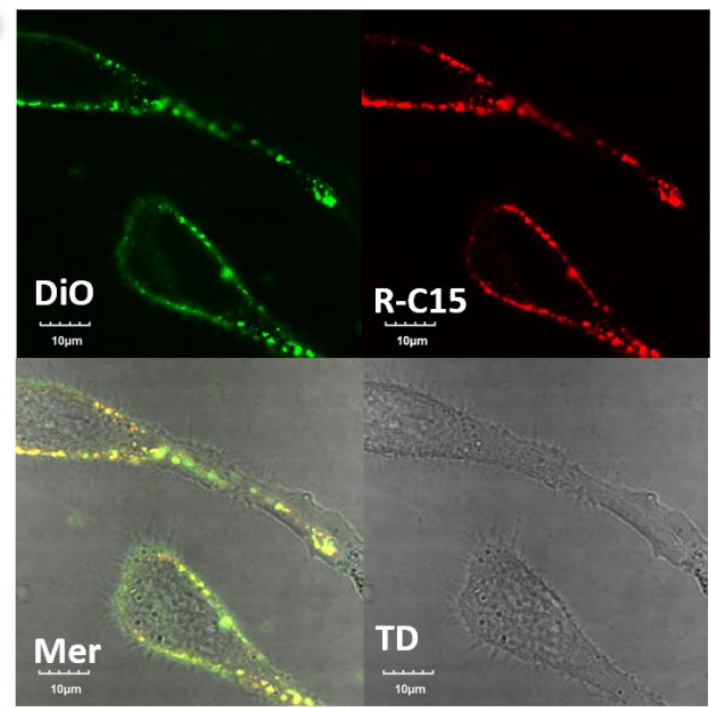

(b)

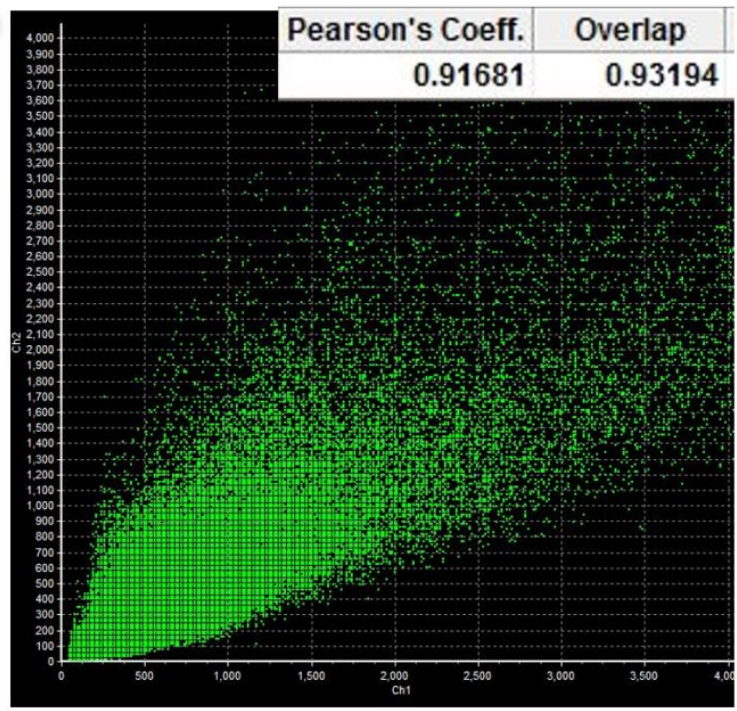

Figure S23 (a) Confocal fluorescence images of HeLa cells' mitochondria stained with TPNPDA-C15 and DiO. Scale bar is $10 \mu \mathrm{m}$. (b) Co-localization scatter plot and correlation coefficients for Red channel of TPNPDA-C1 with DiO. Pearson's correlation coefficient is 0.92 .

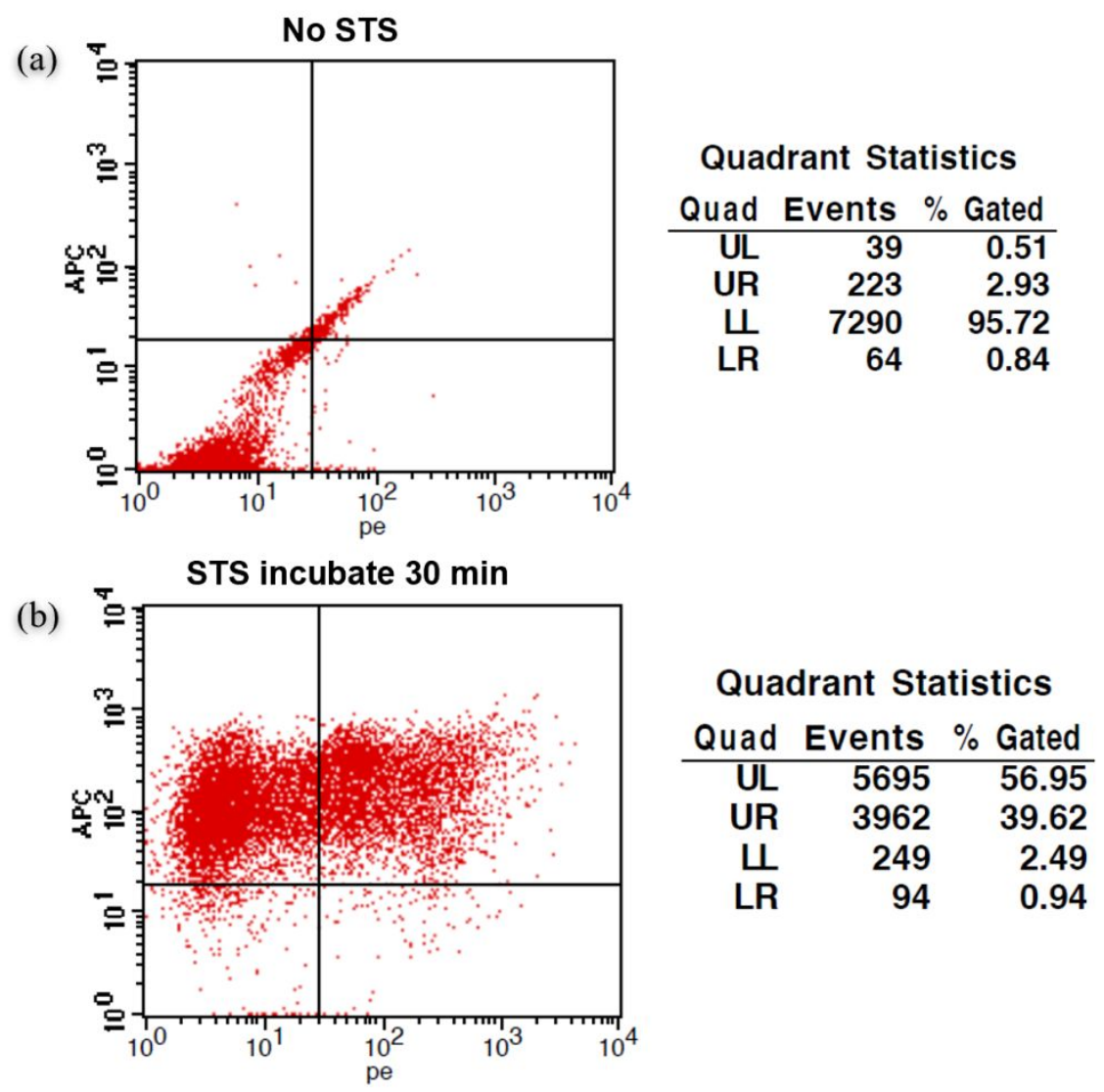

Figure S24 Flow cytometric analysis of HeLa cells (a) incubate 30 min after adding $5 \mu$ L DMSO (b) incubate $30 \mathrm{~min}$ after adding $5 \mu \mathrm{L} 1 \mathrm{mg} / \mathrm{mL}$ STS-DMSO stock solution using apoptosis assay kit with the dual fluorescence of Annexin V-APC/PI double staining. 


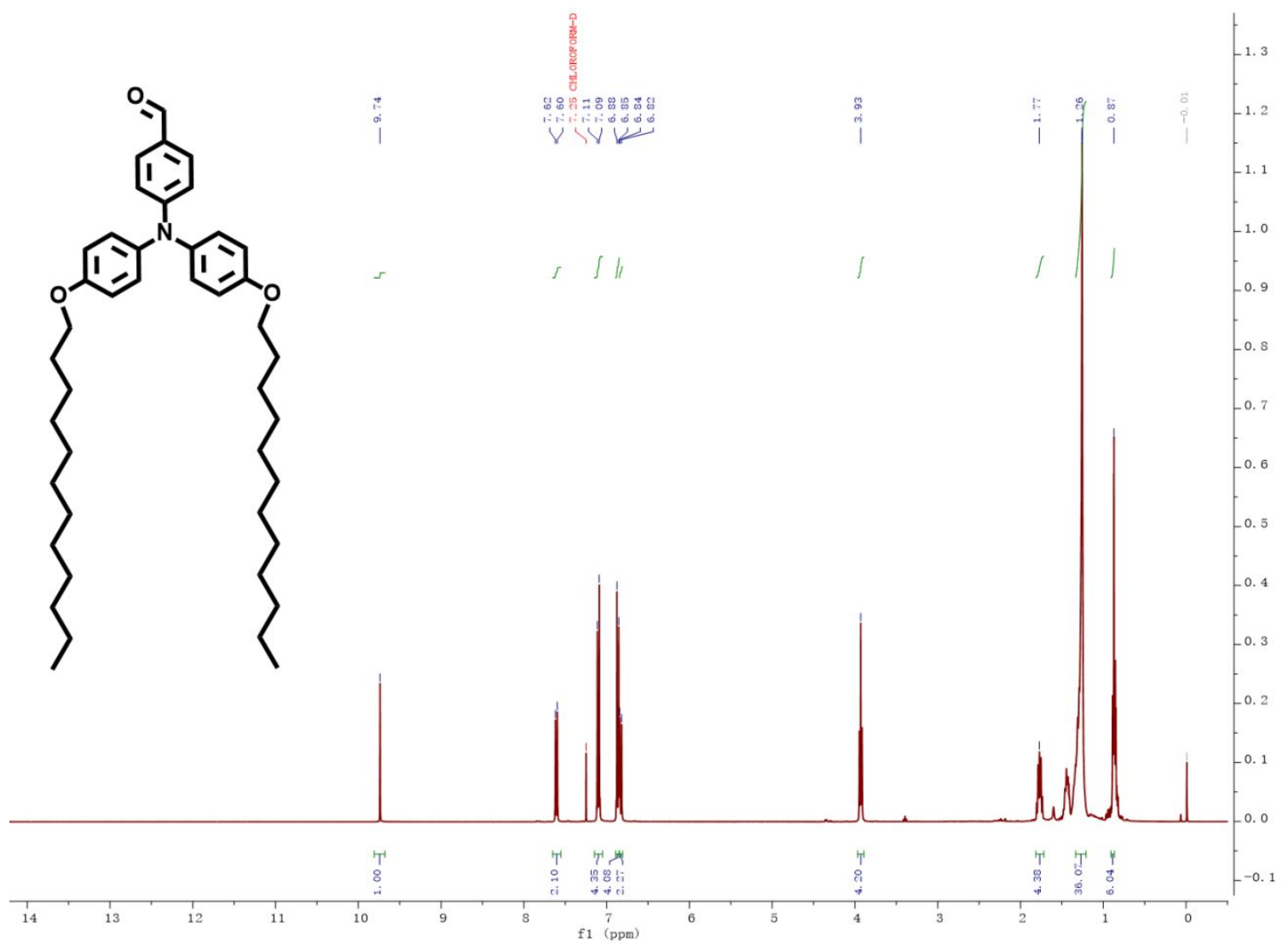

Figure S25 ${ }^{1} \mathrm{H}$ NMR spectra of TPN-C12

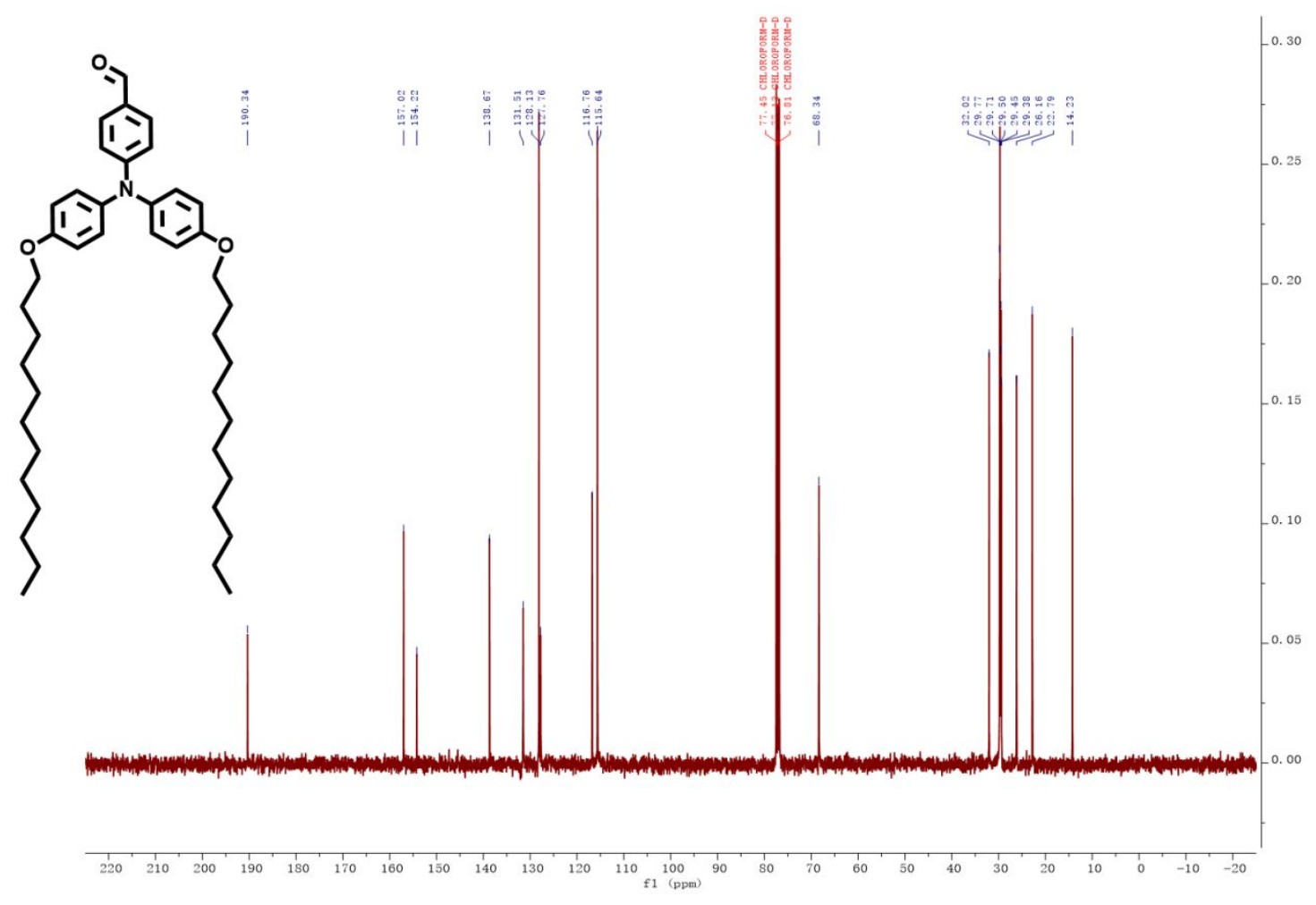

Figure S26 ${ }^{13} \mathrm{C}$ NMR spectra of TPN-C12

S29 


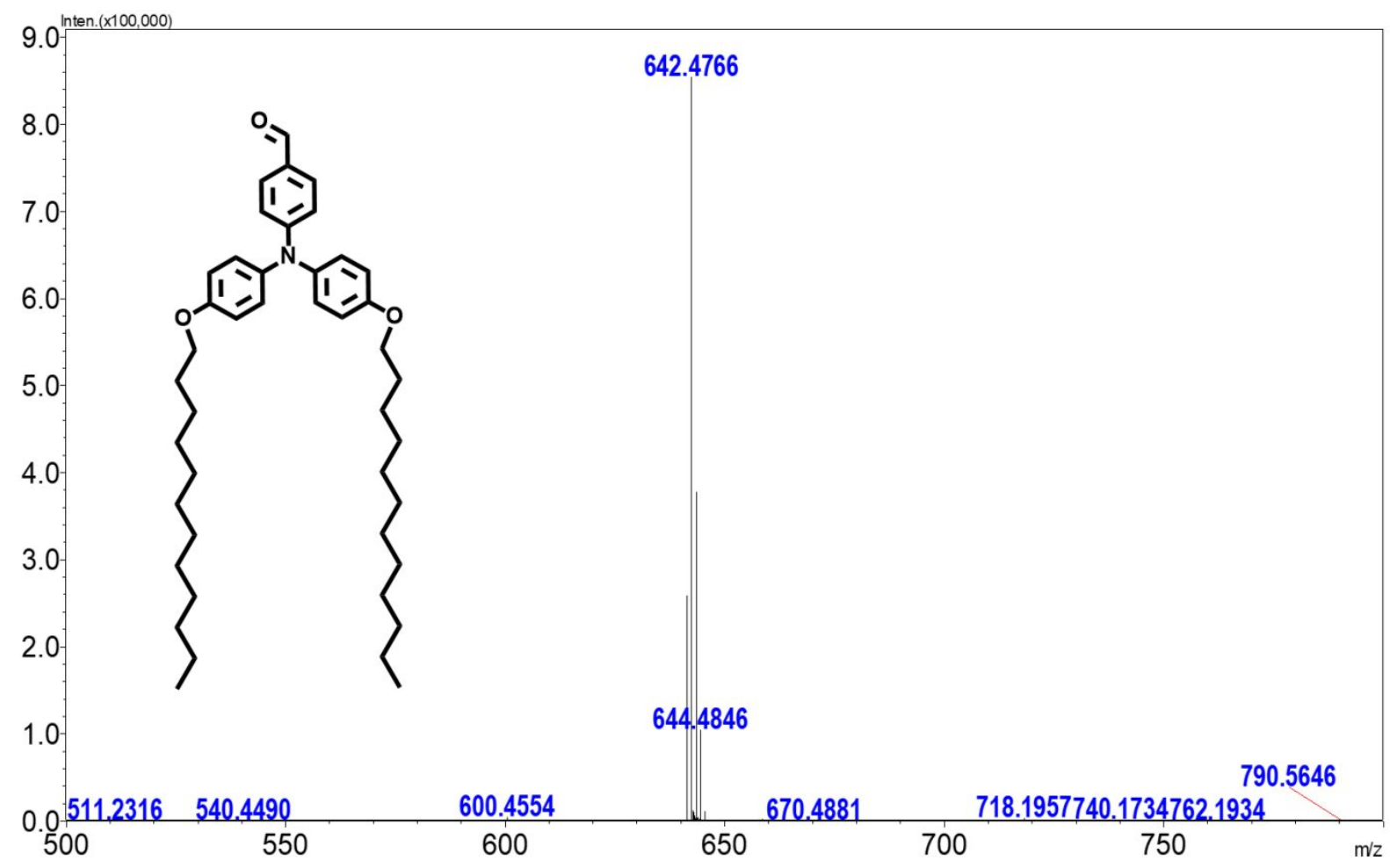

Figure S27 ESI-MS spectra of TPN-C12

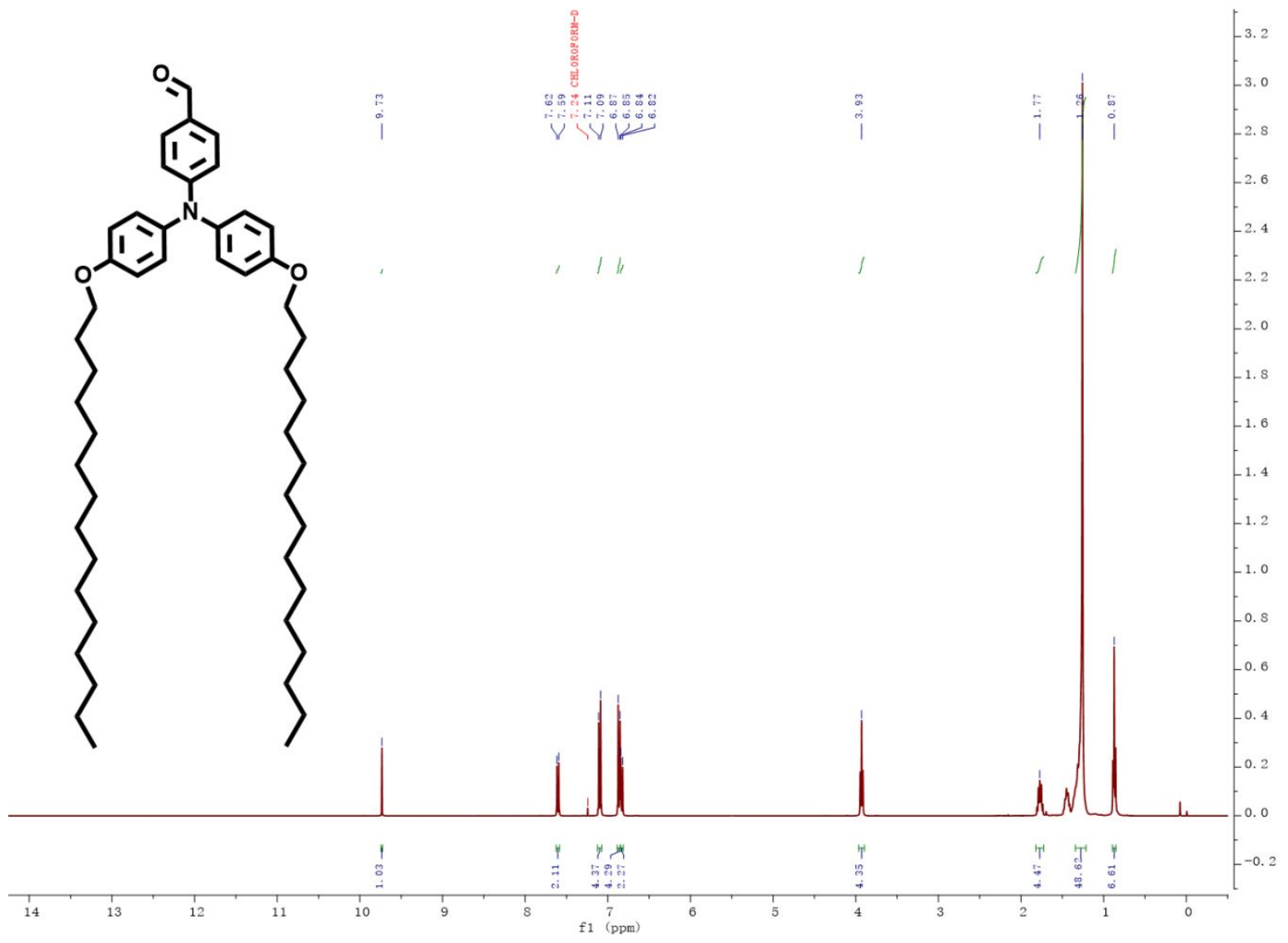

Figure S28 ${ }^{1} \mathrm{H}$ NMR spectra of TPN-C15 


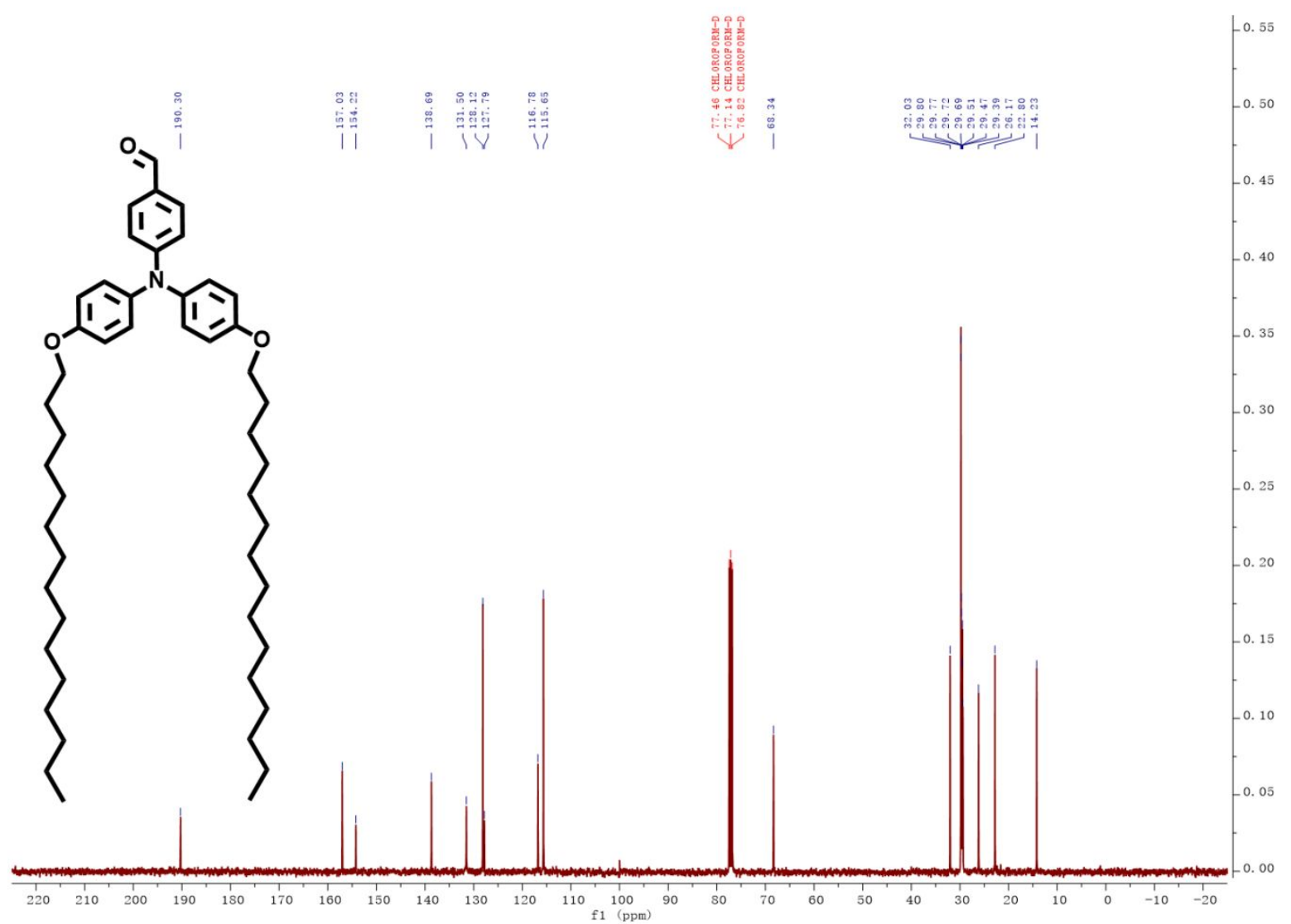

Figure S29 ${ }^{13} \mathrm{C}$ NMR spectra of TPN-C15

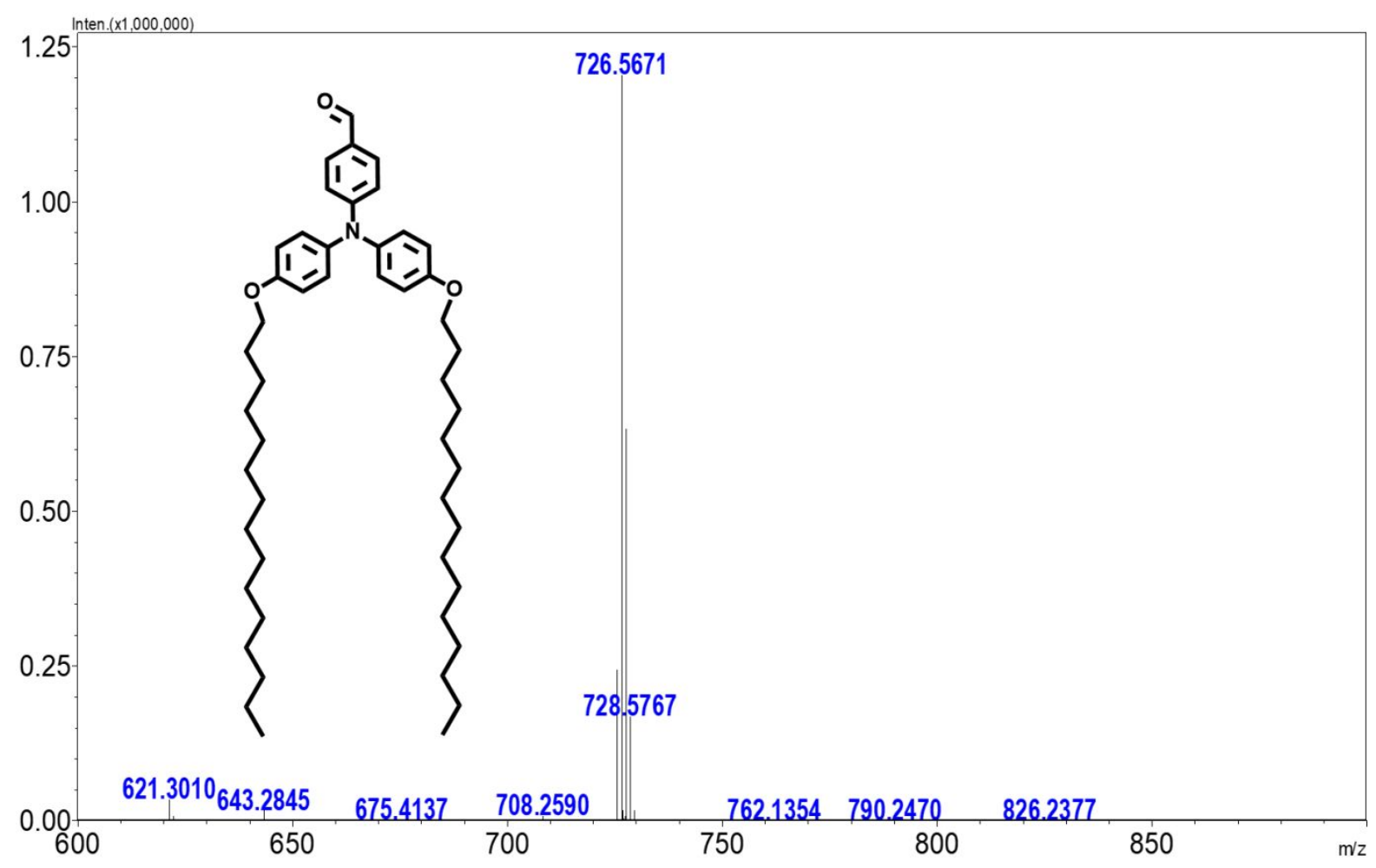

Figure S30 ESI-MS spectra of TPN-C15 


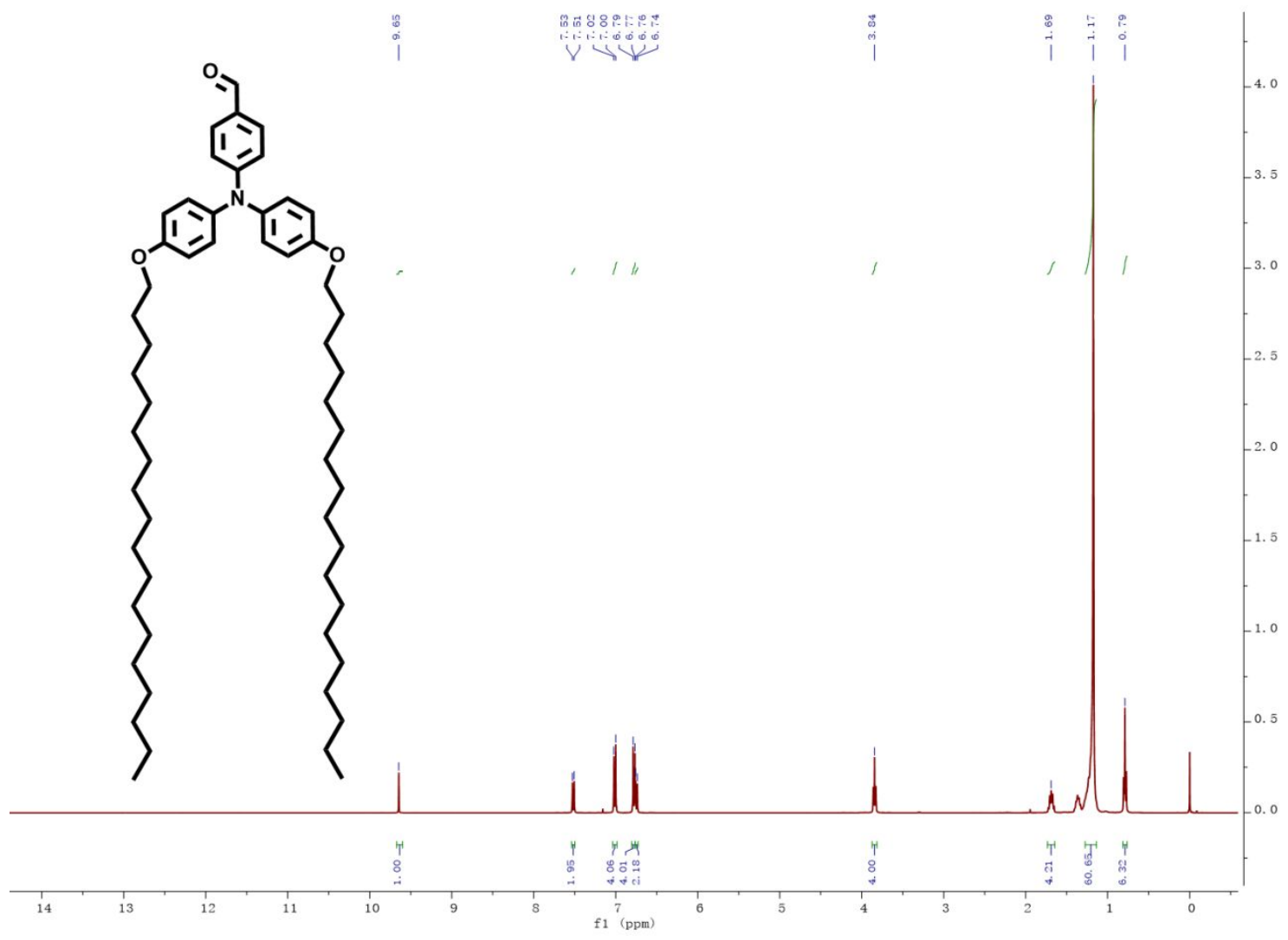

Figure S31 ${ }^{1} \mathrm{H}$ NMR spectra of TPN-C18

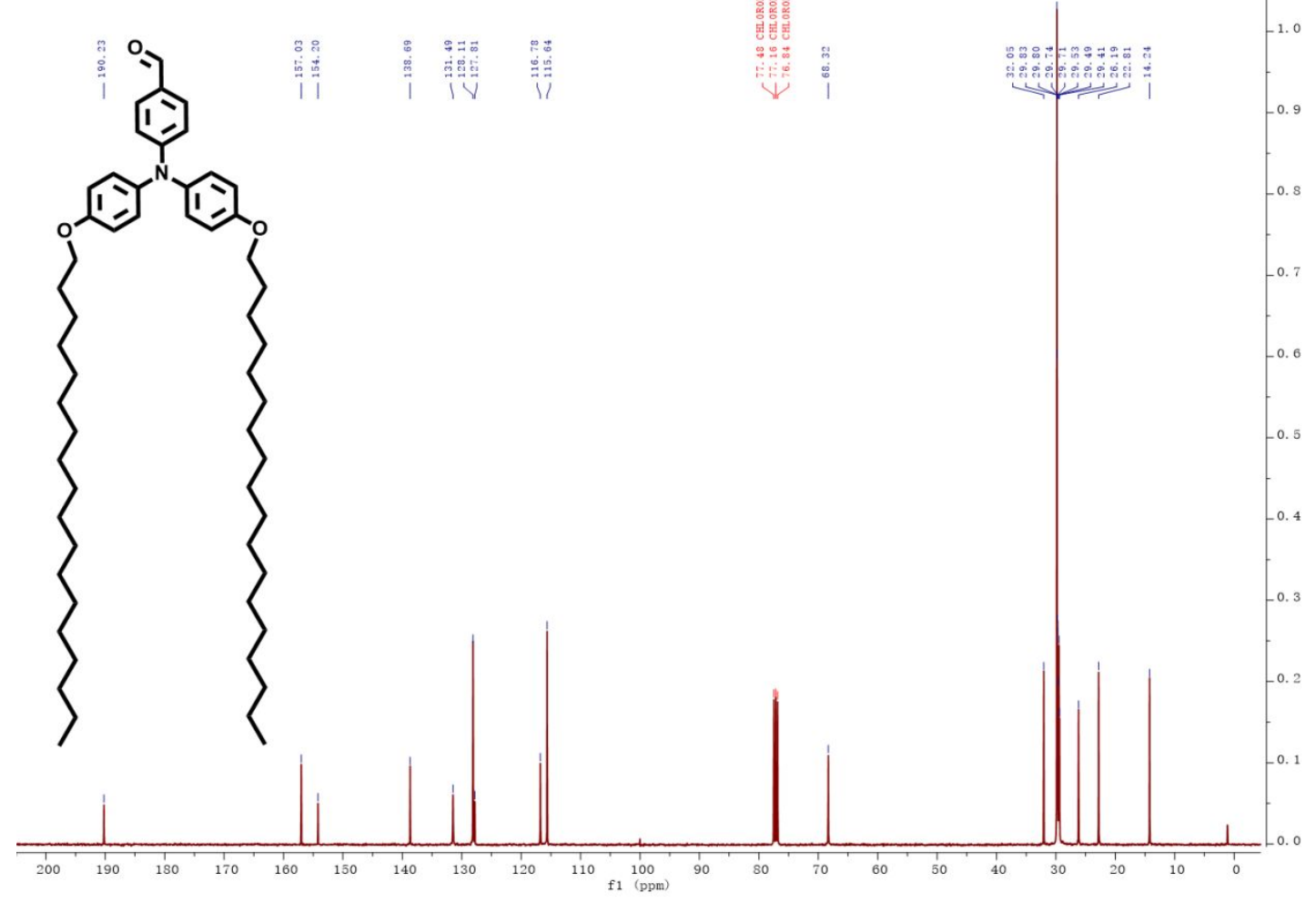

Figure S32 ${ }^{13} \mathrm{C}$ NMR spectra of TPN-C18

S32 


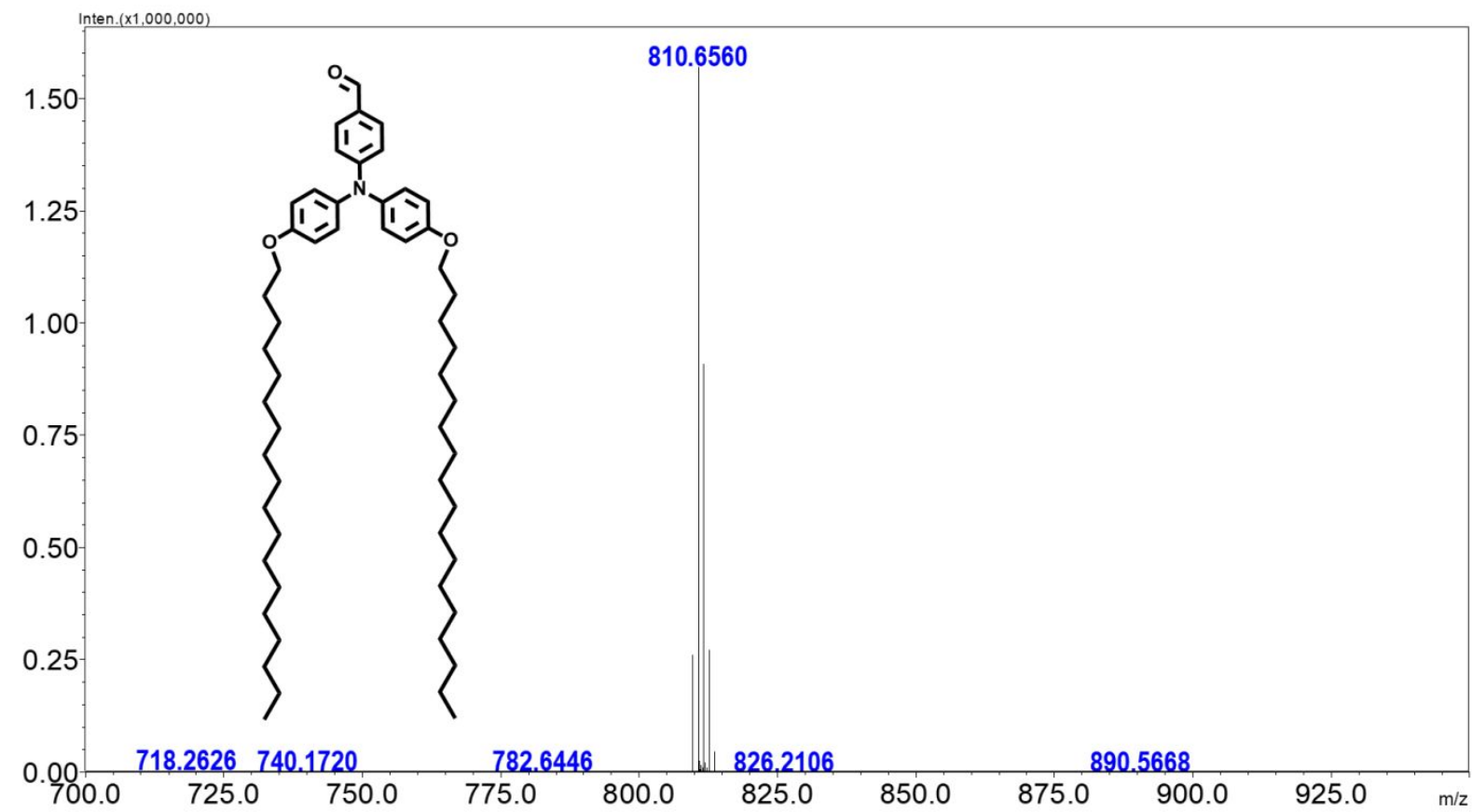

Figure S33 ESI-MS spectra of TPN-C18

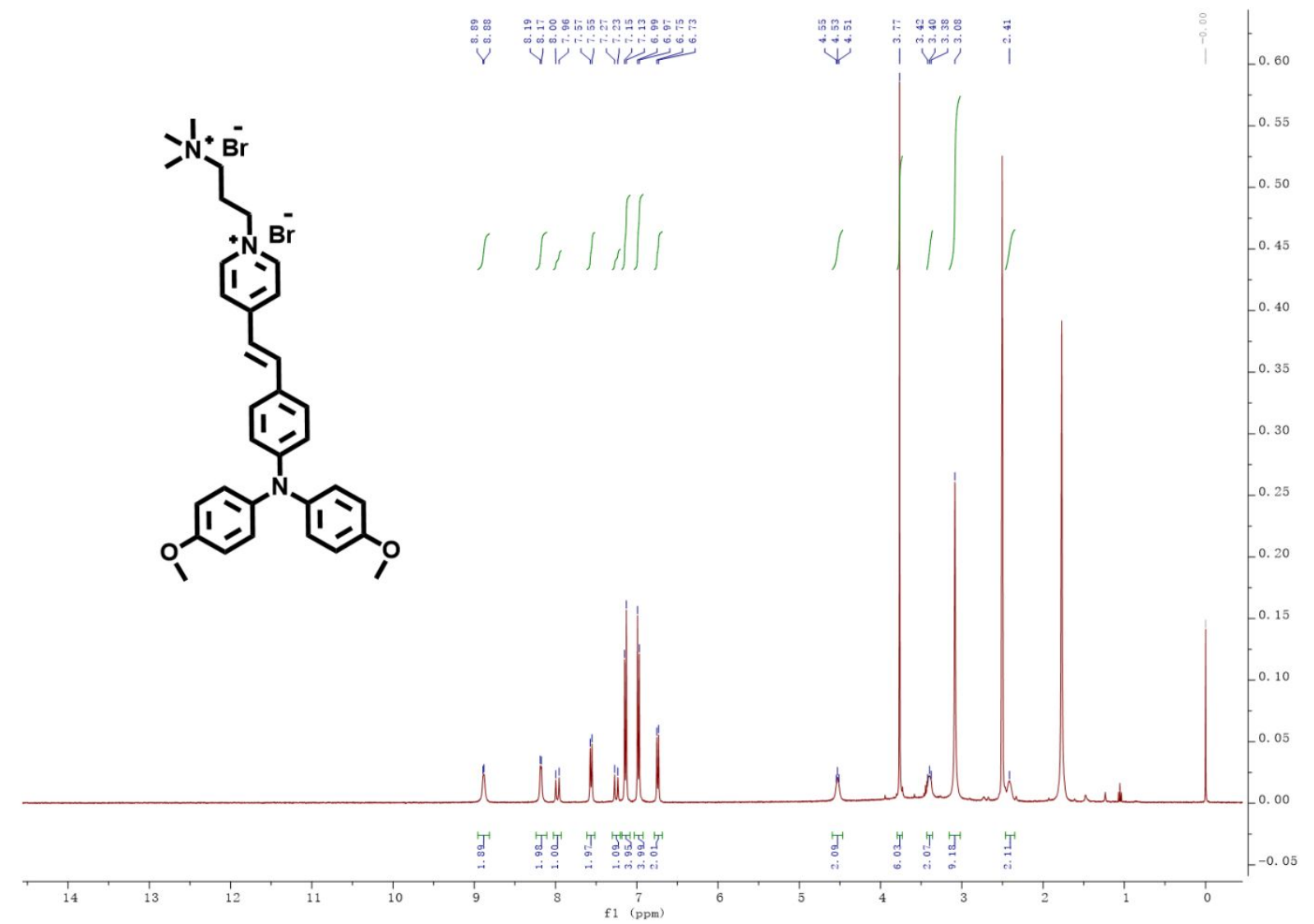

Figure S34 ${ }^{1} \mathrm{H}$ NMR spectra of TPNPDA-C1 


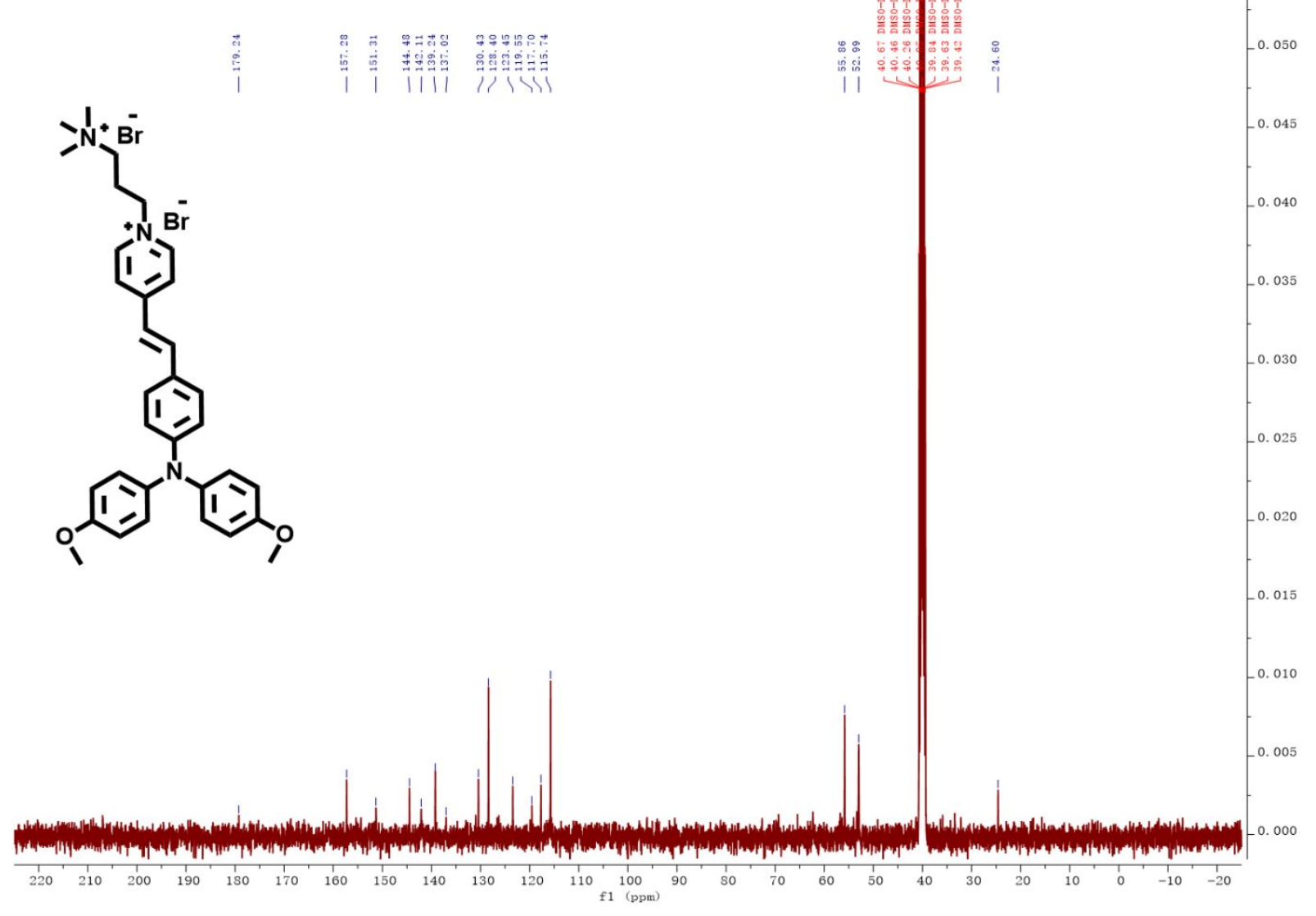

Figure S35 ${ }^{13} \mathrm{C}$ NMR spectra of TPNPDA-C1

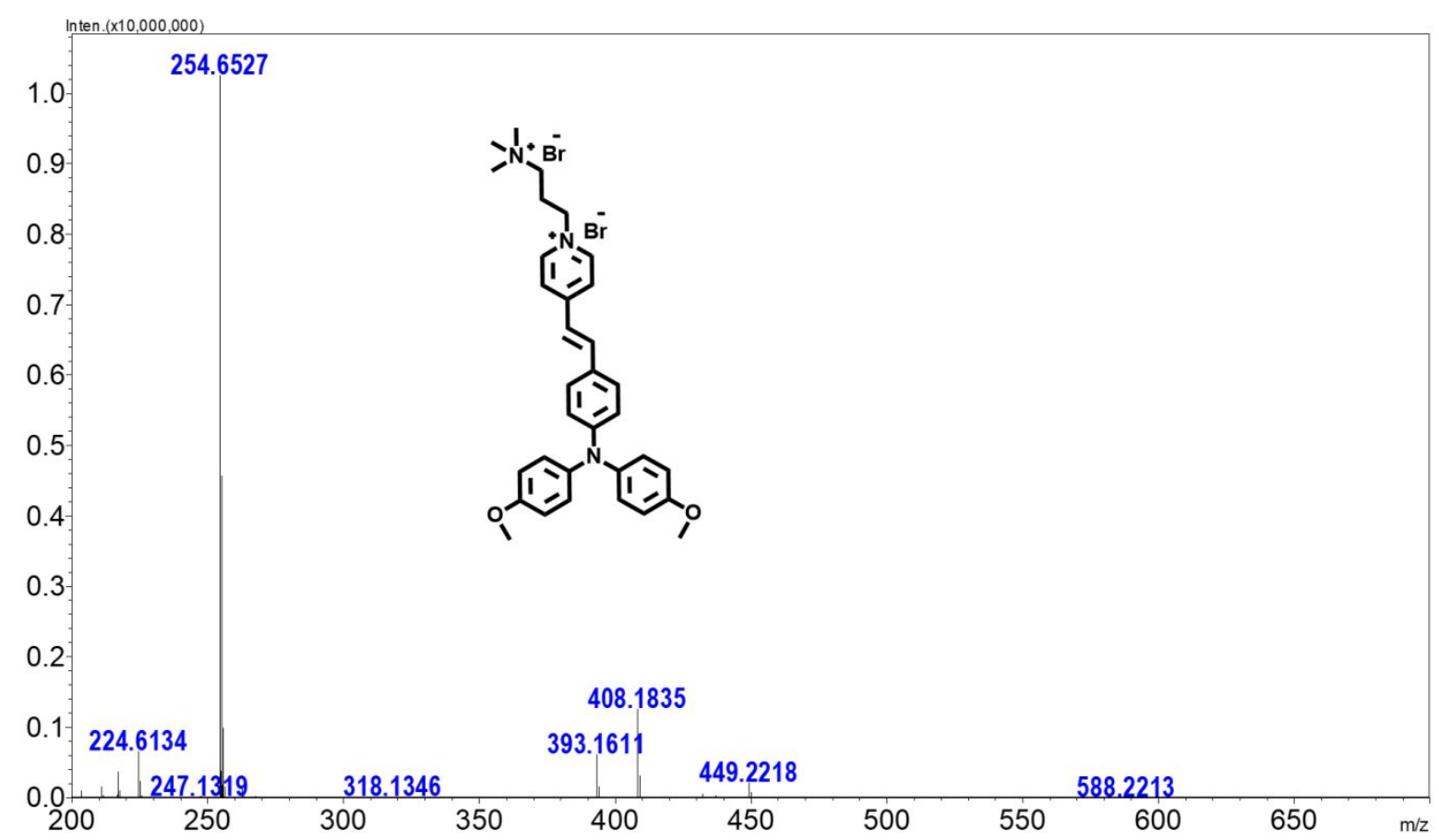

Figure S36 ESI-MS spectra of TPNPDA-C1 


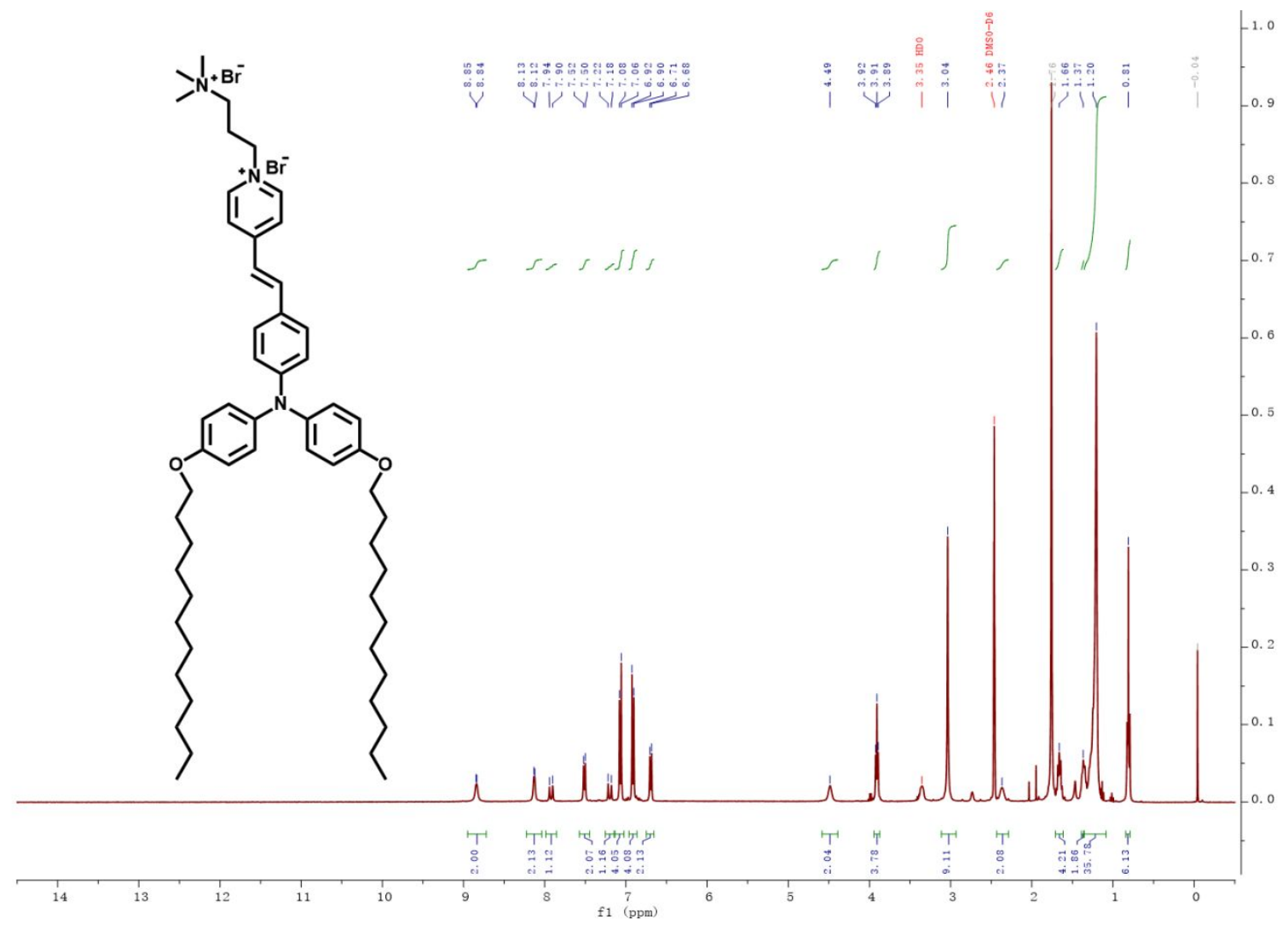

Figure S37 ${ }^{1} \mathrm{H}$ NMR spectra of TPNPDA-C12

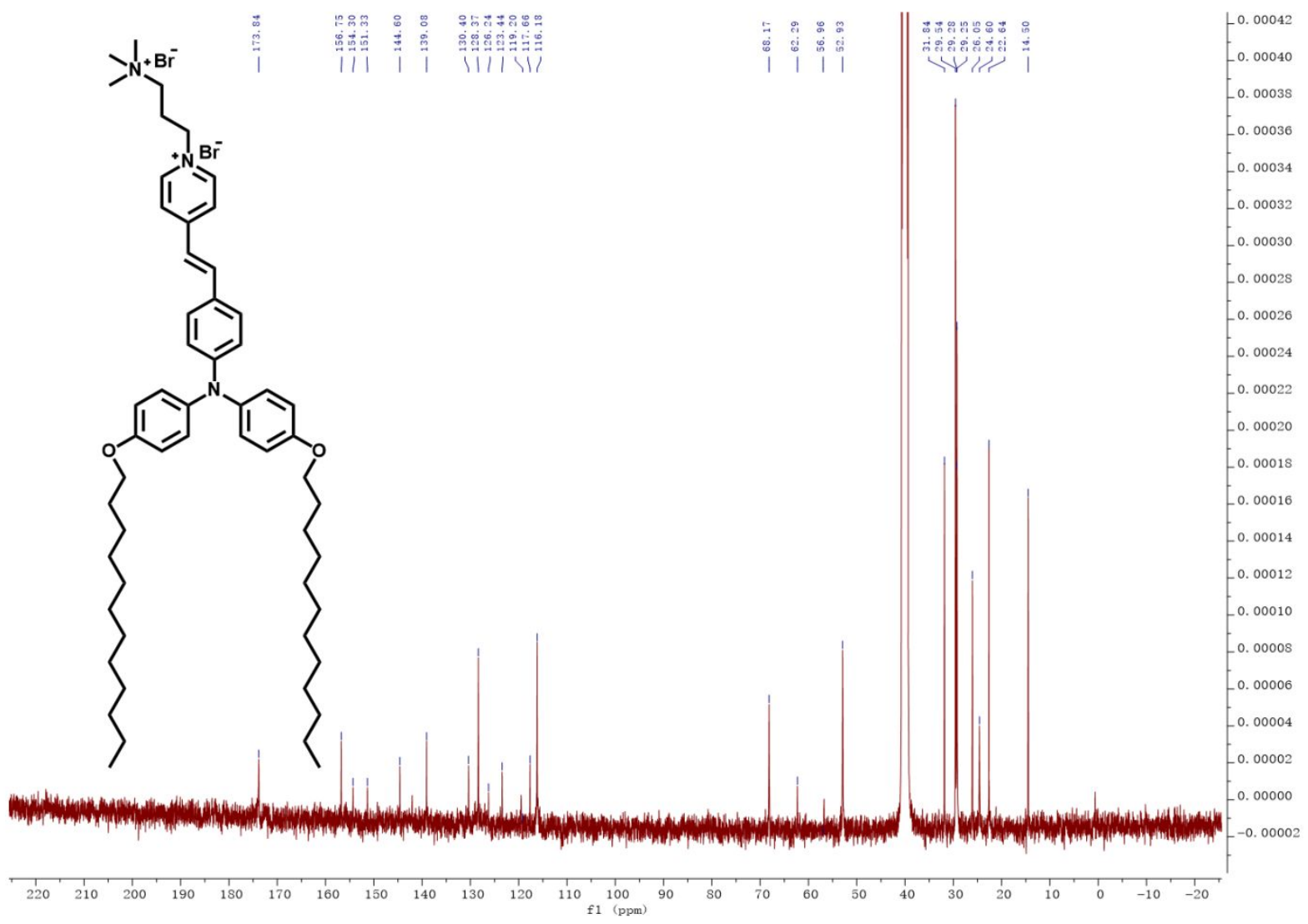

Figure S38 ${ }^{13} \mathrm{C}$ NMR spectra of TPNPDA-C12 


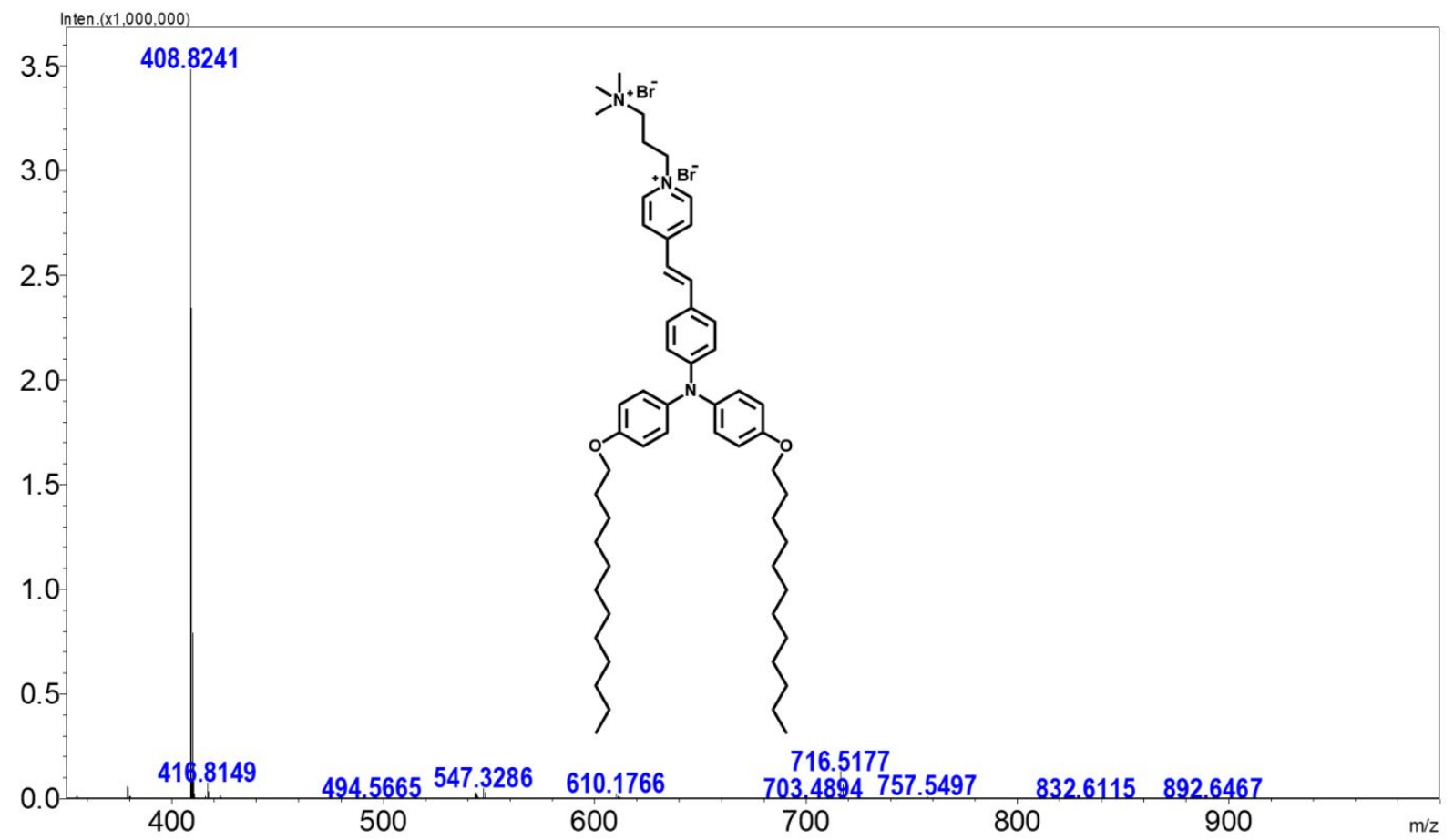

Figure S39 ESI-MS spectra of TPNPDA-C12

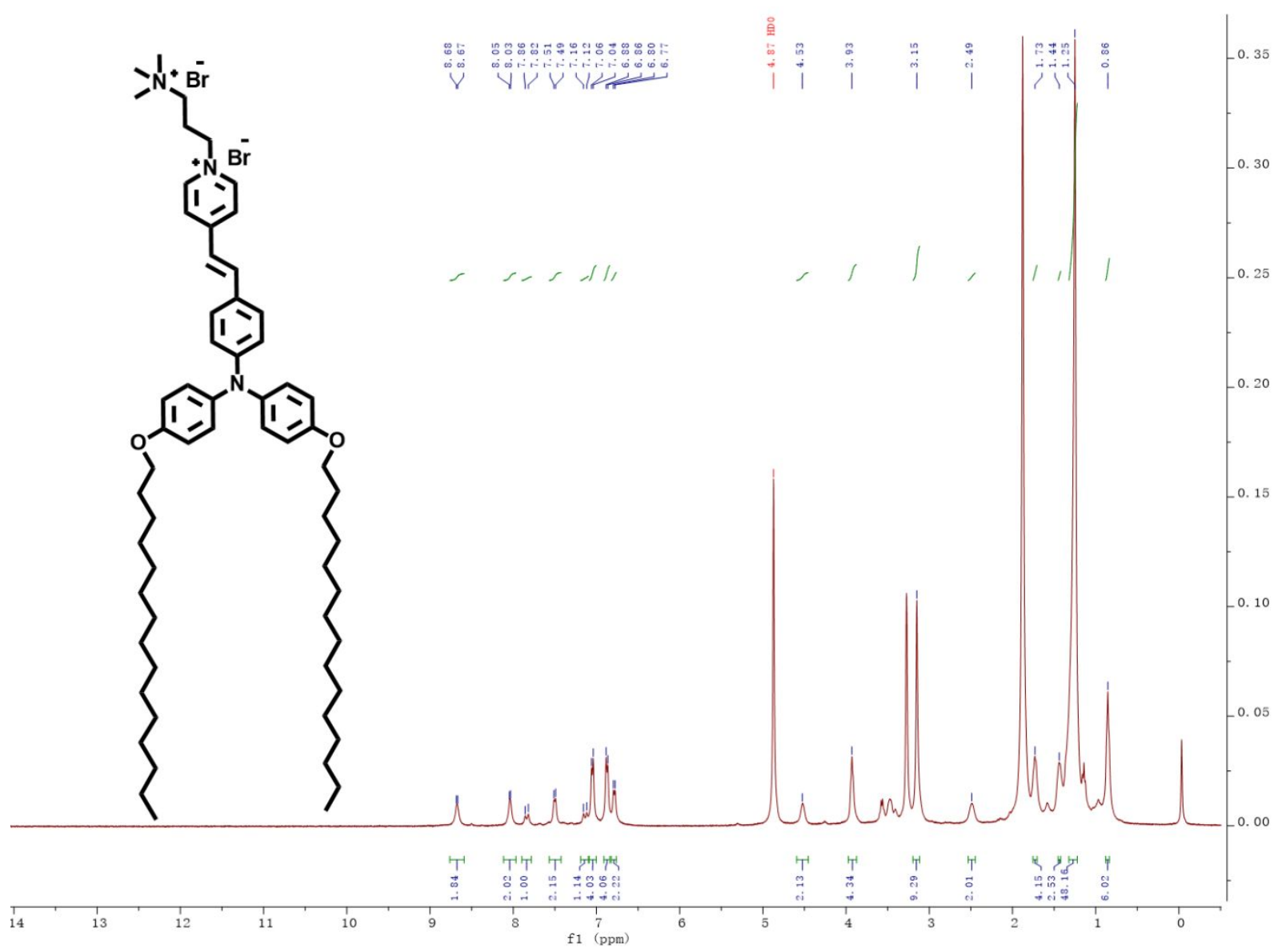

Figure S40 ${ }^{1} \mathrm{H}$ NMR spectra of TPNPDA-C15 (solvent: methanol-d3) 


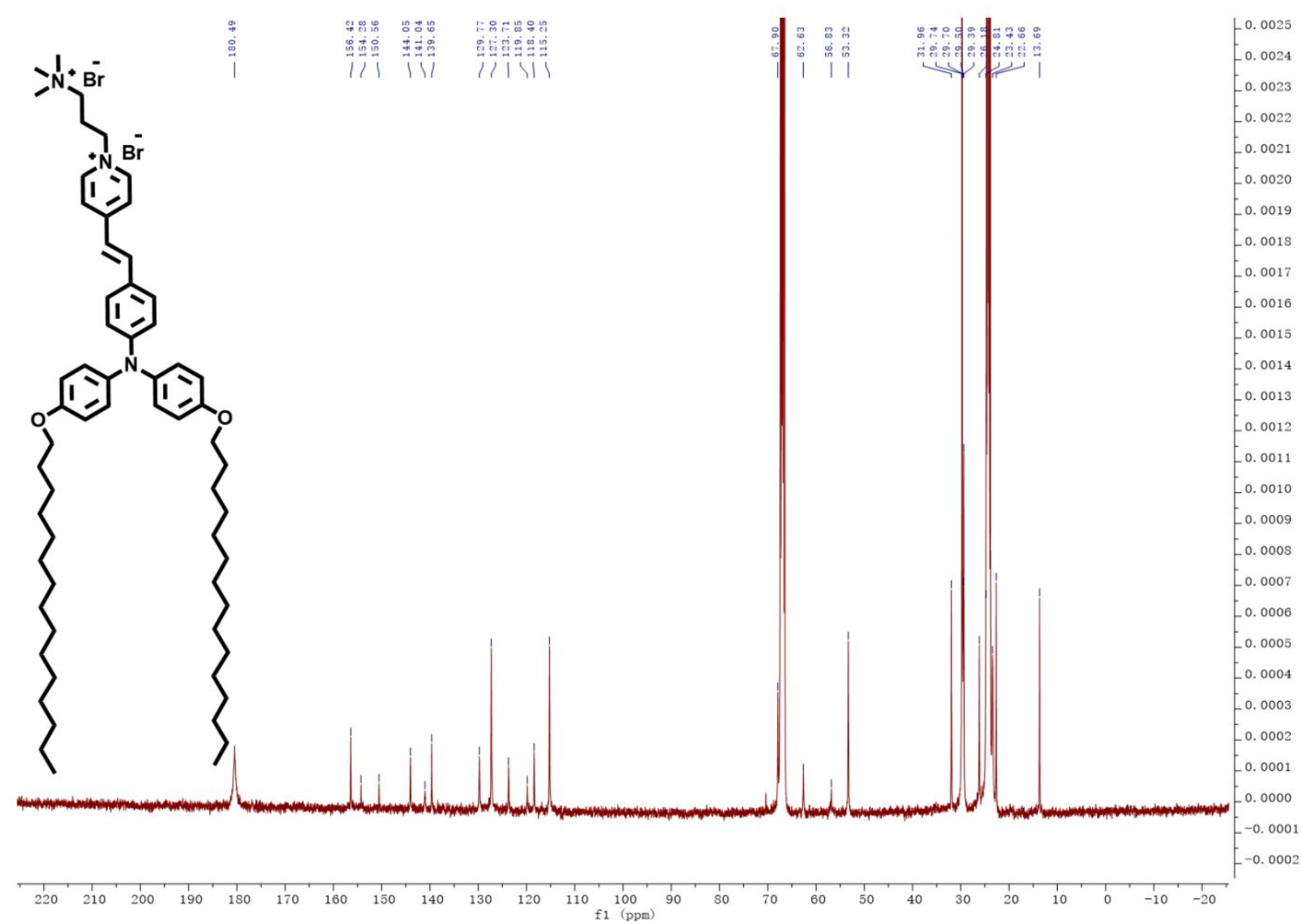

Figure S41 ${ }^{13} \mathrm{C}$ NMR spectra of TPNPDA-C15 (solvent: THF- $d 8: \mathrm{D}_{2} \mathrm{O}=1: 1$ )

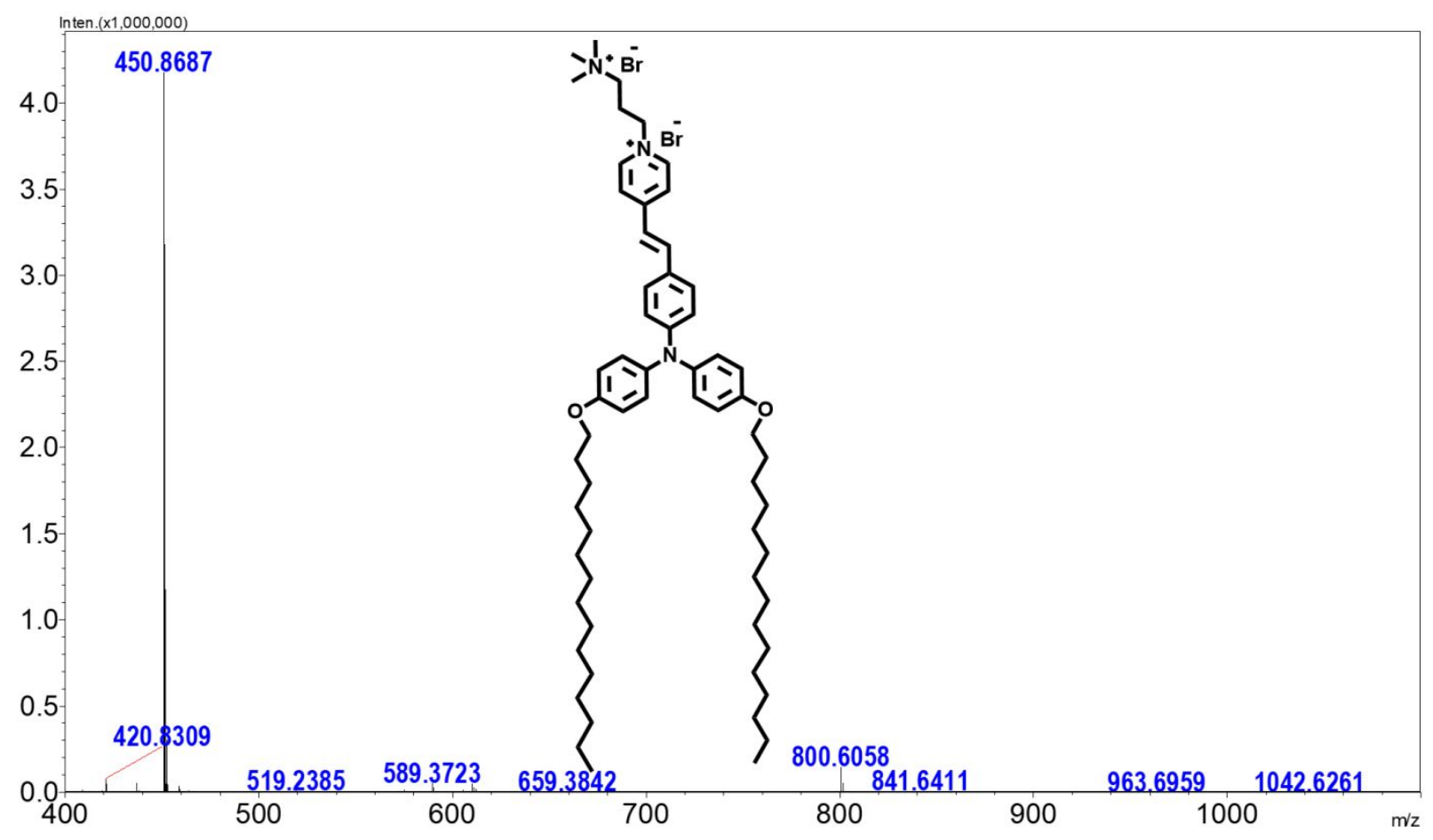

Figure S42 ESI-MS spectra of TPNPDA-C15 


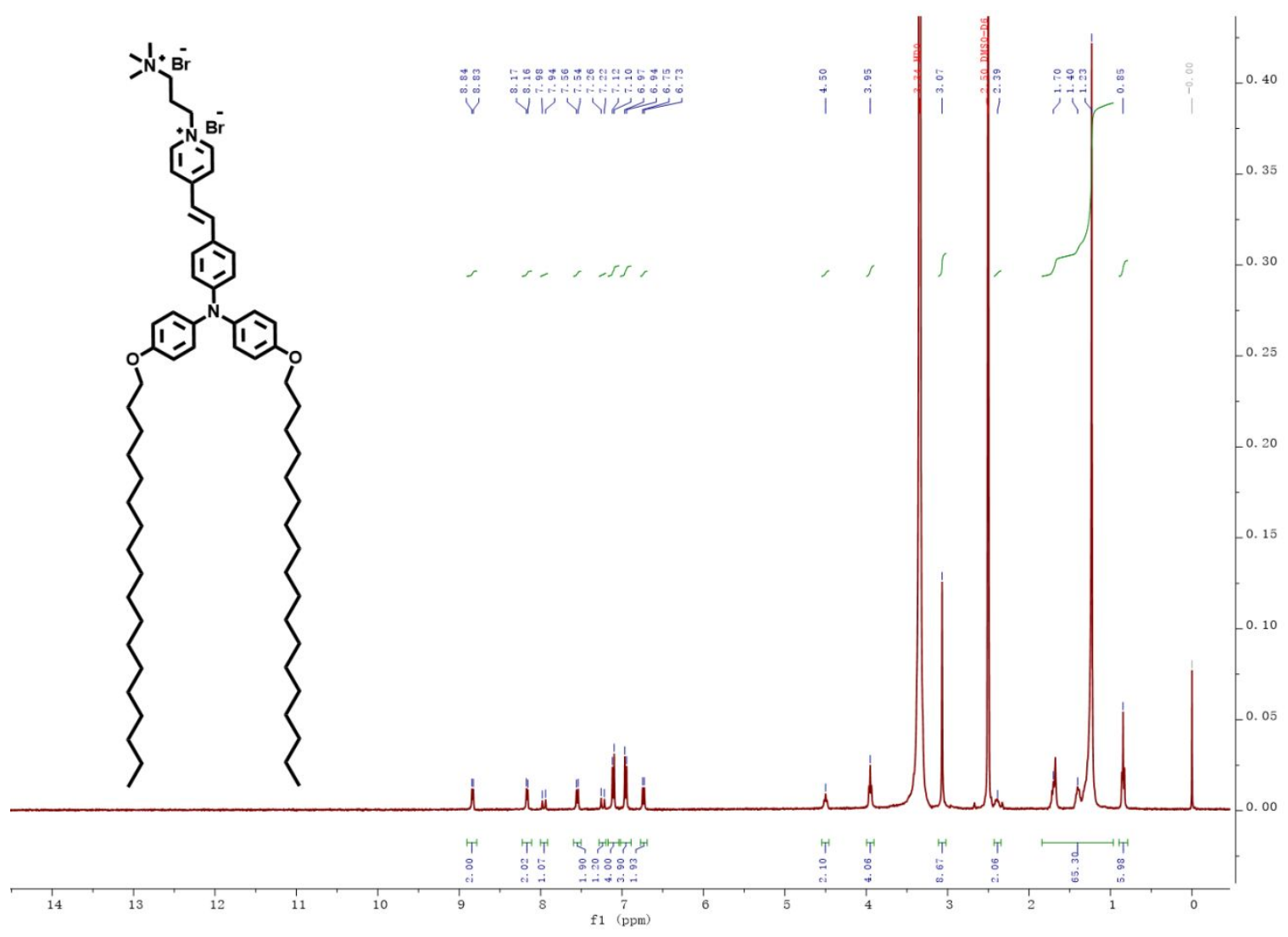

Figure S43 ${ }^{1} \mathrm{H}$ NMR spectra of TPNPDA-C18

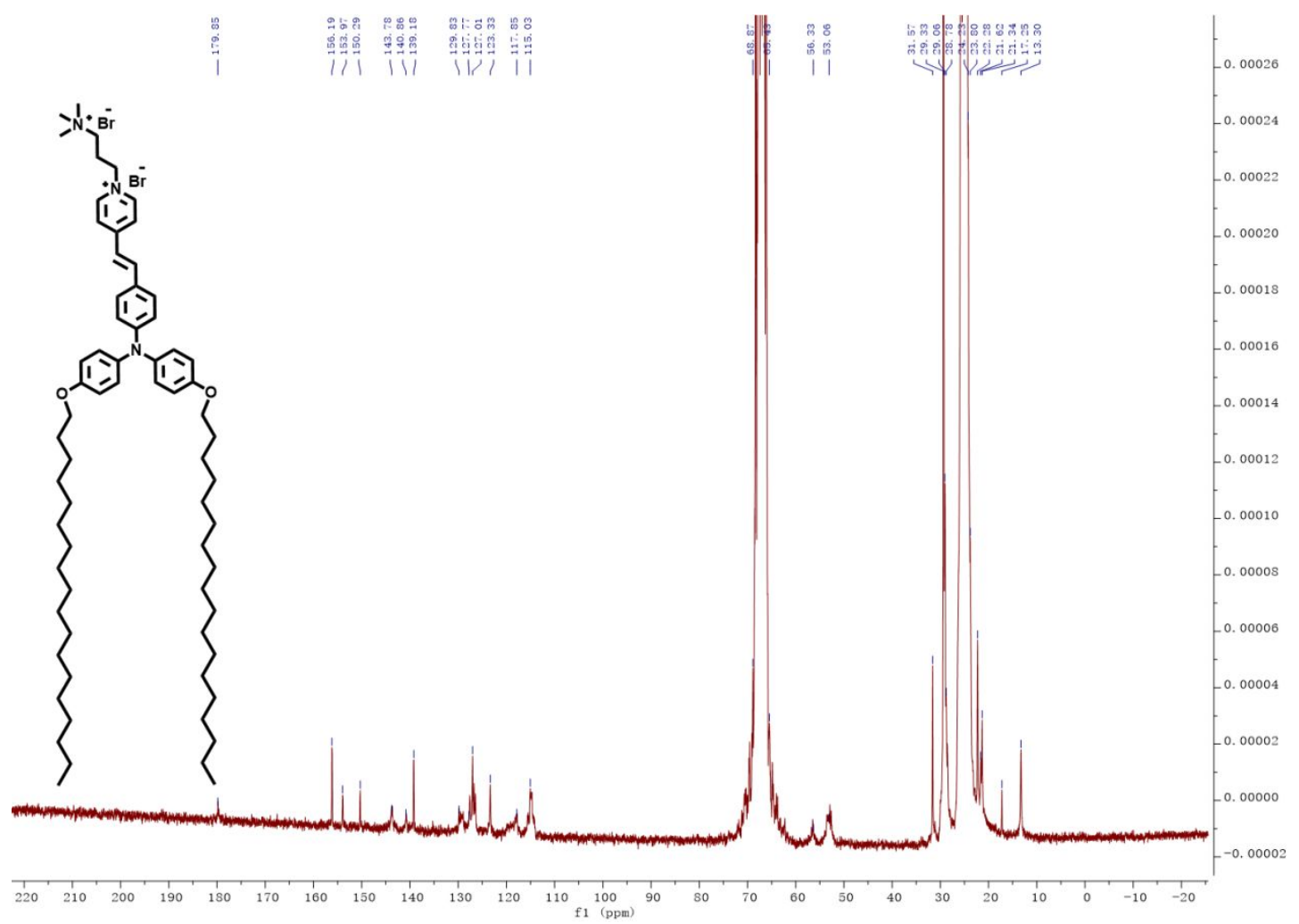

Figure S44 ${ }^{13} \mathrm{C}$ NMR spectra of TPNPDA-C18 (solvent: THF: $\mathrm{H}_{2} \mathrm{O}=3: 1$ ) 


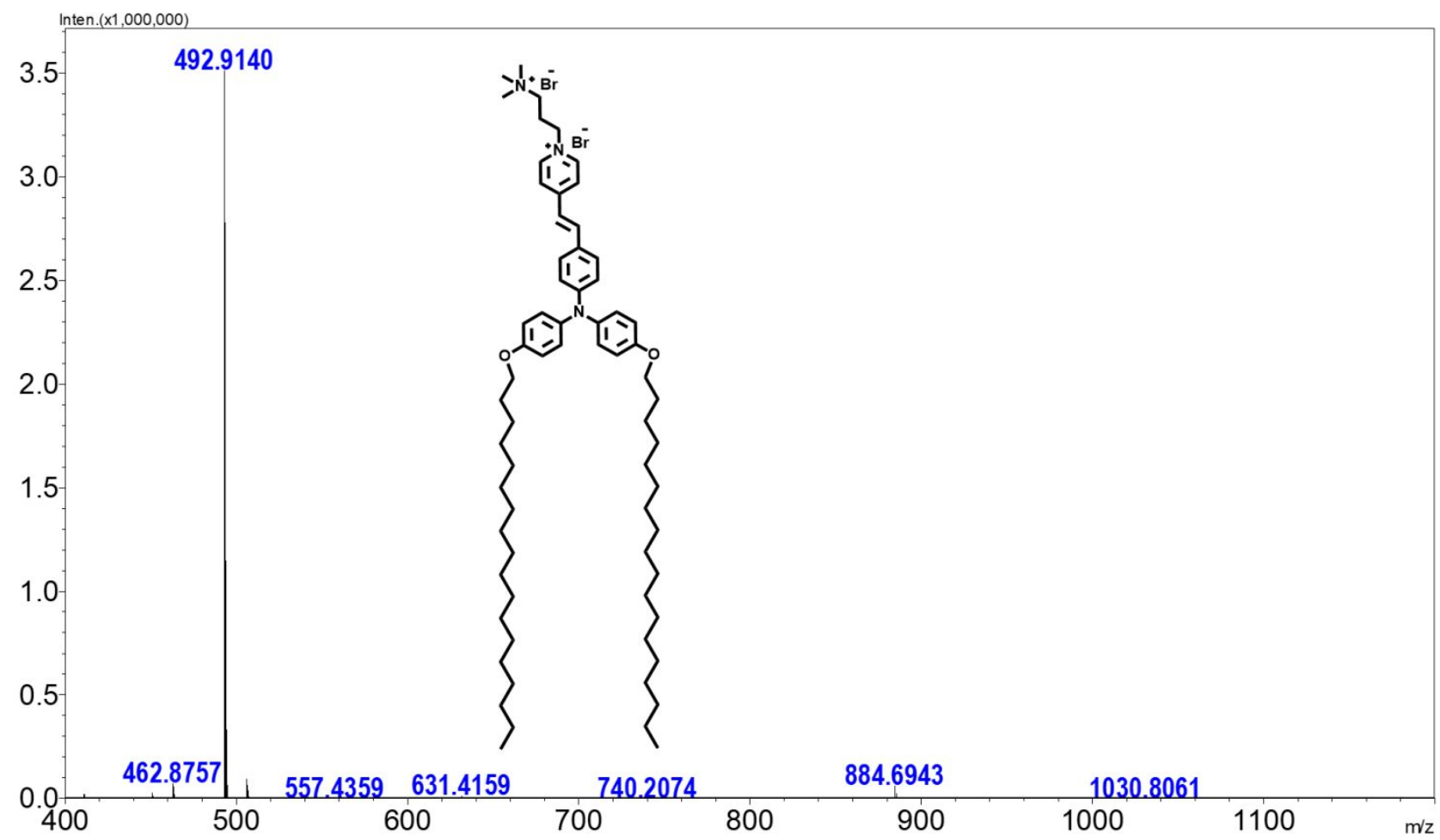

Figure S45 ESI-MS spectra of TPNPDA-C18

\section{Movies List}

Movie S1 TPNPDA-C12 stained HeLa cells after adding $5 \mu \mathrm{L} 3 \mathrm{wt} \% \mathrm{H}_{2} \mathrm{O}_{2}$ solution in water recording for $30 \mathrm{~min}$.

Movie S2 TPNPDA-C12 stained HeLa cells after adding $5 \mu \mathrm{L}$ water recording for $30 \mathrm{~min}$.

Movie S3 TPNPDA-C12 stained HeLa cells after adding $10 \mu \mathrm{L} 1 \mathrm{mg} / \mathrm{mL}$ STS solution in DMSO recording for $30 \mathrm{~min}$.

Movie S4 TPNPDA-C12 stained HeLa cells after adding $10 \mu \mathrm{L}$ DMSO recording for 30 min.

\section{References}

1. Frisch, M. J.; Trucks, G. W.; Schlegel, H. B.; Scuseria, G. E.; Robb, M. A.; Cheeseman, J. R.; Scalmani, G.; Barone, V.; Petersson, G. A.; Nakatsuji, H.; Li, X.; Caricato, M.; Marenich, A. V.; Bloino, J.; Janesko, B. G.; Gomperts, R.; Mennucci, B.; Hratchian, H. P.; Ortiz, J. V.; Izmaylov, A. F.; Sonnenberg, J. L.; Williams; Ding, F.; Lipparini, F.; Egidi, F.; Goings, J.; Peng, B.; Petrone, A.; Henderson, T.; Ranasinghe, D.; Zakrzewski, V. G.; Gao, J.; Rega, N.; Zheng, G.; Liang, W.; Hada, M.; Ehara, M.; Toyota, K.; Fukuda, R.; Hasegawa, J.; Ishida, M.; Nakajima, T.; Honda, Y.; Kitao, O.; 
Nakai, H.; Vreven, T.; Throssell, K.; Montgomery Jr., J. A.; Peralta, J. E.; Ogliaro, F.; Bearpark, M. J.; Heyd, J. J.; Brothers, E. N.; Kudin, K. N.; Staroverov, V. N.; Keith, T. A.; Kobayashi, R.; Normand, J.; Raghavachari, K.; Rendell, A. P.; Burant, J. C.; Iyengar, S. S.; Tomasi, J.; Cossi, M.; Millam, J. M.; Klene, M.; Adamo, C.; Cammi, R.; Ochterski, J. W.; Martin, R. L.; Morokuma, K.; Farkas, O.; Foresman, J. B.; Fox, D. J. Gaussian 16 Rev. C.01, Wallingford, CT, 2016.

2. Zhao, Y.; Truhlar, D. G., Density Functional for Spectroscopy: No Long-Range Self-Interaction Error, Good Performance for Rydberg and Charge-Transfer States, and Better Performance on Average than B3LYP for Ground States. J. Phys. Chem. A 2006, 110 (49), 13126-13130.

3. Chen, X.-K.; Tsuchiya, Y.; Ishikawa, Y.; Zhong, C.; Adachi, C.; Brédas, J.-L., A New Design Strategy for Efficient Thermally Activated Delayed Fluorescence Organic Emitters: From Twisted to Planar Structures. Adv. Mater. 2017, 29 (46), 1702767. 